\title{
The Lebanese American University
}

\author{
The Executive MBA Classroom Environment \\ in the New Millennium
}

By

Sherine Khalife

A thesis submitted in partial fulfillment of the requirements of the degree of Master of Business Administration to the School of Business at the Lebanese American University

Beirut-Lebanon

June 2005 


\section{The Lebanese American University}

\section{The Executive MBA Classroom Environment in the New Millennium}

By

Sherine Khalife

Approved by:

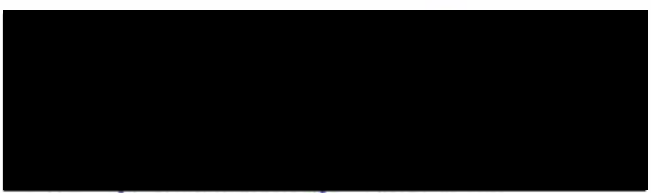

Dr. Walid Touma, Advisor

Thesis Committee:

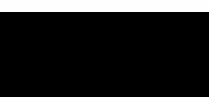

Dr. Ramzi Haraty

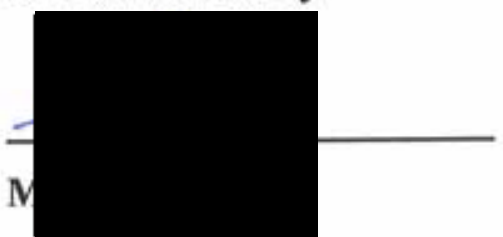

Date of thesis defense: June 22,2005 


\title{
The Lebanese American University
}

\author{
THESIS RELEASE FORM
}

I, Sherine Khalife

Authorize the Lebanese American University to supply copies of my thesis to libraries or individuals upon request.

$\square$ do not authorize the Lebanese American University to supply copies of my thesis to libraries or individuals for a period of two years starting with the date of the thesis defense.

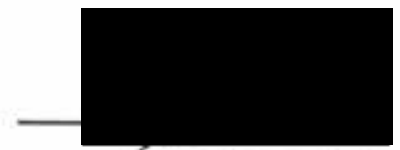

Signature

Tune 24,2005

Date 
Student Name: I/s. Sherihe

We hereby approve the Thesis or project of candidate for the Master of Business Administration (MBA) Degree*

Advisor Signature:

Dean Signatur

Date: 23.00 .05

* We also certify that written approval has been obtained for any proprietary material contained there in. 
To be signed by the student:

I grant to the LEBANESE AMERICAN UNIVERSITY the right to use this work, irrespective of any copyright, for the University's own purpose without cost to the University or to its students, agents and employees. I further agree that the University may reproduce and provide single copies of the work, in any format other than in or from microforms, to the public for the cost of reproduction. 


\section{Dedicated To \\ Manal \& Magda \\ For all the help and support \\ For all the guidance \\ For your love \\ Thank you}


Thankful acknowledgment goes to Dr. Walid Touma for his effort and motivation that were of great help towards achieving this study. A Thank you is also addressed to Dr. Ramzi Haraty for his work with me.

My greatest acknowledgement and deepest gratitude is to Ms. Manal Yunis for being supportive, helpful, and without Ms. Yunis this work would not have become a professional piece of work. Thank you for giving me the strength when I was weak, for helping me when I could not reach and guiding me to be on the right path not only in my studies and work but also in life. Thank you my dear Ms. Manal.

My sincere appreciation and gratefulness go for Magda Yunis Khalifa, a very great person who was so helpful, supportive, loving and caring. Thank you very much for everything.

I truly thank my beloved mother, Nisrine and Talal for their love, support, and patience.

My hope and expectations are that this effort will be a helpful work towards assisting further studies aiming to implement the recommended EMBA classroom design for the new millennium. 


\section{ABSTRACT \\ Sherine Housein Khalifeh for Masters of Business Administration \\ Title: \\ EMBA CLASSROOM IN THE NEW MILLENIUM}

The world is experiencing an information explosion of unprecedented proportions. Not only is the volume of new information large, but it is also growing exponentially. Rapid changes in many fields are making basic knowledge and skills obsolete.

In the technological world of the 21 st century, the meaning of the phrase "to know" means more than simply having information stored in one's memory; it means having access to information and knowing how to use it. The challenge for education is to design technologies for learning that draw both from knowledge about human cognition and from practical application of how technology can facilitate complex tasks in the workplace. "Like training wheels," computers enable learners to do more advanced activities, and engage in more advanced thinking and problem-solving than they could without such help.

In this rapidly transforming world, where employment requirements and fundamental literacy expectations are quickly changing, the EMBA education must also change to meet these demands. The essence of the EMBA education has always been to enhance the experience level of senior level professionals who aim to get to higher level positions in their career, and to foster competencies that will permit these professional to have a stronger contribution into the well off of their organizations. To that end, Information technology must become an integral part of the general education curriculum so students are prepared to meet future technology challenges. 
This study is introducing a new design for the EMBA classroom in the new Millennium.

Different studies were done on the EMBA program worldwide, a certain research was conducted in the Lebanese American University (LAU) and American University of Beirut (AUB) on MBA EMBA students and instructors. This study elaborates the concept of EMBA and its importance in addition to the environment needed for an EMBA classroom in the new millennium where a high level of interaction will take place and high technological state will be implemented. 


\title{
TABLE OF CONTENTS
}

ACKNOWLEDGEMENTS

\author{
ABSTRACT \\ LIST OF ILLUSTRATIONS \\ LIST OF TABLES
}

\section{Chapter I: INTRODUCTION}

\subsection{Overview}

1.2 What is EMBA?

page 1

1.3 The Classroom Context page $2-4$

1.4 Making the Transition to

1.5 Need for the Study page $9-10$

1.6 Purpose of the Study page 11

1.7 Study Outline page $12-14$ page 15

\section{Chapter II: Review of Literature}

2.1 Overview

2.2 A Deeper look at EMBA page 16

2.3 Leaning Model page 17 - 33

2.4 Integrating Technology into the Leane $34-57$

2.5 Classroom Design Features for the New Millennium Page 58 - 73 page $73-80$

\section{Chapter III: Designs of Other EMBA classrooms worldwide}

3.1 Overview

3.2 Fisher College of Business Page 81

3.3 South Florida Business School page $81-82$ Page $82-85$ 
3.4 Allen Center page $86-87$

3.5 Columbia EMBA Program page 88

3.6 Boston University page $89-90$

3.7 Duke University page $91-95$

3.8 Washington University in Saint Louis page $96-100$

3.9 Loyola Marymount University Page $101-102$

Chapter IV: Design \& Methodology page $103-106$ Chapter V: Findings \& Analysis page $107-120$ page $121-133$

Chapter VI: Our EMBA Classroom page $134-137$

Chapter VII: Conclusions and Recommendations

APPENDIX: Questionnaires REFERENCES 


\title{
CHAPTER I
}

\section{INTRODUCTION}

"To allow experienced professionals in Lebanon and the Middle East to combine a full-time career with an executive educational program culminating in an academic degree".

Executive MBA Program- LAU

\author{
"Creating new generations of managers and \\ entrepreneurs who can understand profit \\ from the daunting challenges we face".
}

Executive MBA Program- AUB

\subsection{Overview:}

The dynamic and global nature of today's economy requires effective managers who can understand and deal well with the various new and rapidly changing factors technological, legal international, cultural, etc. To be an effective manager requires a broad and deep understanding of certain traditional business principles while internalizing the rapidly changing marketplace from the use of technology to the application of new business rules. If this understanding is not acquired on the job, it must be learned in a special kind of a classroom.

Few questions that come to the mind of a person who wants to enrich his career life and develop certain very important skills needed for going up the career ladder would be:

- Is the MBA the right choice for me?

- Can an MBA truly enhance a career?

- Should I invest in MBA or EMBA?

- Does such an investment justify the expected return?

- What true value does an MBA bring to the company and why should employers play a role in the graduate business education of its employees? 
With over five hundred graduate business programs worldwide, and hundreds of MBAs entering the workforce each year, attention and motivation to attend business schools remain intense. During recession times when corporations react with downsizing and laying off employees and new jobs become scarce, pursuing an MBA seems like a viable option. When the economy is booming and jobs are plentiful, people confident in the economic health of their country, and already interested in the MBA, may be more inclined to make the move and apply to a graduate business program, either on part-time or full-time basis. No matter what the economic environment is, it seems that business schools will always have a steady stream of applicants year after year.

This study is about EMBA. More specifically, it is an attempt to generate a model for a classroom design that would enhance the learning process and the benefits derived from an EMBA class. The following sections will compare and contrast the MBA and the EMBA programs, identify the need for this study, and state the major questions that this study will try to answer.

\subsection{What is EMBA?}

Most people are familiar with the "traditional" MBA. This is a two-year, full-time program, typically attended by motivated young men and women in their early to late twenties. A high percentage of these students are recent undergraduates; however, a significant number are men and women returning to school after a few years building their experience while working with a company in an entry or mid-level position. This group has consciously made the decision to pursue an MBA while still working or withdrew from the workforce to enhance their current job standing or change their career.

The traditional MBA also includes the part-time program, which usually requires completion within 5 years. Part-time students tend to be slightly older with, on average, three to five years work experience. They are equally ambitious as students attending the full-time program, but prefer to stay employed to earn salary, maintain good positions, 
attain high positions on the corporate ladder, or perhaps, change careers. Both the full and part-time MBA programs include the same courses, have the same number of credits, and hold the same accreditation.

Included in the business school, but kept separate from the full- and part-time program, is the Executive MBA. Not all the graduate business schools worldwide offer the Executive MBA. The Executive MBA, or EMBA, is designed for working professionals with practical business experience seeking an MBA on an accelerated schedule while maintaining full-time employment. The average age of the EMBA student is 33 years, with class ages ranging from 28 to 55 years old. They have a minimum of seven years work experience and, preferably - a requirement in some schools - 3 to 5 years experience in middle to upper management. Students represent their companies and are expected to remain with the company long after graduation. Students on fast track to attain executive status are not attending the EMBA to change employers or careers, although both may happen on occasion.

According to Jason Price, "approximately six thousand men and women graduate through the executive MBA program each year." (Price, p.11) EMBA students are expected to enhance their existing position at the company they work for. According to the executive MBA council, "the EMBA offers an exceptional learning experience for highly motivated professionals in the form of the relevant, focused, and graduate business education that compliments professional and personal life."(Price, p.11)

The Executive MBA is a fully accredited MBA. Upon graduation, the certificate will state Master of Business Administration. An EMBA class consists of managers, vice presidents, directors, business owners, founders, and mid-to-senior level business professionals, even CEOs. They work in corporate, nonprofit, and family-run businesses. They bring to the classroom examples of their successes and failures after working full time for many years. Some are lawyers, some are doctors, others are moms, dads and working parents; but they all have in common an understanding of the business world, the maturity to explore business concepts beyond the theoretical, and an intense desire to 
improve their skills and apply newly acquired knowledge in real time. Some may attend to just satisfy a desire for intellectual growth.

The Executive MBA curriculum is equally rigorous as the traditional MBA. Practically the same textbooks and business cases are used in such core classes as accounting, finance, marketing, and statistics. The curriculum differs by introducing executive level topics on management and leadership, requiring, but not necessarily, international travel, and addressing certain thematic topics that may constitute the overall character of the program. Integrated within the program is an education that uniquely capitalizes on the collective experience and knowledge of the classroom-a key differentiator when compared to a traditional MBA.

The Executive MBA course work bridges a gap between the business school and the corporate world. Companies may sponsor employees to attend the EMBA and can play an active role in the delivery of the education. This participation can be in the form of sponsoring projects, offering corporate facilities as classrooms, and involving corporate management in the course study.

EMBA classes are typically held in executive training centers, corporate board rooms, and even simulation centers in some universities worldwide. Rather than in an academic environment on a school campus, most programs prefer the corporate atmosphere. The state-of-the-art facilities and enriching executive study environment are ideal for concentrated, focused learning, and team building. Housing, meals, and recreation are usually provided.

\subsection{The Classroom Context}

The classroom - the way it is organized, the technology being used, and the level of interactivity - has a tremendous influence on the effectiveness of the learning process and the achievement of the program objectives. Nowadays, information technology is playing 
a crucial role in expanding the walls of the physical classroom to create a virtual space for learning. Just as many business organizations are using communication technologies and innovative organizational designs to transition into "virtual" or digital organizations, many institutions of higher education are now seeking new forms of organizations and methods of delivering knowledge through innovative technology to increase the richness of the learning experience as well as broaden their reach to students and educational resources. In less ambitious efforts, the objective is simply to deliver traditional curriculum to students who can not work within the restriction of the traditional classroom. In more ambitious efforts, the objective is to construct new models of curriculum delivery based on collaboration, knowledge sharing, and interactive learning.

While discussing the classroom context, the aspect of communication needs to be considered. In fact, four aspects can be discussed here:

\section{A. One-to-Many Communication}

The primary purpose here is the broadcast of information or knowledge. In the physical classroom, this form of communication can be typically facilitated during the class times and in lecture halls through syllabi, handouts, textbooks, chalkboards, and the overhead projector. The broadcast communication can be improved with PowerPoint slide shows. Although this technology outperforms the traditional broadcast technologies in terms of graphics, color, and sound, it should be kept in mind that it still supports a traditional form of communication and operates within the same set of assumptions as traditional technologies. Some of these assumptions include the following:

1. The delivery of information can only occur during class time.

2. The delivery of information can only occur within the boundaries of a physical classroom space.

3. The major broadcast medium is the lecture.

4. The major broadcast content is the textbook.

5. The instructor is the sole owner of the lecture. 
Of course, adhering to these assumptions of the physical classroom can only limit the transition to the virtual classroom. Introducing the virtual classroom challenges each of these assumptions. In a more specific form, the use of web pages as a mechanism for coordination and display of topics and content facilitate the introduction of updated material and information in a form that cannot be offered by traditional hard copy or print media. E-mails, groupware, and communication technologies that facilitate the exchange of audio and video data over data networks also have the potential to change the features of one-to-many communication within the classroom context. In fact, the concept of a physical classroom occurring within the boundaries of time and space will be challenged by the innovative communication and broadcast technologies. It is worth mentioning that such technologies can be employed, not only at predefined times, but also as particular situations arise, as for example when an instructor has his students video conference with some corporate executives abroad or watch a presentation being aired on a TV station.

\section{B. Many-to-One Communication}

This type of communication primarily prevails in information monitoring and reporting. In this respect, information technology will be used here to filter, organize and share information from varying sources. The assumptions that govern this kind of communication flow in a classroom context are:

1. The best reporting medium is the paper.

2. Classroom discussion is the best form for sharing ideas.

3. As a broadcast medium, this type of communication is inefficient and time consuming.

4. It is difficult to access the knowledge of individuals through this type of communication.

5. Many-to-one communication can only occur at preplanned and predefined points in time.

Based on these assumptions, and within the context of the physical classroom, instructors usually conduct very well coordinated and orchestrated class discussions. Student assessment is done through exams, assignments, or projects. Whereas feedback 
regarding the performance of the instructor and quality of content is gathered at the end of the semester.

In a virtual classroom, some of the assumptions listed above are challenged as well. Information systems like interactive GDSS (Group Decision Support Systems) allow any participant to contribute in a fair and equal concept, without being influenced by certain personality and conflict factors or constraints. As these systems become webbased, class discussions and feedback on material and instruction methods can be managed regardless of time and space constraints. Furthermore, as the class progresses, instructors can tailor the topics and teaching style according to the particular needs of the students. This means that the virtual classroom offers students with unique opportunities not existent in the traditional classroom. Once again, the conclusion is that technology enabled classrooms offer the instructors' new and innovative ways of gathering opinion and managing knowledge sharing continuously without being influenced by physical constraints or social biases that may impede the presentation of ideas by some parties or individuals. Such interaction is an exciting advantage over traditional forms of classroom discussions.

\section{One to One Communication}

Considered as the richest form of communication, the purpose of this information flow is the sharing of information and knowledge. The role of technology here is to facilitate interaction and shareability beyond time and space boundaries. Technology-enhanced one-to-one communication can be exemplified in a phone call or sending of an e-mail. In the physical classroom context, several assumptions underlie one-to one communication:

1. One-to-One communication takes place during "office hours" or at a prearranged time.

2. It is best accomplished through face-to-face interaction.

3. Most of the time, the student initiates one-to-one communication with the instructor. 
4. Discussion of topics or content takes place within the context of peers, faculty, or other constituencies within the educational institutions.

Again here, technology is changing the nature of one-to-one interaction and is challenging these assumptions. Office hours, for example, are deemphasized in favor of e-mailing, where instructors can send certain information important to individual students. This might be replaced in the future by voice and video messages over data networks. Also, access to executives, students at other institutions, managers or experts will become much easier through advances in technology. In this virtual or technologyenabled classroom, students will be able to interact "one-on-one" with their professor as well as with constituencies not possible within the domain of the traditional physical classroom. The major advantage here is the transfer of knowledge, not only information. In the traditional classroom, this is not possible unless one is close to one of these knowledgeable and expert peers or those acquainted through social interaction. In the virtual classroom, these barriers are removed, and each student would have the opportunity to get exposed not only to the knowledge of the instructor but also to the knowledge held by each peer.

\section{Many-to-Many Communication}

This is important for group decision support processes. Similar to many-to-one communication, this information flow has been supported through the gathering of participants in a common place at a common time. This form of communication is the most difficult to support within the boundaries of a physical classroom. Many-to-many communication assumes the following:

1. It is best conducted outside the time and space of the classroom.

2. The formal presentation is the best medium for transforming information from many to many.

3. It is the least efficient form of information and knowledge transfer.

4. Progress and performance must be assessed through formal meetings among groups at different intervals. 
In a physical classroom context, this type of communication occurs as groups of students address each other through formal presentations. Team composition itself could become a function of compatible schedules, prior experiences, instructor assignment, or proximity within the physical classroom. In this case, the cost of coordination is perceived to be very high by both instructors and teams.

Relative to the physical classroom, the cost of coordination within the virtual classroom is low. With the availability of e-mail, discussion lists, chat rooms, and video conferencing, teams of students are no more confined to meetings and meeting space. A project Website for instance provides a means through which team members can share information and knowledge on a continuous basis. Furthermore, websites that link common aspects of all active projects (e.g. finance, marketing, competitor intelligence) will provide a means of sharing knowledge across project efforts as well as facilitate the sharing of people across project teams. For instance, a student that is an expert in some area of finance may work on this aspect of the group task and then contribute his or her expertise to other projects. Barriers of time and space associated with group coordination no longer limit project work to isolated group efforts. In essence, the assumption that a person belongs to one group and that coordinating between groups is too difficult is directly challenged through emerging information technologies. In contrast, the virtual classroom may facilitate the creation of market structures within the classroom in which project teams form and reform as the need arises. Furthermore, these teams may learn more readily about each other's efforts, facilitating efficient transfer of information and adoption of "best practice." In sum, improvement in many-to-many communication though the high-technology classroom creates a very different context for creating and managing group projects.

\subsection{Making the Transition to the High-Technology Classroom}

Assuming that we want to develop high-technology classrooms and see their capability used extensively and effectively, how do we go about it? In our view, there are two distinct approaches, one passive and one active. In the passive approach, an investment is 
made in providing technology in the classroom and the extended classroom, and the technology is made available to the faculty to use as they wish. If high technology is made available to faculty in this manner, some will exploit it in advanced and innovative ways, some will make minimal use of it, and some will make no use of it at all. To achieve more, we recommend an active approach in which aggressive steps are taken not only to supply the proper technology but also to create a strong culture supporting its use and application. With the proper environment, culture, and norms in place, the hightechnology classroom will become much more than using PowerPoint to make presentations. Moreover, the active approach will result in greater and faster knowledge transfer, and the types of technologies used will be far more extensive.

The key elements in the active approach include:

(a) Clear and active support from the top administrative levels (including the provision of adequate resources)

(b) Use of a reward system that supports innovation with the technology and its use

(c) Formal mechanisms for sharing knowledge and lessons learned on the effective use of technology

(d) Adequate support for the technology (the technology must be available when needed and made as easy to use as possible)

(e) The proper design of both physical classroom facilities with imbedded technology and the selection of technologies that extend outside the physical classroom

(f) Training that is well thought out and well delivered (some of which may be outsourced)

(g) Security at the physical and software levels to ensure that the technology is available as needed by both faculty and students. 


\subsection{Need for the Study}

An Executive MBA program provides an opportunity for experienced professionals to obtain a master's degree in Business Administration on a schedule that minimizes disruption of work and personal pursuits. Such programs include a cohort class structure that offers a professionally designed and planned curriculum in an executive setting. In other words, members of each class begin the program at the same point, move through the curriculum together, and typically complete the degree requirements for graduation as a group. Executive MBA (EMBA) students are required to complete their degrees in two years or less. During that period, they gain a wide range of new skills and sharpen their analytical abilities by combining course-work with day-to-day professional experiences. A unique aspect of an EMBA program is the collective professional experience of its participants which greatly enriches the educational environment. A team approach should therefore be used to allow for the sharing of diverse perspectives on various topics; this interaction results in a challenging and stimulating learning experience that provides for maximum return on time and resources invested.

EMBA students possess several years of significant career experience. Most students are sponsored both financially and through release time by their employing organizations, and all continue to work full time while enrolled in the program. To ensure optimum benefits to participants and the sponsoring organizations, class size and class structure should facilitate close interaction between faculty and participants.

Technology nowadays can offer a wide range of options regarding how classrooms should be designed - content and context wise - in order to maximize the learning benefits gained from any educational program. Despite its importance, no previous research work has tackled the issue of introducing a technology-based design for an EMBA classroom and studying the effect of such 
a design on the outcomes of the program and the performance of its participants. This is basically where the need for the study has stemmed from.

Another need originates from the fact that the Lebanese American University is going now through major changes entailing strategic planning and accreditation processes. The quality of the programs and the way they are being offered will play a significant role in this respect. Of course, integrating technology into these elements will make a big difference.

\subsection{The Purpose of the Study}

The use of technology in business schools has made graduate-level education more attainable. The executive MBA is designed as a learning model for people with busy lives and for many, this means managing full-time work, full-time parenting and full-time school. Everyday technologies which allow us to communicate with work, home and university make the EMBA a practical and achievable educational objective. A lot of resources are available at our disposal and as opportunities: wireless mobile computers, hot-zoned classrooms, virtual private networks, PDAs, WI-FI, mobile phones and cable TV. All have become part of the student's repertoire and academic setting.

EMBA programs vary in their use of technology. Click-and-brick programs integrate class lectures and course delivery through intermediaries such as DVD and computer-facilitated virtual meetings.

The executive MBA is a fully accredited and rigorous education program. Offered by more than 200 universities around the world, more than 5,000 working professionals graduate each year with an executive MBA degree. The flexible learning schedule and use of technology in a balanced manner make the executive MBA education as rewarding as it is attainable. People planning on pursuing this 
type of education would consider their learning style and find a program that can meet the balance of technology and classroom experience that suits them.

Currently, the EMBA class at LAU is held on Saturdays (2 Saturdays per class) in the School of Business Conference Room. The Saturdays-only Executive MBA study pattern provides an opportunity for a participant to obtain his/her master's degree in Business Administration on a schedule that minimizes disruption of work and personal pursuits.

The program includes a cohort class structure that offers a well defined and planned curriculum in an executive setting. In other words, members of each class begin the program together and complete the degree requirements for graduation as a group. The level of interaction amongst participants, however, is very minimal, and the instruction delivery method is highly based on class lectures. In fact, the number of lectures outweighs the number of case studies, group discussions, and online communication with the business community.

A unique aspect of the EMBA program is the collective professional experience of its participants, the exchange of which greatly enriches the educational environment. A team approach is usually used to allow for the sharing of diverse perspectives on various topics; this interaction results in a challenging, stimulating learning experience that provides participants with a return on time and resources invested.

The purpose of this thesis is to develop a design for a new EMBA classroom that will maximize this return on time and resources invested. In executive classes, a lot of the value revolves around debate and discussion. Because of this, the class design should allow for a very high interactivity level. The technologies used should facilitate this aspect in a better way. In addition to this, it should enrich the program with computer simulations, communications with the local and the international global world, and rapid access to important online information 
resources, as well as efficient and effective interaction with business leaders and students from other universities.

Furthermore, this thesis will examine the current situation of the MBA/EMBA Programs at LAU, the satisfaction level of both students and faculty with these programs, and student/faculty expectations, suggestions, and recommendations for improvement. In addition, the concept of a new EMBA classroom design will be highlighted, including 1) the design of and 2) the technology to be integrated into the classroom. This will be based on the data analysis results as well as the technology integration with and design of EMBA classrooms in well known universities around the world.

Based on this purpose, the study intends to answer the following questions:

1. Are MBA/EMBA faculty and students satisfied with the current program situation?

2. Is the MBA/EMBA program meeting their expectations in terms of content, delivery method, and layout?

3. What do they think about technology integration into the EMBA classroom?

4. What are the factors that are most likely to be associated with student/faculty preferences for designing a world class technologyequipped EMBA classroom?

5. What is the optimum design in terms of cost, interaction level, and learning outcomes?

\subsection{Study Outline:}

This study will follow the following outline: 
Chapter One: Introduction about what an EMBA is, about the classroom design, and about classroom technologies.

Chapter Two: A literature review of the major articles and studies conducted regarding EMBA classroom design, delivery methods, and technology used.

Chapter Three: This chapter will portray some selected classroom designs adopted for technology-equipped classes in some universities.

Chapter Four: (Study design and methodology) This chapter describes the methodology used to gather and analyze the data, and describes the approach followed in developing the new EMBA classroom design.

Chapter Five: Survey Findings and Analysis. This chapter reports the information gathered about the current EMBA program at LAU, students' and faculty's attitudes, and their suggestions and recommendations.

Chapter Six: The EMBA Classroom Design for the New Millennium.

Chapter Seven: Conclusions and Recommendations. 


\section{Chapter II}

\section{REVIEW OF LITERATURE}

\subsection{Overview}

Today's business environment is characterized as highly competitive, global, technologically intense, and fluid. The focus is on being a flexible thinker, a quick problem solver, a team player, an effective communicator, and a cross-functional manager capable of helping the organization adjust to rapidly, ever-changing markets (Verville 1995; Tanyel and Mitchell 1999). Universities, like business firms, need to monitor and adapt to the continuous changes taking place in the global business environment. Graduate business programs, in particular, are struggling to continually revise and update their curriculums to produce graduates with the skills and abilities they will need to contribute effectively and lead their organizations in this dynamic environment. The challenge for business schools is to develop and refine programs and courses that are responsive to the needs of graduate students, to the needs of the business, industries and government agencies that are employing our students, and to the needs of the local and surrounding communities of which the university is a part. Nowhere is this more evident than in the executive education market where companies continue to create their own in-house training or corporate universities rather than sending their mangers to business schools (SMITH \& FLETCHER, 2004).

Upgrading programs and changing curricula should take into consideration the highly advanced technologies that can be integrated into the teaching and learning processes and make them more effective. Technology offers a wide range of alternatives that can make the learning experience richer, more exciting, and more effective. Technology in the classroom promises instructors new ways of accomplishing tasks and innovative ways of teaching. Technology also offers a variety of options to help students effectively learn. Yet, technology has still not reached its full potential in institutions, largely because many instructors do not know how to implement technology into their teaching methods. 
This study intends to investigate the current situation of the EMBA program at LAU and AUB and suggest a design for an electronic EMBA classroom for LAU that matches with the challenges and dynamic environment of the new millennium. Though it is very important, there is no significant body of literature that tackled this issue. This chapter will address what researchers have contributed to the aspects of classroom design, integrating technology into the classroom, and the impact of an electronic classroom design on the participants learning processes and performance levels.

\subsection{A Deeper Look at EMBA}

Experienced professionals are savvy businesspeople, but their past education and experience cannot prepare them for today's dynamic global economy. To be an effective manager requires a broad and deep understanding of certain traditional business principles while internalizing the rapidly changing marketplace, from the use of technology to the application of new business rules. If this understanding is not acquired on the job it must be learned in the classroom.

The following are typical statements overheard from people entering the Executive MBA (Price, p.16):

"I've got a strong quantitative background but wanted to round out my management skills."

"My family business needs new thinking to stay competitive and I know a smarter competitor is a savvier competitor."

"I am at a point in my life where certain goals have been achieved and certain needs satisfied. Now it's time to make new challenges."

"My knowledge in banking is narrow and deep, just what is needed to get my job done. I need to round out my skills for the long term not just what awaits me around the corner."

"As a consultant, I need to learn how to better leverage knowledge as an asset to reach new markets."

"It's simple-you bit that wall, the feeling you get when reached a plateau. I surpassed my boss long ago. I have all this experience. I need to take myself to the next level." 
"If you are not swimming you are sinking especially at my age. I love to learn and am glad to be surrounded by distinguished and highly motivated professionals."

"No one reads their financial performance reviews at my medical practice. Anything with spreadsheets scares my partners. Someone has to start addressing these cost management issues or we'll sink."

"I am looking for a new career outside of accounting. I don't want to transition over to the client but shake up my career by getting exposed to a diversity of business issues."

What cannot be achieved on the job may be possible at school and vice versa. When the two are intertwined as in the Executive MBA, the educational experience becomes alive. Write a business plan, conduct a strategic analysis, dissect income statements, study on location at the corporation, brainstorm with a group of senior managers, and present to a board of directors or to a company's CEO. These exercises become lively activities and will open new doors at one's own place of employment.

\subsubsection{EMBA: History, Advantages, and Disadvantages}

The EMBA (Executive Masters of Business Administration) is a concept that was created at the University of Chicago 70 years ago. It came out as a method for senior management to gain an MBA whilst still working for their companies. The traditional MBA (Masters of Business Administration) is a full time 1-2 year course, tailored more for students with less management experience who want a good academic grounding in basic management theories.

The choice between enrolling for an EMBA or an MBA first comes up if the candidate is someone of relatively senior management experience for between 5-10 years. In exploring the decision to choose between the two, it's important to think of the advantages and disadvantages of the EMBA, which is a lesser-understood option. In his article, “The Executive MBA: Is it right for you? " Ching mentioned the following advantages and disadvantages for the EMBA choice of study: (Ching, 2005) 


\section{A. Advantages}

1. Whilst the EMBA does not offer the full choice spectrum of core courses as the full-time MBA, there is significant choice. The students decide the classes offered. If a class is not offered, the administration will accommodate and provide one if there is enough interest.

2. Classes are typically smaller than that of a traditional MBA. However, a class of 80 people gives you the opportunity to be very close to most of your classmates. All students in campus MBAs with 500 to 800 students agree that there is a big amount of anonymity.

3. Additionally, instead of networking with a younger traditional MBA crowd of 2528 year olds with two to four years of work experience, the EMBA only accepts more experienced candidates. The faculty is made up majorly of a powerful network of senior management, CEOs, CFOs, or Senior VPs of major companies or start-ups. The key to networking is not necessarily the number of people, but the quality of the crowd.

4. If you attend a very good university, your professors are the best of the best, chosen not only from your school, but others as well. They are paid consulting rates on the EMBA as it typically has no requirement to use solely internal professors.

5. Companies tend to pay for the course or subsidize a large portion of it.

6. You earn a full salary while going to school, so your opportunity cost is greatly decreased. This will offset the extra expense if you had to pay yourself.

\section{B. Disadvantages:}

1. Many business schools do not provide the same level of academic depth and technical expertise to the EMBAs as they do to the regular MBA students. Traditional MBA students have the ability to work harder in their classes (willing to prepare more, do more research, solve more problem sets etc.) EMBAs cannot handle it, due to their time constraints and work obligations.

2. The catch is that if a company paid for its employee's EMBA course, they also have to sign off on his/her participation in recruiting. This prevents him/her from 
finding another job through notorious campus recruitment efforts if he/she wishes to complete the EMBA.

3. Traditional MBA students are more academically qualified on average (there are always exceptions on either side) and are generally more challenging to teach. This can be due to the fact that EMBA students are qualified for entry based on more practical work experience, rather than academic credentials.

4. Professors re-write the EMBA courses at times. They may have to, because relative to the regular MBA course, there's less class time, less time to do exercises, and EMBA students often have taken fewer prerequisites, so they cannot be expected to come in at the same level. They might use the same textbook, but the emphasis of what is discussed in class, assigned as homework and most importantly, tested at the end, is different.

In a later section, an analysis will be made regarding how technology plays a major role in reducing these disadvantages.

Essentially, the bottom line is that both the MBA and the EMBA at a top school are fine programs, but have very different characteristics. They are remarkably well tailored for their audience, which means that one suits you better than the other. It is not really a matter of choice. Most people who apply to MBA's are not qualified with enough work experience to enter an EMBA program. Conversely, most EMBA applicants would likely be frustrated with the lack of experience and contacts of the younger traditional MBA student. (Ching, 2005)

Price (2004) also mentioned a list of "Overwhelming Pros" and "Traditional Cons" for attending an EMBA. They are the following: (Price, P. 28, 31)

\section{A. The Overwhelming "Pros" for Attending an EMBA}

1. Prestigious faculty

2. Student driven classroom discussions

3. Great networking opportunities

4. Exposure to real-life business issues

5. Study on location-residencies

6. Global consulting projects

7. Accomplished within two years

8. Immediate payback by applying lessons at work 
9. Focused curriculum

10. Corporate sponsorship

11. Maintain employment

12. Supportive administration and faculty

According to Price, there is no "one" reason to attend an Executive MBA program; there are least twelve. The EMBA offers "hands-on" experience in starting, building, expanding, and managing a business. Typically accomplished in two years, the program draws many of the best and the brightest both in faculty and in student body. A classroom full of business professionals, many are on fast-track to executive status, drive classroom discussions facilitated by the best and most experienced faculty the university has to offer. The following are reflections of EMBA students, as quoted by Price:

Ifeel the EM BA is an incredibly valuable degree. It means that the candidate is someone with tremendous practical experience, the kind of experience I evaluate to hire. I also feel that the EMBA offers the company, along with the individual, a richer more thorough perspective of the issues facing a competitive environment ... I got my MBA early in life between the ages of 22 and 24 years of old. Now looking back, I earned this degree early in life, possibly too early without first getting my feet really wet with experience. I am actually evaluating the decision to get a Ph.D. or an EMBA. Getting an EMBA is not just about getting a degree, but it is about getting educated.

-Synthia Molina, Claremont University, the Ducker School, CEO of Mission Accomplished/ Intelliworks

I believe the value of professional training is not what you learn from a book but what you learn from people around you and the application of that learning: Living it, being it. That's why you need to have five or ten years of work experience to truly grasp the value of the MBA. You need that maturity level. Obviously, attending the EMBA allowed me to continue to work, but it also allowed me to apply what was happening in my career. What ever I was studying in school, the application of it was close by and reinforced the instruction.

-Shelley Boyce, Wharton EMBA, CEO MedRisk

While theory is part of the academic experience, classroom discussions are intense, challenging, and stimulating as well as interspersed and enriched with real-life cases. A business class case study on the launch of a new pharmaceutical treatment may be 
theoretical for one student while a real-life application for another. "Apply what you have learned and learn what you've applied-that's the EMBA experience!" (Price, P. 29)

The learning environment varies from executive training center to corporate boardroom. Some programs rarely utilize their own campus, instead holding classes at company headquarters or executive training center. Students not only study practical business issues, many evaluate these issues firsthand at the company and on foreign soil. Students meet with corporate leaders across the globe and participate in global joint-consulting projects. For example, NYU students consulted on media and technology for the Walt Disney Corporation while visiting the Silicon Valley. Similarly, Fordham University students consulted on a market entry strategy for a fast growing computer company while studying in Beijing, China. Likewise, Wharton students studied the transition of Chinese rule on business practices while visiting Hong Kong. Georgetown students consulted on the privatization of air traffic control services for the British and Scottish governments. These are just a handful of the many dynamic and highly practical business school projects available in the Executive MBA curriculum.(Price, P. 30)

Attending the Executive MBA also affords a certain level of convenience not open to the traditional MBA program. For example, the university assigns a program administrator to handle most administrative responsibilities such as scheduling classes, picking up books and coursework, and arranging study tours. Some schools even provide students with customized laptop computers, for a fee. Whenever necessary, administrators provide students with the resources to remain connected with the office while sitting in class.

\section{B. The Traditional "Cons "for Not Attending an EMBA}

1. Not for everyone

2. Unorthodox learning style and teaching format

3. Requires predefined years of work experience

4. Lack of corporate support: time away from office and/or tuition reimbursement

5. Applicant may seek a broader more generalist business degree

6. Too demanding a commitment for student, family, and employer

7. May turn a 50-hour workweek into an 80 to 100 -hour workweek

8. Limited class meeting schedule makes absences from class not tolerated

9. No participation in career services 
An MBA is a terrific learning experience, whether part-time or full-time. But the Executive MBA is not an experience for everyone, especially if you prefer to work alone rather than in groups. The EMBA is heavily focused on group projects and student collaboration. Groups are usually permanent throughout the two years and if certain personalities within the group do not mix, the potential for conflict can drag down the entire business school experience.

The course work and class discussions are intense, hard, and participation is obligatory. Members of the group hold each other in check with high expectations, even though one may prefer more private time and project independence. Some schools may require corporate financial sponsorship. The EMBA is considerably more expensive than a traditional MBA or five-year, part-time MBA. Additionally, employers may not accommodate the hectic and potentially erratic work absences vital for fulfilling the EMBA.

The EMBA is not to be taken lightly; it is a true MBA experience. We had a combination of exams and papers. You have to stay on top of the work, stay disciplined, and communicate with your group and professors often ... Time management is critical and the potential for conflict was always present. Client needs drive my business and I can't leave work unfinished, especially without sufficient backup. Neither my management nor the client would stand for a reduction in service levels. Therefore, it's key to have backup in the office. There may have been some difficulty at times back in the office when I traveled for school and a big project was pending completion, but by and large, it was handled. Effective personal time management, coordination with the team, and support from your superiors were the necessary ingredients.

James Cecere, Duke University, VP JP Morgan Chase (Price, P. 32)

The timing may be right to pursue a full-or part-time MBA. Only the participant can decide this. One may have less than the preferred number of professional or managerial years sought for an EMBA. One may prefer a generalist focus in management or marketing and have no use for, or interest in, such specific exercises as Latin American business practices. One may desire greater academic freedom such as the ability to select certain classes and set schedule, and attend a broader mix of electives typically unavailable to the EMBA. (Price, P. 32) 


\subsubsection{Motivation for EMBA}

What motivates people to join an EMBA program? As could be noticed, with a certain level of experience, and with a strong aspiration to climb up the career ladder, the advantages listed above outweigh the disadvantages. Following is a narration of an experience that a manager lived before and during the time he joined the Fordham University Executive MBA program.

'When considering returning to school for my MBA, I had seven years of work experience, an MBA in its own right! I was earning a competitive salary at a top-ten marketing firm on Madison Avenue as a creative team manager for several large pharmaceutical accounts. Each workday I interacted with senior staff, managed a team of copywriters and designers, and built a solid rapport with my Fortune I00 clients. Everything should have seemed right, but I was greatly troubled. I frankly yearned for a change of pace, a desire for more and not necessarily at the company either. I knew if I returned to school I would add a lot to the classroom discussions and projects from a marketing and brand management perspective. I felt I practically wrote some of the chapters in the great unpublished book on pharmaceutical marketing. But I also knew the world is much bigger and technology, operations, finance, and governance were issues worth deeper exploration. My desire to achieve a senior position with my employer would require broader expertise that I simply did not have.

Returning to school had to meet certain conditions: 1) I wanted to be surrounded by people more knowledgeable than myself from a diversity of industries; 2) I wanted to use my years of work experience as a source to draw from for school; and 3) I needed to maintain full-time employment until I was ready to make a shift within or outside my company.

I found a perfect fit. I attended the Fordham University Executive MBA program because of its concentrated global management focus. I fulfilled my academic aspirations, met a group of elite professors, studied with a group of talented businessmen and women, and traveled across the globe working on real-world, practical, yet academic, projects in 
School work accommodated my hectic work schedule. While attending school I helped create a technology company, managed offices in the U.S. and Europe, won a prestigious technology and business award from Microsoft Corporation, and even made some money. Could I have achieved all this without attending business school? Perhaps, but the contacts and skills I developed, the discipline to solve complicated problems, and ability to negotiate and manage work groups across geographic borders all significantly enhanced my two years while attending the Executive MBA' (Price, P. 21). This is a real motivation for joining and benefiting from a good EMBA program.

The fact is that studies have shown an MBA does add value to a person's career prospects regardless of the school. In fact, in corporate life a large proportion of middle and upper management personnel have some form of graduate or executive level training. It is also clear that valuable theoretical and practical skills can best be taught in a formal classroom setting.

Corporations are growing increasingly reluctant to pay for training and education, therefore entering the work force with an MBA may give the person a strong advantage. The long-term value of an MBA is well established. Candidates might join an EMBA for a variety of reasons, such as: (Price, P.22)

- A desire for the credentials

- A desire to make more money

- A yearning to change careers

- An opportunity to advance in job status

- An opportunity to buy a productive time-out to search for career alternatives

- Shelter from a recession

- One or more of the above

\subsubsection{Who Attends the Executive MBA?}

"Last year, an estimated six thousand students attended any of the estimated one hundred eighty business schools that offer the Executive MBA worldwide. Attendees were divided equally between employees from Fortune 500 companies and small and medium sized businesses. Some students were CEOs and private business owners while others were managers at non-profit organizations." (Price, P. 24) EMBA classes may consist of doctors, lawyers, men, women, and parents of young children, all from a broad range of 
industries. The majority, if not all, are highly motivated and possess an intense desire to learn. A number of them may drive long distances to attend classes. All maintain full employment, many in high-pressure positions. Many of these students are self-sponsoredpaid their own way receiving little or no corporate financial sponsorship.

The ideal candidate has on average seven years of work experience and is between the ages of twenty-eight and fifty-five. Some of these work years are in management. The typical candidate has not only many success stories to shape with fellow classmates but also a few job failures and other professional disappointments. The typical candidate can demonstrate examples of leadership on the job as well as in the classroom; and balance in other areas outside of work, such as personal, civic, political, or religious activities. The ideal candidate also looks for new challenges and has a passion for learning (very important). At this stage in life, the candidate understands the short and long-term benefits of why an MBA is necessary. Realistically, the right time to attend business school comes after a period of personal growth and professional work experience, not early when the career is just beginning to take shape. Graduates of the Executive MBA agree that an MBA is a career tune-up.

The average age of my class was thirty-three years old. You got to a certain level in your career and now you want to take the next step. You are not so much interested in switching careers as you are at advancing your career. For others in my class, they do wish to switch careers. There are several doctors and the EMBA allows them to earn a salary while at the same time be surrounded with people their own age group and experience level, not necessarily the post college crowd. From New York, the longest commuters we have, I believe, are from Boston and Washington $D C$. We are diverse culturally and professionally. Represented in the classroom we have law, medicine, advertising, entrepreneurs, and nonprofits. B-school offers a unique opportunity to connect with people and build strong dialogue and bonds with people you would not necessarily connect with. The EMBA creates an opportunity to make these connections and I have created life long relationships.

-RP Singh, New York University, Director of Business Development, Reuters News Service 
The average age was between 30 to 35 , the youngest being 26 or 27 and the most senior was a physician in his early 50s who flew in from Atlanta and another physician from Phoenix. Most were married and about half had children. The profile was 60:40 male to female, and there were 100 students. Geographically we were primarily from the East Coast. About $30 \%$ were from Philadelphia, 30\% from DC, and 30\% from NYC. The balance was from Rochester, Atlanta and Phoenix-no one from outside the country.

-Shelley Boyce, Wharton EMBA, CEO of Med Risk

The EMBA has helped my career in a way no other program can. Unlike a full-time program, I was able to continue to advance my career while in school. Rather than putting my advancement on hold for two years, $l$ was able to maintain my status and achieve economic and title increases while attending business school. Perhaps more importantly, I was able to apply what I was learning as I learned it. This increased my retention and lifted my abilities on the job.

-Kevin McNally, New York University, Director, Solomon Smith Barney

At TSM, the distribution of work experience and age is as follows: (TSM, 2004)

\section{Work Experience}
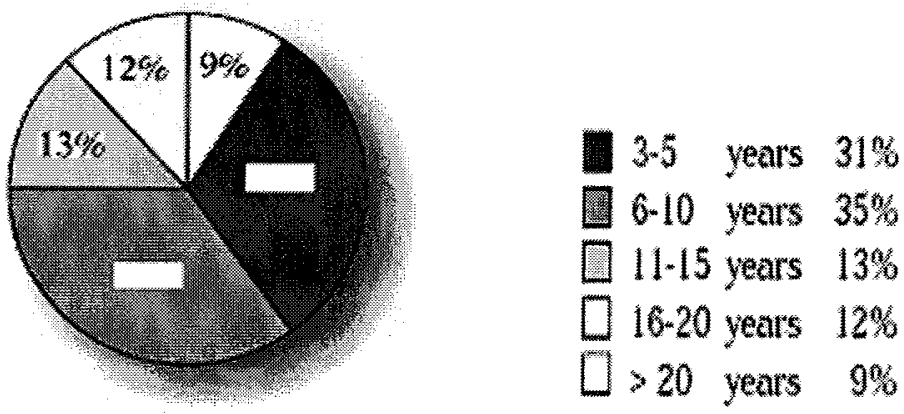


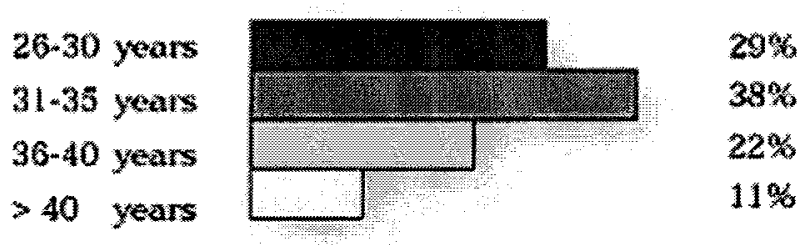

The percentages reported are in conformity with what Price mentioned in his study that included many EMBA programs in many universities. The EMBA participants have a great deal of experience and most of them are at their mid career level. Based on the reported results, one can figure out the importance of having a learning environment that is conducive to a lot of interaction, knowledge sharing, and experience transferability.

\subsubsection{Why is the Executive MBA Important?}

Business executives have to deal with multiple demands: they are expected to be visionaries, wise strategists, charismatic leaders, and fast decision makers, able to operate in and with any culture, and of course, flexible, innovative, rigorous managers.

And all this is required in a world where information, ideas, and the speed at which they flow have primacy. In this kind of world, rigid organizational hierarchy can often get in the way of effective customer response and strategy implementation. The ability to readily adapt is crucial. Executives need to continuously build their individual competencies, their human capital.

At the same time, the only sustainable competitive advantage that companies now have is their intellectual capital, the sum of the "hidden" assets in their organizations. This includes the multitude of talents possessed by each individual worker and manager, the human capital, as well as the knowledge assets that the company can actually document 
and control, the structural capital: databases, copyrights $\&$ trademarks, business processes, customer \& supplier relationships, etc.

One of the roles of executive development is to help increase the human capital, (i.e. increasing the competence of each individual manager), while at the same time helping the organization to convert as much of this human capital as possible into structural capital, assets that don't go home at night. It is not enough to build up the individual skills of each employee: when they leave your firm you lose this. Ways have to be found to do this while also benefiting the company. The IMD Executive MBA is structured to respond to this challenge. (IMD, 2003)

The demand for general managers with a technical and professional background is now beyond question. Today's companies have to operate in a market that is becoming ever more complex and in a world where the speed of technological development is growing exponentially. As a manager you need sufficient skills and know-how to handle in the processes that are intrinsic to a technically oriented environment.

The international Executive MBA program at any Business School in general is a personal general management development program with an international orientation, designed for managers who wish to fully exploit their talents and enhance their capabilities. The objective then is to support participants and generate out of them highly effective managers that can drive their companies to outstanding performance, success, and competitive advantage. The next section will highlight the characteristics of the effective manager that an EMBA program should take into consideration while designing the program - content and context wise.

\subsubsection{The Effective Manager}

According to the TSM Business School at the University of Twente, the effective manager should possess the following qualities: (TSM Business School, 2004)

- Relevant management experience

- Extensive managerial knowledge

- Dynamic learning capabilities

- Broad interpersonal skills

- An enterprising and responsible attitude 
These five characteristics should be made explicit and are vital to the success of any school of business EMBA program.

\section{The competent manager}

To manage all kind of new developments effectively, a purely technical and professional background is clearly no longer sufficient. An integrated knowledge of a wide range of disciplines such as strategy, marketing, finance and law, and of organization and innovation concepts, provides EMBA participants with a basis for making the right decisions, and for integrating new developments effectively within the company.

\section{The learning manager}

Moreover, as knowledge increasingly and more rapidly becomes obsolete, managers especially have to develop learning capabilities. They have to care of not only of themselves, but also of their (management) teams and their organizations.

\section{The proficient manager}

People are not born managers. At TSM, the program starts with an assessment of the abilities of each participant. The idea is to identify the candidate's strong points and skills that still need to be acquired. Among the management skills that are taught, special attention is paid to the development of the leadership qualities and the 'style flexibility'. In addition, the practical exercise of team building and conflict resolution skills is also an important part that needs to be considered by a successful Executive MBA program.

\section{The enterprising and responsible manager}

Effective managers take responsibility for their own actions, for their team's actions, and for the way the available resources are employed. They also bear responsibility for 
broader aspects, such as the environment. Entrepreneurship and responsibility go hand in hand. As the goal is to train managers who can strike the right balance between hard word and relaxation, the program, according to TSM, should also include time for sport and other activities designed to improve participants' physical and mental condition.

\section{Your experience as a manager}

As a participant in the International Executive MBA program the participant has something very personal to contribute to the course: his/her experience. Interactive exchange, both between participants and with lecturers, is one of the most important aspects of the program. According to TSM Business School, the EMBA program employs a model of mutual exchange of experience via interactive teaching involving group discussion of individual assignments and group meetings/networking between seminars.

It's worth mentioning at this stage that it is not only important to have cognitive abilities (financial, marketing, information systems...), it is vital to be able to share those abilities with others as well. Throughout the program, personal development should be worked on extensively. Providing professional services requires an ability to manage people, both staff and clients. TSM Business School, for example, has built up a solid reputation in the field of personal development. Their starting point is each individual and his or her actions, which are kept under constant review (action learning). In addition to individual assessment, there is peer-group counseling in small groups of fellow students. Plenary sessions provide excellent opportunities for further developing participants' leadership skills, under the guidance of experienced coaches. Personal development includes:

\section{$\underline{\text { Individual Assessment }}$}

This includes how a person functions as a manager. What are his/her strengths and weaknesses? At the beginning of the course, all participants are put through an accurate and detailed self-analysis. This sets the benchmark for measuring progress in selfdevelopment on the path to becoming an expert engineer/manager. 


\section{$\underline{\text { Negotiation Skills }}$}

The art of getting things done through people involves securing support and commitment from all parties. Negotiation skills are crucial to accomplishing this goal. At TSM, the EMBA Program not only communicates the techniques and methods of successful negotiation, it places participants in practical situations where they have to apply and practice them. Feedback on the application of these techniques is provided by skilled trainers.

\section{$\underline{\text { Communication Skills }}$}

Doing good work or having good ideas is simply not enough. The results of your efforts and ideas must be effectively communicated in order to be of practical use. During communication skills training, the TSM EMBA participants deal with all types of communication.

\section{Team Learning}

Teamwork requires special skills, including discipline and the ability to recognize and respond to key characteristics of team behavior: At TSM Business School, for example, the learning groups are kept small to enhance the effectiveness of team interaction.

\subsubsection{Recent Trends in the Executive MBA}

The course work and meeting structure of the Executive MBA allows for experimentation and some trends have surfaced in recent years. Some of these trends deal with the design and delivery of the Executive MBA, the rise of the global economy, and ubiquity of information technology. 
EMBAs are rapidly gaining credibility and the number of programs around the world is growing. Schools gain access to wider pool of applicants, capitalize on contacts with an international name and reputation, and help students gain cross-cultural experience. It is quite common for students to cross continents to attend classes. For example, $30 \%$ of Duke's Global Executive MBA students are from outside the US. The London Business School reports as many as $10 \%$ of its students come from outside the UK and up to $50 \%$ are non-British by nationality (Price, P. 26).

Another big trend that continues unfolding is the increased intensity of the delivery of the education. Driven by increasing demands made on students at their place of employment, the goal is for students to extract more value while in the classroom. Many schools now offer longer, more intensive training sessions yet meet for sessions less frequently-once you have them, teach them approach. One successful example of this is the recently launched Accelerated Executive MBA (AEMBA) offered by Fordham University, an intensive one weekend per month program. The AEMBA is a right fit for the incoming class of regional managers, senior VPs, and executives who are expected to work even longer hours and are short staffed in the lean economy. The design and price appeal to these job ranks. Many business school applicants who would have opted for traditional MBA are attracted to the concentrated EMBA programs.

Technology has clearly impacted the Executive MBA program. Many schools are adapting e-Learning models that incorporate web-based applications into their curricula. Schools are demonstrating novel uses with technology to connect, deliver, and archive the delivery of course work. For example, Duke University issues DVDs for many of its class lectures while the University of Illinois bridges multiple campuses throughout Greater Chicago using real-time digital conferencing. Most EMBA programs subscribe to group-ware platforms to link students, faculty and administrators in virtual private networks.

However, the efficacy of technology as a tool to deliver and augment graduate business education is open for discussion. A few programs use technology in place of the 
classroom. Some programs are building the entire learning model around computer applications. Others have taken a completely opposite approach and minimize the use of technology for only research and assignments. Most EMBA programs fall between the extremes.

\subsection{Learning Models}

A learning model (LM) is an unambiguous established model (as yet qualitative) of phenomena (usually knowledge increase) as they occur when using learning or instruction tools. (Min et al, 2000) It is well known that different people have different learning styles. It is well noticed that some people prefer to learn by listening to someone talking to them about the information. Some people prefer to read about a concept to learn it; others need to see a demonstration of the concept. Learning Style Theory proposes that different people learn in different ways and that it is good to know what students' preferred learning style is. (UMD, 2002)

On the other side of the coin, one can find learning strategies. These refer to methods that students use to learn. This ranges from techniques for improved memory to better studying or test-taking strategies. For example, the method of loci is a classic memory improvement technique; it involves making associations between facts to be remembered and particular locations. In order to remember something, you simply visualize places and the associated facts. (UMD, 2002)

Some learning strategies involve changes to the design of instruction. For example, the use of questions before, during or after instruction has been shown to increase the degree of learning.

According to a study done by the University of Minnesota Duluth (2002), Research on metacognition may be relevant to the study of learning strategies in so far as they are both concerned with control processes. A number of learning theories emphasize the importance of learning strategies including: double loop learning (Argyris), conversation 
theory (Pask), and lateral thinking (DeBono). Weinstein (1991) discusses learning strategies in the context of social interaction, an important aspect of Situated Learning Theory. (UMD, 2002)

\subsubsection{Learning Models in Relation to Management-Related Disciplines}

For some types of education in certain disciplines and fields, there are some common grounds regarding the type of learning style that is advisable. The following sections will talk about the learning styles recommended in the areas of management, decision making, problem solving, reasoning, and sales. It's worth mentioning that all of these are crucial skills needed by managers and executives.

\section{A. Management}

Management education encompasses a broad range of philosophies, techniques, and topics concerned with helping managers become more effective in their job. Management education sometimes focuses on specific skills (e.g., negotiation, budgeting), general abilities (e.g., communication, planning), or personal development (e.g., leadership, handling stress).

The double-loop learning theory of Argyris is especially relevant to management education. According to this theory, individuals must learn to discriminate the difference between their perceptions or intentions and reality (espoused theory versus theory-in-use). Such learning takes place primarily through interaction with others. Because of the importance of human interaction in management, social learning theory (particularly modeling and role playing) provides a general framework for many aspects of management education. Coaching and mentoring are commonly used management development techniques that attempt to harness social learning in the workplace. (UMD, 2002)

Theories of adult learning (e.g., Cross, Knowles, Rogers) that emphasize the importance of building upon the learner's experience are also very relevant to management education. The experiential theory of Kolb (1984) suggests that the learning cycle consists of four primary stages: concrete experience, reflective observation, abstract conceptualization, 
and active experimentation. According to Kolb, individual differences in these stages give rise to learning styles. (UMD, 2002)

The theoretical framework of action learning (Revans, 1980) has been widely applied to management education. Action learning involves structured projects in organizations rather than traditional classroom instruction. The key elements of action learning are: commitment to learning, social interaction, action plans, and assessing the results of actions. (UMD, 2002)

Creativity and problem-solving are usually considered important topics in management education (e.g., Roth, 1985). A major focus of DeBono's lateral thinking approach is to teach managers how to be more flexible in solving problems. Decision-making is also a critical skill domain for managers.

\section{B. Decision-Making}

From a practical point-of-view, one of the most important human skills is decisionmaking (judgment and choice). Both at a personal level, and in the context of organizations, decision-making skill strongly affects the quality of life and success. The topic has received considerable study since it is so fundamental to management education. (UMD, 2002)

A major focus of research on decision-making is how people don't usually stick to rational decisions. For example, Simon (1976) has made the case that "satisficing" (i.e., making a choice that is good enough) is the most common decision strategy. On the other hand, social psychologists look at decision-making as a matter of conflict resolution and avoidance behaviors due to situational factors (e.g., Janis \& Mann, 1977). Others discuss the role of probability and the limits to processing capacity in human judgment. (UMD, 2002)

Most theories accept the idea that decision-making consists of a number of steps or stages such as: recognition, formulation, generation of alternatives, information search, selection, and action. Furthermore, it is well recognized that routine cognitive processes such as 
memory, reasoning, and concept formation play a primary role in decision-making. The study of attitudes, creativity, and problem-solving is closely associated with decisionmaking. In addition, decision-making behavior is affected (usually adversely) by anxiety and stress.

Adult learning theories are also relevant to decision-making because they emphasize the role of experience and personal strategies in learning. The double loop learning theory of Argyris is especially relevant to decision-making skills since it focuses on analysis of the assumptions and implicit rules underlying the learning process. (UMD, 2002)

\section{Problem-Solving}

Theories of problem-solving are dominated by the work of Newell \& Simon on GPS (General Problem Solver). This work established the information processing paradigm for the study of problem-solving and the concepts of "means-ends-analysis" and "problem space". According to the GPS framework, problem-solving involves the identification of sub goals and the use of methods (especially heuristics) to satisfy the sub goals.

The Gestalt psychologist Wertheimer also conducted research on problem-solving and emphasized the importance of understanding the structure (i.e., the relationship among parts) of the problem. In his lateral thinking theory, DeBono stressed the importance of looking at a problem with a fresh perspective. (UMD, 2002)

Problem-solving skills appear to be related to many other aspects of cognition such as schema (the ability to remember similar problems), pattern recognition (recognizing familiar problem elements) and creativity (developing new solutions). The issue of transfer is highly relevant to problem solving. A good summary of problem-solving research as it applies to instruction is provided by Tuma \& Rief (1980). (UMD, 2002) 


\section{D. $\quad \underline{\text { Reasoning }}$}

Reasoning encompasses all thinking activities that involve making or testing inferences. This includes inductive reasoning (i.e., concept formation) and deductive reasoning (i.e., logical argument). Reasoning is also closely related to problem-solving and creativity.

Concept formation has always been a central concern of learning theories over the decades. Furthermore, the principles of stimulus generalization and differentiation account for categorization behaviors.

Research on deductive reasoning has historically focused on the solving of logical or mathematics problems. Indeed, one of the central questions of this research has been why people are so poor at logical reasoning. It has also discovered that people generally perform better with relations that can be visualized, leading to a spatial representation theory for reasoning. Also, recent research has focused on "informal" reasoning or argumentation, particularly in the context of attitudes and social or everyday settings. (UMD, 2002)

Finally, there have been a number of theorists who have attempted to develop a single framework that account for both inductive and deductive processes. For example, Margolis (1987) argues that all rule-following processes can be reduced to pattern recognition sequences and Holland et al. (1986) use the concept of mental models to explain reasoning.

\section{E. Marketing and Sales}

Marketing and sales training is a major category of instruction for most corporations and an area that has received considerable attention because of the significance of sales to profits. There are many philosophies of how to sell and different approaches to marketing and sales training (see Craig \& Kelly, 1990; Russell, Beach \& Buskirk, 1982). However, most sales methods encompass the following steps: (1) gaining customer attention, (2) understanding customer needs/wants, (3) presentation of product features/benefits, (4) handling objections, (5) closing, (6) follow-up. 
Theories of adult learning (e.g., Cross, Knowles, Rogers) that emphasize the importance of experience and self-direction are especially relevant to sales training. Theories of attitude change and persuasion are directly related to selling. Since selling depends upon human interaction, theories of social learning (i.e., Bandura, Vygotsky) are highly relevant to sales training. Techniques such as role-playing, simulations, and apprenticeship are frequently used in sales training. Coaching is also an important aspect of sales training in order to ensure transfer of learning to the job setting.

Creativity is usually considered a critical element of successful marketing and selling. While individual differences in selling methods are acknowledged, most sales approaches assume a person who is assertive, outgoing, and self-disciplined. Theories of motivation are applicable to how to make sales training meaningful to trainees. Many aspects of the selling process involve decision-making and problem-solving. Since selling often involves considerable stress, the role of anxiety in learning is also relevant to sales training. (UMD, 2002)

\subsubsection{Learning Models in University Settings}

Along with the learning models related to domains as mentioned above, the literature has talked about some learning models that are more pertinent to university classrooms in general, and others that are more specifically related to the EMBA Classroom. The following sections will discuss the models that the researcher believes would be enhancing to the learning process in an EMBA Classroom, namely, active learning, cooperative learning, learning by sharing, and experiential learning.

\subsubsection{Active and Cooperative Learning}

In the traditional approach to college teaching, most class time is spent with the professor lecturing and the students watching and listening. The students work individually on assignments, and cooperation is discouraged.

Such teacher-centered instructional methods have repeatedly been found inferior to instruction that involves active learning, in which students solve problems, answer 
questions, formulate questions of their own, discuss, explain, debate, or brainstorm during class, and cooperative learning, in which students work in teams on problems and projects under conditions that assure both positive interdependence and individual accountability. (Felder, 2001)

According to Felder, active learning is anything course-related that students do besides listening to a lecture. They may write, reflect, discuss, and solve problems, whatever. They may do it individually or together. As long as it is something other than watching and listening to the instructor, it is active learning. Cooperative learning is a more formal kind of activity where students work in teams that stay together for extended periods of time under conditions that involve five criteria. These are the following: (Felder, 2001)

Positive Interdependence - the team members have to count on one another to do what they are supposed to do, otherwise everyone loses.

Individual Accountability, which means everyone is held responsible for understanding both their part of the work and everyone else's parts.

Face-to-face Interaction at least part of the time. That rules out the familiar "You do problem one, you do problem two, I'll do problem three," and then participants come together, staple the problems together, and hand them in. That happens a lot, but it isn't cooperative learning.

Development of Interpersonal Skills needed to work effectively in teams. Students are not born knowing how to do conflict resolution, communication, leadership, time management, and so forth—some attention must be paid to helping them learn how to do those things. Therefore, if team assignments are to be given, explicit steps should be taken to help students learn those skills and to equip them to deal effectively with the logistical and interpersonal problems that commonly arise in collaborative efforts. 
Regular Self-assessment of Group Functioning. Periodically, teams have to stand back from what they're doing and ask themselves, "What are we doing well as a team? What could we be doing better? What are we going to do differently next time?"

Of course, the extent to which group work has those five elements in place is the extent to which it qualifies as cooperative learning.

This conclusion applies whether the assessment measure is short-term mastery, long-term retention, or depth of understanding of course material, acquisition of critical thinking or creative problem-solving skills, formation of positive attitudes toward the subject being taught, or level of confidence in knowledge or skills.

In the literature review conducted by Becker et al. (2004), it was mentioned that the benefits of collaborative learning have been demonstrated in countless studies and several meta-analyses (Johnson, Johnson, \& Stanne, 2000; Springer, Stanne, \& Donovan, 1997; Terenzini, Cabrera, Colbeck, Parente, \& Bjorkland, 2001). Compared to students taught traditionally, students taught in a manner that incorporates small-group learning achieve higher grades, learn at a deeper level, retain information longer, are less likely to drop out of school, acquire greater communication and teamwork skills, and gain a better understanding of the environment in which they will be working as professionals. These benefits are not automatic, however. Being part of an ineffective or dysfunctional team may well be inferior to independent study in promoting learning and can lead to extreme frustration and resentment.

According to Felder (2001), "my students learn the things I want them to learn to a much greater extent than they ever did when all I did was lecture and give individual homework assignments. They learn the course content, and they learn how to solve complex engineering problems that call on them to use high-level thinking skills. But even more important than that, they are acquiring some of the critical social skills they will need to succeed as professionals. They are learning how to communicate. They're learning how to work in teams, which they will have to do no matter whom they go to work for. They're acquiring leadership skills and time management skills, and they're learning 
a lot about themselves and how they learn best".(Felder, 2001) Of course, these are all lifelong learning skills, which are much more important than learning to solve an accounting problem or analyzing an econometric problem. When instructors use cooperative learning, their students acquire those skills; watching them and listening to them in class won't help them gain such valuable highly needed skills. This technique is a very important one.

\subsubsection{Learning By Sharing}

This model has been developed by the University of Amsterdam as a response to the strong need for a successful combination of life-long learning, entrepreneurial behavior and self-development. Based on this, "organizations will have to be redefined as generic learning environments for individuals”. (Thijssen et al, 2003)

This integrating concept learning model generated by the University of Amsterdam involves three types of participants in the learning process and three methods of learning. The participants are: business individuals, teachers/researchers and students. The three methods of learning are: learning by experimenting, learning by investigating, and learning through practice.

The Learning by Sharing Model came as a solution to the problem posed by the passive learning still followed and adopted by certain universities that insist on not changing the instruction and learning methods and not making use of the learning technologies now available in the market.

Looking at the description of the model, one can find that it incorporates and extends the solutions provided by the collaborative, constructivist, and cognitive learning models. These are elaborated in the sections below based on the literature review done by Thijssen et al. (2003)

\section{A. Learning by Sharing and the Collaborative Learning Model}

The basic premise of the Learning by Sharing model is drawn from the collaborative approach, and that is, "Learning emerges through the shared understanding of more than 
one learner" [Leidner and Jarvenpaa, 1995: 270]. It is argued that learning should not be a solitary process: "Knowledge is created as it is shared, and the more it is shared, the more is learned" [Leidner and Jarvenpaa, 1995: 268].

\section{B. Learning by Sharing and the Constructivist Learning Model}

Secondly, drawn from the constructivist approach, the Learning by Sharing model is learner-centered and not teacher-centered. For the student this means that the notion of self-guided study is complemented with a self-guided educational program [Kaldeway et al, 1998]. This extends the constructivist belief that "Individuals learn better when they discover things themselves and when they control the pace of learning". In the Learning by Sharing model, therefore, students design their own curriculum. They create an individual learning route according to their interests, abilities and learning style. (Thijssen et al, 2003)

What's the role of the teacher then in this model? The teacher in this model plays the role of coach, and presents the student with various opportunities and possibilities for designing a personal curriculum. The teacher coordinates the entire learning process and gives feedback when and where needed. Ideally, the teaching style will match the learning style of the student [Kaldeway et al., 1998: 274]. The learner-centered approach transforms the passive attitude of the student into an active attitude. The student constructs his or her own knowledge structure. (Thijssen et al, 2003)

\section{Learning by Sharing and the Cognitive Learning Model}

The Learning by Sharing Model draws from the cognitive approach the importance of the monitoring process. Teachers need to help students develop their abilities to direct their own learning process. An essential feature of the Learning by Sharing Model is "its emphasis on the meta-level of the learning process, that is, the meta-cognitive level. This entails the need to reflect on the learning process, for both teacher and student. The teacher is in a process of learning to educate and the student is in a process of learning to learn." (Thijssen, 2003) For the teacher, this means constantly reflecting on the teaching 
approach and improving it where possible. For the student it means ongoing selfevaluation of the course of the self-guided learning process. As noted by Kaldeway et al. [1998] this self-evaluation includes assessing whether or not the intended learning goals have been met.

In order to introduce real-life experience and hence to establish a learning community, the Learning by Sharing Model introduces a third party into the learning process: business individuals. By bringing in business individuals, the learning process changes drastically. In contrast to the traditional student-teacher relationship, the business individuals introduce a real-time and real-life link to everyday practice. Business individuals, students, and teachers learn by interacting in three ways. The learning experience gained here will thus be richer, more effective, and more pertinent to what the students will find when they go out for work.

\subsubsection{Experiential Learning}

Experiential learning is a vast field of practice. In his article, "What is Experiential Learning?" Henry Saddington (2004) presents what this learning model means to different people. He mentions that for some people it is all of education, while for others, it is narrowed down to a specific practice or curriculum model. He then refers to Jane Henry's work to show the vast array of educational activities using the term experiential learning.

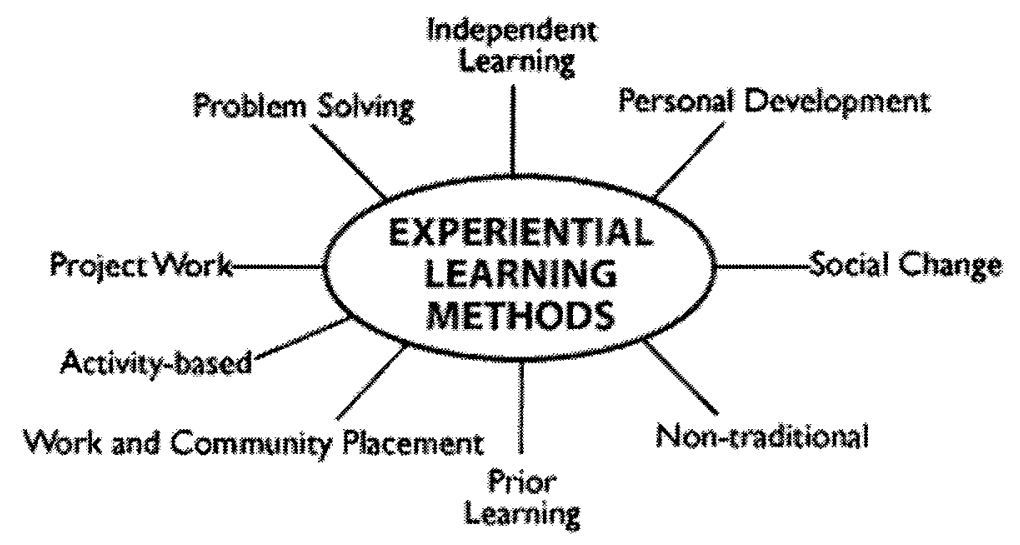

Source: Saddington, What is Experiential Learning, 2004. 
Another useful categorization of the field of experiential learning was developed out of the work of the First International Conference on Experiential Learning in London in 1987. (Saddington, 2004)

According to the proceedings of the conference, "Experiential learning refers to a spectrum of meanings, practices and ideologies which emerge out of the work and commitments of policy makers, educators, trainers, change agents, and 'ordinary' people all over the world." 'Experiential learning' means to them different things - as relevant to the challenges they currently face: in their personal lives, career lives, in education, in institutions, in commerce and industry, in communities, and in society as a whole.

As a learning model, experiential learning can be described as a "process by which the experience of the learner is reflected upon, and from this emerge new insights or new learnings." (Saddington, 2004)

David Kolb developed the most established model of experiential learning. In his model the process begins with an experience ("concrete experience"), followed by reflection ("reflective observation"). The reflection is then assimilated into a theory ("abstract conceptualization") and finally these new (or reformulated) hypotheses are tested in new situations ("active experimentation"). The model is a recurring cycle within which the learner tests new concepts and modifies them as a result of the reflection and conceptualization. This is shown in the diagram below: 


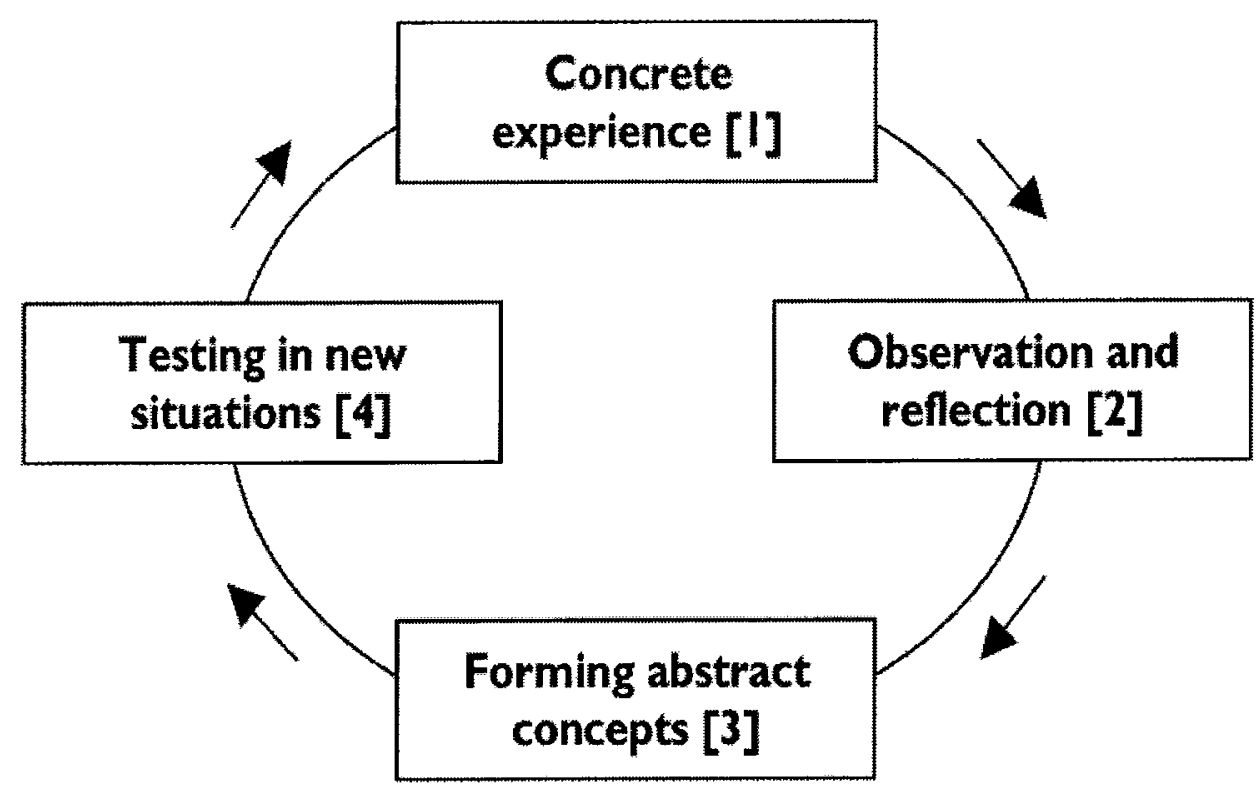

Source: Smith, David Kolb on Experiential Learning, 2005

In his article, "David Kolb on Experiential Learning" (2005), Smith mentions that Kolb and Fry (1975) argue that the learning cycle can begin at any one of the four points - and that it should really be approached as a continuous spiral. However, it is suggested that the learning process often begins with a person carrying out a particular action and then seeing the effect of the action in this situation. Following this, the second step is to understand these effects in the particular instance so that if the same action was taken in the same circumstances it would be possible to anticipate what would follow from the action. In this pattern the third step would understand the general principle under which the particular instance falls. (Smith, 2005)

Most models of experiential learning are cyclical and have three basic phases: an experience or problem situation; a reflective phase within which the learner examines the experience and draws learnings from that reflection; and a testing phase within which the new integrated insights or learnings are applied to a new problem situation or experience.

Experiential learning can therefore be defined in terms of a learning model "which begins with the experience followed by reflection, discussion, analysis and evaluation of the experience. The assumption is that we seldom learn from experience unless we assess the 
experience, assigning our own meaning in terms of our own goals, aims, ambitions and expectations. From these processes come the insights, the discoveries, and understanding. The pieces fall into place, and the experience takes on added meaning in relation to other experiences. All this is then conceptualized, synthesized and integrated into the individual's system of constructs which he imposes on the world, through which he views, perceives, categorizes, evaluates and seeks experience." (Albert Wight, "Participative education and the inevitable revolution" in Journal of Creative Behaviour, Vol. 4, No 4, Fall 1970, pp. 234-282, quoted from: Smith, 2005)

In fact, the theoretical work done on experiential learning has established it as a method of learning which is useful to both educators and learners. This methodology helps learners to develop capacities to reflect on experience and appropriate significance through such reflection.

After discussing the learning models mentioned above, the researcher will now emphasize the Learning by Sharing Model. The researcher believes that this is an important model to be emphasized in the EMBA program and classroom environment.

\subsubsection{Learning by Sharing: A Model Enhancing Collaboration}

The Learning by Sharing model incorporates the collaboration of three parties in real-life learning: "the outside world as represented by business individuals, universities as represented by teachers/researchers, and the young generation as represented by students." (Thijssen et al, 2003) These three parties interact in various ways. As shown in the figure below, their interactions are shown along the three sides of the learning triangle: learning by experimenting, learning by investigating and learning through practice. These will be discussed in the following sections. 
Fig. : Learning By Sharing

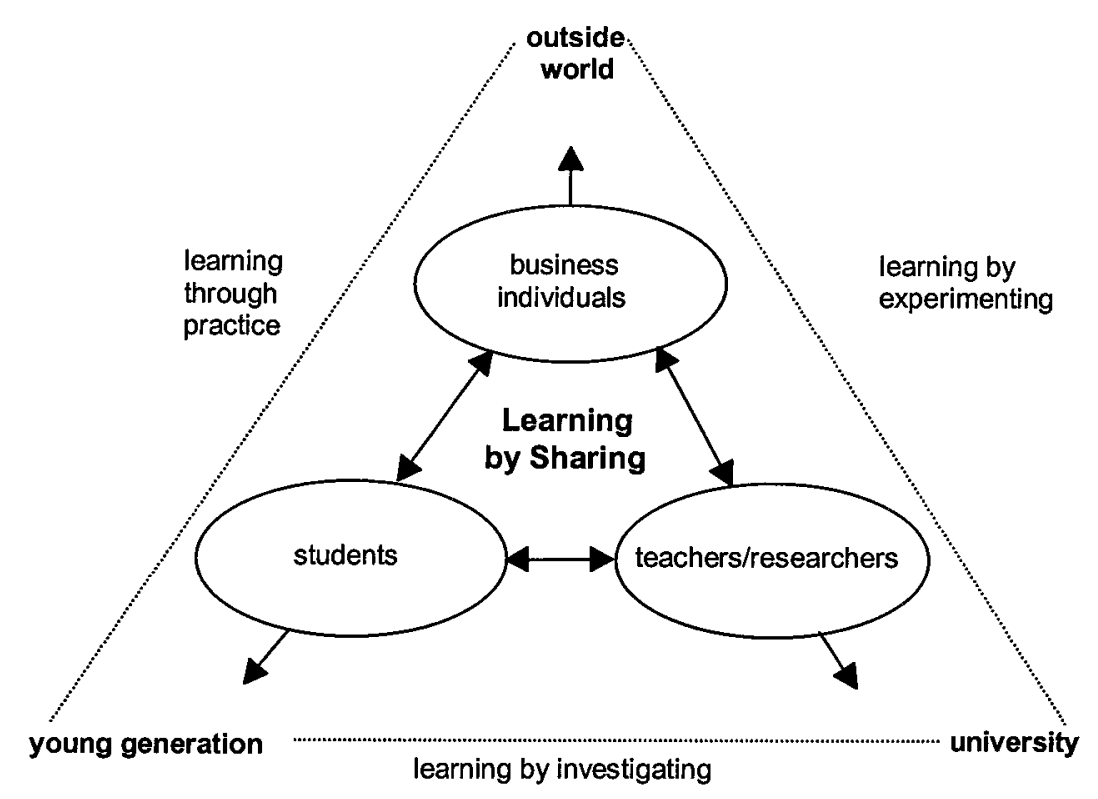

Source: Thijssen, Learning by Sharing: A Model for Life-long Learning, 2003

\subsubsection{Learning by Experimenting:}

This indicates more interaction between teachers/researchers and business individuals. The key to enhancing the social character of academic learning is the collaboration of universities with communities of practitioners. Many universities already maintain such partnerships (For example, University of Oxford and Hewlett-Packard), but some don't take full advantage of the possibilities. To achieve this, these partnerships should not only be intensified but redefined as well. Traditionally these relationships are dominated by the stereotypical notion of the practitioner as "... the passive (and theoretically ignorant) recipient of the expertise of academics" [Argyris and Schön, 1996: 34], and of the academic as "... the theoretically well grounded scientist, lacking considerable insight into the real world". (Thijssen et al, 2003)

In the Learning by Sharing model, the notion of learning by experimenting is important: teachers/researchers and business individuals work together in research projects. (Thijssen et al, 2003) This joint research work results in a sustainable information exchange between the parties involved. To this end, teachers/researchers in business economics, management, operations, management information systems, 
marketing and others should engage in dialogue not only with others in the academic community but also with business individuals actually working in the field. Such dialogue can develop into practical collaboration, both in research and in teaching, on specific topics of mutual interest.

As far as research is concerned, the direct link between the two communities enables researchers to identify areas in which to conduct truly relevant and innovative research. This ensures the production of useful knowledge, that is, knowledge useful for the business community. The notion of researchers as practitioners refers to the empirical testing of a theory, after which it can be adjusted according to (business) practice. In this way, applied research becomes research that matters, research where results are immediately applicable. (Thijssen et al, 2003)

On the other hand, the notion of practitioners as researchers refers to practitioners putting theories to everyday use [Argyris and Schön, 1996: 50]. They can adjust their insights by incorporating new theories.

For the research community, the combination of new theories and practical topics ensures that the contributions made by the collaboration of researchers and business individuals (joint applied research) are not only grounded in theory but also relevant to business practice. At the same time, participation in research activities enables practitioners to significantly enhance their operating abilities (operational excellence), and to keep abreast of state-of-the-art developments in academic disciplines. Partnerships between academics and practitioners on key issues in business practice are therefore mutually beneficial.

As far as teaching is concerned, a second exchange is possible. Business individuals can also be called in as teachers in educational programs: practitioners as teachers. This provides students with an opportunity to learn from the first-hand experience of business individuals. When interacting with students, the visiting teachers are called upon to reflect on their business practices, because students question particular cases from the perspective of the theories they have studied. 
A final aspect of "learning by experimenting" is that researchers are called in as advisers in a business environment: researchers as consultants. In this role the researcher reflects upon business practices from a theoretical point of view. (Thijssen et al, 2003)

\subsubsection{Learning by Investigating}

This leads to more interaction between students and teachers/researchers. Universities today face two major educational problems. Firstly, since the 1950 s research has outgrown teaching in importance [Leggon, 1997: 221-243]. The amount of time needed to introduce new research topics into current curricula results in a curriculum being continuously outdated. Secondly, the traditional perspective in which the student is considered a "knowledge consumer" and the teacher a "knowledge provider" results in impersonal student-teacher relationships and a one-way flow of knowledge. To cope with these educational problems, new ways should be found to integrate research and educational activities. (Thijssen et al, 2003)

To tackle the problem of outdated curricula, teachers and students should collaborate in research projects. In the Learning by Sharing model this collaboration is an important notion: learning by investigating. Students formulate their educational needs and look for teachers to do research with. Teachers serve as coaches and facilitate the self-guided education of students.

This collaborate research solves as well the problem of a one-way flow of knowledge. Students can influence future research by pointing out the topics that interest them and participate in this research. They may publish their findings and should explain what they have discovered, leading to the notion of students as teachers. Teachers receive direct response from their students on the curriculum which may encourage teachers to change their teaching method. In the research, teachers may find new teaching material, leading to the notion of teachers as students. (Thijssen et al, 2003)

\subsubsection{Learning through practice:}

This means more interaction between students and business individuals. In fact, a gap is often noticed in the relationships between university students and business individuals, 
between learning and working, between theorizing about practice and putting theory into practice. This is why a lot of universities advocate learning through practice to bridge the gap on the way to life-long learning. One common way to solve this problem is through internships or traineeships. (Thijssen et al, 2003)

Traditionally, internships are intended to diminish the gap between learning and working. But, according to Thijssen et al's literature review, there are some problems. The first is that a common objective between students and business individuals is often missing [Ghoshal and Bartlett, 1997]. The second is that most internships lack academic challenge because students are exploited as cheap labor. The third is that the duration of internships varies tremendously from several weeks to an entire year [Ontwerp Hoop 1998, 1997]. This makes it difficult to organize supervision of students in their work situation. The fourth problem is that the quality of guidance by both the university and by business individuals often falls short. (Thijssen et al, 2003)

In the Learning by Sharing Model, learning through practice is an important notion. It bridges the learning-to-working gap. By intensifying interactions between students and business individuals, the traditional boundaries are reduced. Students and business individuals interact in an earlier stage of the study with high frequency. During their entire academic career, students should participate in projects with various business individuals. This leads to the notion of students as practitioners. For example, students might work one day a week in a business environment and build up relevant working experience.

At the same time, business individuals are confronted with fundamental questions students pose about traditions of the companies they are working with. Business individuals are forced to think about the logic of their behavior in the context of new practices emerging from information and communication technology. This results in the notion of practitioners as students.

The benefits of theorizing about practice and putting theory into practice are shown in Table 1 [adapted from Roobeek and Mandersloot, 1998]. The student is a learning worker and the business individual is a working learner. Simultaneously, the student and the business individual learn how to assess the benefits of combining theory and practice. "As just one example, both become aware of the occurrence of confusing homonyms and 
synonyms, like costs, expenses and expenditures, in textbooks and in the business environment" (Thijssen et al, 2003). The student can reflect on his own body of knowledge and learn from this reflection. At the same time, the business individual benefits from the immediate employability of the working student.

It is important to state that for students, "learning through practice" is a basis for life-long learning, and for business individuals, it is part of life-long learning.

\section{Table A: Learning through practice}

\begin{tabular}{|l|l|}
\hline \multicolumn{1}{|c|}{ Students: } & \multicolumn{1}{|c|}{ Business individuals: } \\
theorizing about practice & Wutting theory into practice \\
\hline Learn and work & Relevant theories for practice \\
\hline Relevant practical situations for & \\
\hline Imeories (work experience) & Immediate employability of student \\
acquired knowledge & \\
\hline Do practical research projects & Gain from research findings \\
\hline organizations) & \\
\hline Basis for life-long learning & Students and universities) \\
\hline Networking (learning to know various & Networking (learning to know various \\
\hline
\end{tabular}

Source: Thijssen et al, Learning by Sharing: A Model for Life-long Learning, 2003 
Learning through practice enables students to carry out research projects in practical situations. For example, research questions for graduation projects might be derived from problems encountered in the business environment. These problems are tackled by students, and business individuals can apply the findings of the students. This way the business individuals possibly gain from the improvement of their businesses by the application of new knowledge, derived from the student projects.

At the same time, both students and business individuals are expanding their network of relationships. Students are exposed to business individuals from several organizations. Business individuals get acquainted with students from different universities.

The building of the curriculum on "learning through practice" has certain effects on the university. Firstly, the university must establish an intermediary between students and business individuals. Secondly, the university must ensure the educational value of the learning-through-practice relationships. Thirdly, the university must offer guidance to students in developing relevant ways of thinking and practicing.

\subsubsection{Using Simulation in Learning}

Model-driven (computer) simulation (MDS) is an open interactive learning environment (here) - based on a reality model - whereby the underlying mathematical model will ultimately determine how it will react on an action of a user (here: a learner). (Min et al, 2000)

The primary goal of a learning tool like a computer simulation program should be motivation for possible further study in boring books or dull lessons. In our type of learning tools and simulation program learning comes only second. A computer simulation program should increase the insight into a matter. Students should be taught to think in a wider perspective; they should see the cohesion between things. Present knowledge and insights should be strengthened; the learner should learn to think in concepts.

Computer simulation programs "teach one by doing". Because one is working on a task or case one learns. A simulation environment is a "do" and "work" "environment" at the 
same time. Computer simulation programs and other learning tools are important to organize a curriculum in such a way that students are offered differentiated learning tools. This guarantees the individual student that he can follow the right learning course. It helps break the curriculum's or learning program's monotony. It is purely for personal change (optional) and because some students can be better motivated this way (possibly because of the different approach; perhaps because of their visual or auditive preference for the one or the other learning tool).

\subsubsection{Learning Models Adopted By Some Universities}

After discussing the various kinds of learning models, especially those pertinent to universities, it is worth mentioning at this point some examples on learning models adopted by some well known universities, and more specifically in their MBA or EMBA programs. The following sections will depict the learning programs in three universities: The UCLA Anderson MBA Program, The University of Amsterdam, and the Duke University.

\section{The UCLA Anderson MBA Program}

The UCLA Anderson MBA Program works to increase participants' capacity and prepare them to be effective business leaders. The program uses a student-centered approach and emphasizes the close connection between management education and management practice. The UCLA Anderson learning model focuses on the fundamentals of business, analytical problem-solving skills, and the development of an explicit point of view on both strategic leadership and what it means to lead.

In the Anderson's MBA Program Brochure, it is mentioned that Anderson's MBA faculty collaborate to provide educational experiences that enable MBA students to develop and integrate the knowledge and skills they will need to address significant strategic issues and lead complex organizations. A faculty team supervises the program culminating Applied Management Research Project, a six-month original applied research project that integrates and expands students' capacity to solve complex business problems. 
The Brochure also states that teamwork has been central to the UCLA Anderson learning model for more than 30 years. In today's highly competitive business environment, success most often belongs to the organizations with the strongest teams. Today's successful managers must be effective team players who can blend collaboration, leadership, and communication skills to cooperate with others, and who can instill similar values in their employees. The UCLA MBA Program uses innovative methods to engage students in goal-oriented projects that draw upon and refine teamwork skills. Teambuilding exercises, simulations, cases, and conceptual models all help MBA students become more effective both as team members and as leaders.

From the beginning of their MBA studies, Anderson students find new ways to integrate their academic education with the practice of business leadership. The combination of study, teamwork, and interaction with the business community ensures that Anderson MBAs develop:

- A sophisticated awareness of the global, technological, and competitive forces shaping business

- Analytical problem-solving skills that directly relate to critical business issues

- A high-level ability to exercise sound judgment, make effective decisions, and take appropriate responsibility

- Strong interpersonal, communication, teamwork, and leadership skills

- A strategic understanding of the role of information and communication technologies in business and management

All UCLA Anderson MBA students take active responsibility for integrating their own learning, and all have many opportunities to develop and apply the skills required both to organize and to function within a productive team. 


\section{The University of Amsterdam MBA Program}

In the University of Amsterdam, an integrative learning model, Learning by Sharing, is adopted as a model for life-long learning. According to the University, the main improvements of this model on existing learning models are the systematic introduction of the external world into the learning process and the reciprocal nature of the interactions involved: business individuals with students, students with teachers/researchers, and teachers/researchers with business individuals. All learn from the shared learning experiences.

The Learning by sharing model is under full implementation at the University of Amsterdam. To facilitate contact between participants, meetings and informal gatherings are held to bring students, teachers and business individuals together. These gatherings result in many new ideas, out of which several useful projects have already been developed. The use of the Learning by Sharing model increases the speed and depth of learning considerably, and the interaction satisfies the educational needs of all three parties involved.

\section{The Duke University MBA and EMBA Program}

Duke University is a good example of building the learning model around the use of technology: it enables students from all over the world to access lectures and it facilitates joint projects as classes are bridged to sister schools. (Stuart, 2005)

With the advanced computer and communication technologies, students can stay connected to the classroom and their classmates whether they are in class or on the road. As a demonstration, consider the following examples: 
Take Sandy, a pharmaceutical marketing professional from New York who is also a fulltime mother and MBA student. While getting the children ready for school, she looks at the prior evening's e-mail exchanges and posts a question to the professor. After dropping the children at school she heads to the office where she uses her cell phone to call classmates and confirm the evening meeting. At lunch time she logs onto the class's private virtual network and reviews the professor's response. There, she has on online chat with him, then saves the conversation to a digital file which she then forwards to the group, printing out a copy for the evening discussion.

Jeff, who lives in Boston, is a banker and member of the group. His unexpected business trip to the West coast means he'll miss the usual group meeting by conference call. He is scheduled to fly home on Thursday knowing he has to complete a section of the paper and slides for the Friday presentation. In LA he reviews Sandy's chat record, a summary of the group discussion and completes his section of the assignment on the flight home. At the airport, he uses his wireless computer to send his work to Sandy for review. As the semester's leader, Sandy consolidates the work and disseminates a draft by e-mail to the group. The group convenes on campus an hour before class to rehearse and polish the paper before presentation. (Stuart, 2005)

Considering the Learning by Sharing Model as the most effective for the learning process to be successful, one cannot ignore the role of technology in this respect. The rapid advancement in computer and communication technologies has paved the way for a lot of constructive applications in the educational sector. The following section will talk about technology use and integration into the classroom environment, the role it plays, the benefits it offers, and the challenges it poses.

\subsection{Integrating Technology into the Learning Environment}

Digital technologies are a potential tool for transforming how we go about learning in deeply meaningful ways. In fact, instructional technology is a continuously evolving field in higher education and its use has increased substantially over the past decade. As early as 1977, the Association for Educational Communications and Technology (AECT) defined instructional technology as a "complex, integrated process involving people, 
procedures, ideas, devices and organizations, for analyzing problems and devising, implementing, evaluating and managing solutions to those problems involved in all aspects of human learning" (Albright, 1996, p.2 cited in Serban, 2002)). Thus, instructional technology involves more than the hardware and software; it includes "classrooms and labs, faculty teaching skills and student achievement, course organization and delivery, and even the subject matter itself" (Albright, 1996, p.3 cited in Serban, 2002).

\subsubsection{Definitions of Technology}

The term technology is used very loosely to describe a variety of ways computers are integrated into the learning process. Descriptors for technology used in the classroom include, but are not limited to, the following:

- technology-mediated learning,

- computer-aided instruction,

- distance education,

- distance learning,

- educational technology,

- home learning technologies,

- computer-based education,

- instructional technology,

- multimedia,

- communications systems,

- Web-based learning,

- educational multimedia applications, and

- Computer-mediated communication.

Simply put, technology is a word that is used to describe different things to different people. Technology is a term that is used by many to describe, study, and evaluate the various ways computers are integrated into education, both inside and outside of classrooms. Some authors are specific in describing specific technologies or applications; 
other authors simply use the term technology to describe everything electronic. Moreover, there is no consensus about what constitutes technology in learning or teaching. However, the common link tends to be some use of the personal computer to aid teaching or learning in some form or fashion. These technologies run the continuum of integration in education from entire courses put on the Web to technology integrated into a specific lesson. Though most research studies focus on computer-based technology, there are other teaching and learning technologies that are not computer-based. These can include overhead projectors, document cameras, laser pointers, robotics, television, VCR, DVD, demonstration equipment, sound systems, CDs, tape recordings, simulation machines, and models. Some evaluators even consider the traditional piece of chalk and chalkboard a type of technology.

In this study, technology is used as a term that could include any type of equipment, inside or outside the classroom that is used to aid the learning process. This can include any of the technologies mentioned above as well as computer-based technologies, hardware, software, or Web-based learning.

\subsubsection{The Role of Technology in the Learning Process}

Following from these definitions, the fundamental roles of instructional technology are:

$>$ To accomplish tasks that faculty cannot do by themselves, such as helping students experience times, places, people, and events that might not otherwise be possible in the class.

To accomplish tasks better than they can by themselves, such as holding a video conference session with the CEO of a well known company.

$>$ To perform routine teaching tasks that instructors can do but prefer not to, for example computer-based drill and practice exercises.

To prepare students for the world of work, training them how to use technologies they will experience on the job after they graduate, and

To reach, via distance learning, those students who cannot attend classes on campus for various reasons." (Albright, 1996, p.4, cited in Serban, 2002) 
Within the literature on technology and learning, there is a debate raging among researchers and theorists concerning the effectiveness of using technology to help students learn.

Generally speaking, there is an assumption that technology fosters learning merely by its use in the educational process. Ehrmann (1999) sums up this assumption very nicely (cited from Achacoso, 2003):

\section{Technologies such as computers (or pencils) don't have predetermined impacts; it's their uses that influence outcomes.}

This statement seems obvious, but many institutions act as though the mere presence of technology will improve learning. They use computers to teach the same things in the same ways as before, yet they expect learning outcomes to be better. However, not all researchers, evaluators, or theorists agree that simply the presence of technology helps the learning process. As such, two groups have formed in regard to this issue.

As mentioned by Achacoso's review of literature, Richard Clark is probably the most outspoken researcher who argues against the view that media by themselves influence the learning process. In his groundbreaking essay, Clark (1983) said succinctly: “...media are mere vehicles that deliver instruction but do not influence student achievement any more than the truck that delivers our groceries causes changes in our nutrition" (cited from Achacoso, 2003). In essence, Clark believed that media do not help students to learn in any circumstance and that the instructional method is the source of the learning:

I accept the point that whenever learning occurs, some medium or mix of media must be present to deliver instruction. However, if learning occurs as a result of exposure to any media, the learning is caused by the instructional method embedded in the media presentation. 
Further, he stated that different types of media could be substituted for each other, because media are not responsible for any learning that might take place. Media are not the causing factors in the learning process; rather, instructional method is the active ingredient or catalyst that causes learning to take place.

Achacoso goes on with his literature review to mention that Clark is not alone in his stance that media (technology) do not influence learning. Thomas Russell's (2001) comparative annotated bibliography, The No Significant Difference Phenomenon, catalogs 355 distance education studies in which researchers found that learning outcomes from distance education did not differ significantly from traditionally-taught courses.

Based on these results, Russell reached the conclusion that both methods are equally effective and one could be substituted for the other depending upon the situation. Russell (2001) did not conclude that distance education should be eliminated. However, he did make the point that having students learn solely by using distance courses is a very costly alternative to traditional courses.

Achacoso's literature review continues to report Kozma (1994), who in contrast to Clark's argument, believed that the more appropriate question was not whether media do influence learning, but will they influence learning. He also contended that simply because we have not established a relationship between media and learning does not mean that one does not exist. He believed that, since we do not fully understand the relationship between media and learning, we have yet to measure it, and the failure to establish this relationship is caused in part by our theories of learning, or more specifically, behaviorism, with its basic assumption that a stimulus causes a response. Therefore, if the stimulus is not present, there is no possibility for response. Kozma (1994) explained that in Clark's view media are simply "mere vehicles" or conduits for an instructional method (stimulus) that elicit a response (learning). Kozma argues that learning is a much more complex process than just a series of stimulus-response connections. Learning, in his view, is defined as "an active, constructive, cognitive and social process by which the learner strategically manages available cognitive, physical 
and social resources to create new knowledge by interacting with information in the environment and integrating it with information already stored in memory" (cited from Achacoso, 2003). Thus, in Kozma's view, since the definition of learning has evolved to embody more of a constructive process, the measurement of this learning process must evolve as well.

Achacoso also found that others have argued for a complete reframing of the debate over technology and its effect on learning. Jonassen, Campbell, and Davidson (1994) for example believed that the Clark/Kozma debates focused too much on instruction and media and not enough on the characteristics of the learner who ultimately constructs the knowledge. They proposed that researchers examine how media can support the learning process. To accomplish this goal they suggested that learning be treated as situationally dependent by taking into account the environment and the context in which knowledge is constructed. For example, we know from learning theory that learning is most effective when it is situated within the context of a meaningful, real-world activity or task (Jonassen et al., 1994 cited from Achacoso, 2003).

Moreover, Jonassen et al also suggested that researchers study how to support maximizing the human information processing system. One example of this maximization is capitalizing on the limited capacity to process information (attention). Technology can be used to design a specific lesson that reduces the cognitive load on a student while freeing up resources for higher-level thinking (Jonnasen et al., 1994 cited from Achacoso, 2003). In sum, Jonnasen et al. (1994) argued that the focus of the debate should be returned to the learner rather than remain on methods or attributes of media.

With all the various opinions on the relationship between technology and learning, the question that is worth raising now is: who is right? It appears that each theorist brings an important perspective to the picture. Clark is correct that technology has not necessarily revolutionized the process of learning. Technology has not helped humans develop a new way to learn. Learning is still something that is performed by the individual. However, in 
Clark's view, all an instructor would need to do is embed the appropriate instructional method into his/her lesson and learning should take place. On the other hand, it is well known however that despite many instructors' best efforts and superior teaching abilities, learning does not always take place.

Kozma is also correct that we must examine technology and learning beyond a behaviorist context. Learning is an intentional act (Jonnasen et al., 1994) and the human being doing the learning should not be discounted. Researchers have established that there is no significant difference between learning with technology in distance education courses and learning in a traditional classroom, but they do not discuss how human motivation is influenced by technology. This could be a very important missing element in the debate.

Of course, the decision to take which side of the debate to take depends largely upon how one defines learning. If one is more into the behaviorist views of learning, then Clark's side will make more sense. If, however, one conceives of learning as a more cognitive or constructivist process, then one's agreement would be more likely to be with Kozma or Jonnasen et al.

\subsubsection{The Benefits of Technology in the Learning Process}

The question asked by academicians and researchers is whether technology improves learning. In the literature done so far, it was shown that technology does not increase learning over and above traditional methods (Ehrmann, 1999 cited from Achacoso, 2003). However, the reality is that learning is still taking place. The more appropriate question therefore should be, how can technology be used to help the learning process? From the literature that follows, it is possible to detail the various benefits to incorporating technology into the learning process.

There's no doubt that technology in the classroom can help improve access to information or types of information. Moreover, we can access the information in an efficient manner. Using Clark's metaphor, the truck that delivers the groceries might not 
cause any kind of change in a person's nutrition, but a truck delivering groceries is more efficient than a horse and a cart. People have made wise as well as unwise decisions throughout history regarding the use of resources at work. Technology simply helps people to make these decisions, be they good or bad, more quickly.

There are appropriate and inappropriate uses for technology in the classroom. Appropriate uses can help facilitate the learning process while inappropriate uses can hinder it. For example, the document camera can be used to show many types of visual aids, well above and beyond the old-fashioned stand-by, the overhead projector. However, learning depends upon how it is used.

Technology needs to tap the cognitive processes we know actually work. For example, encoding through visualization can be accomplished through the use of technology. Because part of a learner's job is to put information into memory using some type of visual cue, a chemistry instructor can use a computer to display three-dimensional images of molecules while explaining a chemical reaction. This type of visualization is much more rich and detailed than simply trying to draw a two-dimensional image on the chalkboard, and so this use of technology makes the reaction easier for the learner to remember. (Achacoso, 2003)

However, technology can be a double-edged sword if the instructor is not properly trained in pedagogy and the technical aspects of using technology. For example, simply slapping up the textbook on the document camera might not accomplish the goal of learning, especially if the instructor fails to zoom and focus on the desired image. Knowing how and when to use various technologies in the classroom will greatly help the students grasp the material during class time.

Other technological advances, such as simulations and/or expert systems, can provide safe experiential learning not possible in the real world and not available from simply reading a two-dimensional textbook. For example, one skill that medical students must learn is how to diagnose diseases. Expert systems have been developed through which 
students are presented with a whole host of symptoms, and they must order the appropriate tests to allow them to come up with a diagnosis and treatment plan for their patients. The expert system evaluates the students' diagnoses and lets them know their patients' health situation. This all takes place in a virtual environment where real lives do not hang in the balance. Moreover, this type of problem-based learning cannot be gained from just reading a textbook.

Learning processes do not change just because technology is integrated into the classroom. Technology allows us to access more information faster and in an efficient manner. We spend less time searching and more time on decisions. We can create realworld simulations, and three-dimensional models that can help us remember information. Instructors can grasp the attention of their students more easily and teach in multiple modes that affect more than one sense (seeing and hearing, for example). Moreover, we know that certain instructional methods influence certain cognitive processes, and for learning to occur, these cognitive processes must happen. To the extent that instruction does not support essential cognitive process, learning will be hindered, unless the student is an expert in learning information on his or her own. Thus it is obligatory for the instructor to take the time to learn how to incorporate technology into his or her teaching, based on sound pedagogical principles.

Achacoso (2003) then wonders why use technology at all in light of this debate about its usefulness and especially when there are other competing factors for an instructor's time? Competition is fierce for keeping teaching positions, and technological failure in the classroom could decrease evaluation ratings (Cardenas, 1998 cited from Achacoso, 2003). Yet, it takes a lot of time to develop and integrate technology in the classroom (Cardenas, 1998), not to mention the expense for hardware, software, and ongoing support.

Going on with Achacoso's review of literature, one finds three advantages of integrating the World Wide Web - and by extension, other forms of technology-into teaching and learning suggested by Owston (1997). These are the following: 
- First, the Web appeals to students' mode of learning. He describes internet use as being "integral to their world" and thus it is a preferred tool for learning. Students start very young using computers and the Web in school. By using the Web, an instructor is tapping into a student's current context for exploring the world.

- Second, the Web provides for flexible learning. Students have access at their convenience. The lack of face-to-face contact can help shy students participate in the learning process. Moreover, asynchronous and synchronous communications are possible.

- Third, there is renewed demand for skills that can be acquired by using the Web in the learning process. In today's global economy, skills such as critical thinking, problem solving, writing, and working collaboratively are required of everyone. While these technically are not new skills, there is renewed demand for their development. Owston argues that the Web is a natural tool for the development of these skills, because students have to surf sites and judge their content and authenticity, compare differing viewpoints, analyze and synthesize vast amounts of information, and construct their own understanding of a topic. Students can also gain practice at writing to a key audience using the Web. Moreover, group projects can be designed for publishing on the Web, encouraging collaboration among students.

With an understanding of the context in which technology and education have been examined over the years, it is important now to examine the factors that would lead to or support the efficient and effective use of technology in learning.

In the project study conducted by Serban (2002), the researcher poses one of the major questions that arises in the discussion of educational technology and that is whether technology enhances student achievement. Similar to what was reported by Achacoso (2003), the response with Serban also varies. As mentioned by him, some authors found 
that instructional technology has many positive influences on student learning processes and outcomes such as: (Cited from Serban, 2002)

- Use of instructional technology positively affects student learning; and

- Use of instructional technology increases student interest and satisfaction (Draude and Brace, 1999).

- Other authors found that online materials are particularly effective at engaging students either by offering the latest images and results which are not available in textbooks, or by allowing students to explore the topic at their own pace and test their understanding as they proceed (McGill et al., 2000; Borkowski and Hazari, 2001 cited from Serban, 2002). These authors also argue that instructional technologies facilitate the shift towards a more student-based learning environment.

Moreover, Buckley (2002) as cited from Serban (2002) provides a concise but powerful overview of what is being called learning-centered technology and discusses implications for transformational faculty development. The author argues that the instructional technologies already available include critical features that can greatly enhance learning processes. The following benefits were mentioned by Buckley (2002) as reported by Serban (2002):

- These technologies allow the creation of interactive environments, which can promote active learning as students make decisions about exploring and interpreting a content area.

- Technologies allow the creation of varied information formats, which in turn allow for different learning opportunities.

- Communication tools can help promote socially situated learning environments, which can enhance the quality of learning and the development of teamwork and learning communities. 
- Perhaps the greatest potential of instructional technologies is the facilitation of formative assessment, both structured and open-ended to encourage the study of foundational information as well as student reflection and development of metacognitive skills.

- Authoring tools promote the construction of knowledge, facilitate students' use of different information formats and associated cognitive styles, and represent major assessment approach for learning-centered and inquiry-oriented pedagogies.

- Simulations enhance students' critical inquiry skills and epistemological skills.

Serban's review of literature also shows that some studies found that faculty are very interested in using technology for teaching and they believe that the use of technology can add value to the total educational experience and be significantly beneficial to learning (Byron, 1995; Draude and Brace, 1999; Beggs, 2000). However, "technology is viewed as an added layer not as a "silver bullet" that magically solves all instructional problems" (Byron, 1995, p. 3). Research suggests that it is not the technology itself but how the technology is used that improves learning and increases student interest (Beggs, 2000; Borkowski and Hazari, 2001).

In a survey of California community college faculty, Luna and McKenzie (1997; cited in Serban, 2002) found that $80 \%$ of faculty were using multimedia as a form of lecture support. $73 \%$ percent of students reported multimedia to be a positive addition to the course. Faculty surveys conducted at other colleges and universities indicated that the top two influences to the adoption of instructional technology are instructional issues improved student learning and clear advantages over traditional methods (Beggs, 2000 cited from Serban, 2002).

Instructional technology could benefit all disciplines. Accounts of the use of technologies in different hard sciences (like mathematics) suggest that technologies help students develop analytical, computational, critical thinking and visualization skills (McGill et al., 
2000 cited in Serban, 2002). Even in these cases, authors point out that student computer skills are uneven and can create situations where technology becomes an impediment rather than an asset to learning. This suggests the need for integrating computer and technology related skills throughout the educational continuum, not just at isolated points or in a few courses. Several authors suggest that all students should be required to attain a minimum set of baseline computer and technological skills early during their higher education experience to enable them to fully participate in and take advantage of the instructional technologies utilized (McGill et al., 2000; Scrivener Agee and Holisky, 2000 from Serban, 2002). An implication of such findings for the training of faculty in instructional technology is the need to establish this set of minimum technological competencies that students should possess and train faculty to be able to transfer this knowledge to students. This type of training should cut across disciplines. However, the teaching of technology is not the mission of most academic departments or schools, thus technology goals must, in many cases, be considered in the content (Scrivener Agee and Holisky, 2000 cited in Serban, 2002).

Similar to what was reported by Achacoso (2003), Serban (2002) also mentioned that other authors indicate that there is no significant difference in academic achievement between traditional and technology-enhanced courses (e.g., Rogers, 2001). However, they argue that there are measurable and critical advantages to investing in technology for teaching and learning, and not necessarily in delivery. Also, to understand the real gains from using technology, the right questions should be asked. Rather than compare live lectures to CD-ROMs, we should reframe our questions to address how technologies are used to enable, facilitate, and support the teaching and learning enterprise, both from the students' perspective and from an investment perspective (Rogers, 2001). Instructional technology allows students to visualize complex ideas and understand abstract concepts in a manner that simply is not possible with the use of just lecture and a chalkboard (Byron, 1995 cited from Achacoso, 2003). Greater learning can be promoted by delivering information through a variety of media and through the use of interactive applications (Passerini and Granger, 1998 cited from Achacoso, 2003). In addition, students' attitudes and perceptions of technology influenced their ability to acquire and 
integrate knowledge, extend and refine knowledge, and use knowledge meaningfully (Daley, Watkins and Wall Williams, 2001).

The more skeptical authors argue that technology presents both danger and opportunity. They acknowledge that technology provides opportunities and its effective use could improve teaching and learning. However, they also caution that incorrect adoptions of technologies, apart from a sound grounding in education research and practice, will result in costly additions to an already expensive enterprise without any value added. "That is, technology applications must be consonant with what is known about the nature of learning and be assessed to ensure that they are indeed enhancing learners' experiences" (Gandolfo, 1998 cited from Serban, 2002).

\subsubsection{Factors Leading to an Effective Use of Classroom Technology}

Effective Use of technology might be defined as the capacity and opportunity to successfully integrate technology into the accomplishment of self or collaboratively identified goals.

"When in pursuit of educational reform via the implementation of technology-rich information age classrooms, educators often seek reform by performing the ritual of acquiring computers, without engaging in the collective redesign of the organization" (Dexter, 1999, P. 10, cited from Dowling et al, 2001). The number of computers in the US schools and universities increased 13 percent, and almost 80 percent of schools have Internet connections (Shelley, 2000, cited from Dowling et al, 2001). However, some universities are experiencing difficulty in effectively integrating these technologies into existing curricula. Many schools treat technology as an addition to rather than an integral part of the regular curriculum.

It is common belief that technology and critical thinking skills are an important way to prepare students for the unknown technical jobs in the twenty-first century. Educational institutions are willing to spend money to be technology compliant, however, more computers, more hardware, software, and increasing the number of computer peripherals without giving teachers training will never impact students. "One of the biggest barriers to effective use of technology in education is the lack of professional development" 
(Norman, 2000 cited from Dowling et al, 2001). Recent research indicates that although teachers are eager to use technology for professional and curricular activities, a lack of teacher development programs and time dedicated to experimentation hinder teachers' skills and knowledge. If teachers are to become the link between students and technology, they must be trained, not only in the skills of how to use technology itself, but on how to use these skills with their students.

As it is well known, many teachers now have access to an unprecedented amount of instructional technology. However, there is little evidence showing that teachers integrate technology within the curriculum on a regular basis. Several factors influence the proper and effective use and integration of technology in the classroom. Following will be a discussion of some of them.

- Pedagogy Change. Before teachers can successfully implement technology, they need a change in their pedagogy. Such change requires a paradigm shift from viewing their role as a giver of knowledge to a facilitator of knowledge (Dexter et al, 1999 cited from Di Benedetto, 2005). Teachers have always been responsible for teaching content. With the expansion of Information Highways and technology, teachers must also take on the added responsibilities of teaching students how to use the computer as a tool and creating innovative strategies to enhance computer literacy and computer based training in the curriculum. In fact, students could use technology to build concepts from existing knowledge and to obtain information from a variety of sources. Bracey (1994) found that teachers who use technology view learning as an active process and knowledge as something students must construct rather than receive passively (cited from Di Bendetto, 2005).

Training. The confidence level toward technology increases as teachers receive formal training. Researchers concluded that teachers should receive in-service training on specific technology applications to integrate computers into the curriculum in meaningful ways. Becker (1999) showed that formal staff training was a significant factor in increasing the use of computers by teachers (as cited 
from Di Bendetto, 2005). This should be combined with a clear definition of both teacher and student expectations and effectively communicating them. Teachers can be successful, but they must take ownership of a new instructional strategy or technological application of change (Dexter et al, 1999 cited from Di Benedetto, 2005). Whereas there is no single all encompassing list of potential instructional technology training needs, most documents reviewed point to several standard training topics in the area of instructional technology:

- Course management systems (these vary from one institution to another. (Examples include WebCT and e-College). Such training sessions, whether short focused workshops, longer seminars or online self paced modules, should combine training in the technical features of the tools as well as their pedagogical implications.

- Multimedia tools (e.g., electronic document creation, electronic presentations, animation and audio).

- Assessment methods using technology (e.g., online quizzes, open-ended tests, etc).

- Electronic collaboration (amongst students and between students and instructors).

- Use of electronic tools for research and evaluation.

- Use of databases to manage information.

- Working knowledge of computers with different operating systems (i.e., both PC and Mac systems with their respective operating systems)

\section{Organizational Culture Support. Teachers' instructional practices are} influenced by numerous personal factors, including their personality and belief system. Belief system and values are a product of teachers' own prior knowledge, development, and experience as an individual. The greatest influence of teacher style appears to be the organizational culture. In order for instructional technology to be successfully implemented, teacher beliefs and values need to be shaped. If 
this shift does not occur, the integration of instructional technology in education will not occur on a broad scale (Dexter et al, 1999 cited from Di Benedetto, 2005).

* Overcoming Contextual Barriers. Researchers have identified steps to follow in order to overcome the contextual barriers faced by teachers as they integrate technology. As mentioned in Di Benedetto's literature review (2005), Dexter, Anderson, and Becker (1999) showed how powerfully contextual barriers influence instructional practices, teaching strategies, classroom management, technical expertise, curriculum directives, and organizational support for teachers. These researchers provided support for the teachers involved in the study which included staff development sessions, technical assistance, support for modifications of laboratory lessons to improve student learning, and problemsolving strategies to support integration. As a result, many teachers shifted their teaching strategies into a more effective, learning - centered approach.

In addition to all the factors mentioned above, proper and effective technology use is also in need for a supportive classroom design that allows for interactivity, collaboration, and knowledge as well as experience sharing. This design should allow for the learning outcomes to be successfully achieved, and should help make the period of time the student spends in the university - especially in the EMBA Program- an exciting, beneficial, and unforgettable learning experience. The following section will talk about the classroom design concept with an attempt to highlight its effect on learners' performance.

\subsection{Classroom Design Features for the New Millennium}

Classroom design has been left behind by rapid evolution in education and learning. But before learning environments can be improved, we need to know exactly what factors go into making a good one. 
E-classrooms in universities are rapidly increasing in number, with greater emphasis on teaching and learning. Presentations are going beyond PowerPoint slides. The focus on assessment is increasing, as well as how the students learn, and how teachers teach. Most e-classrooms have a simple layout. Computers are usually placed on long tables with monitors resting on top of them. The teacher station is a crowded desktop with wires everywhere. Typical equipment at the teacher station includes an overhead projector, frequently accompanied by a VCR. Depending on budget, the classroom is usually equipped with large TV sets (VGA compatible) or some type of LCD projector.

Business changes are taking place at a rapid pace of time. Technology changes faster. Some universities invest heavily to update and integrate the latest technologies into the classroom, creating a stimulating environment that is pure state-of-the-art multimedia. Lectures are enhanced with advanced software applications and telecommunications systems; presentations are strengthened with a wide range of electronic tools. And full access to the web and web-based collaborative software is always provided.

This changing of traditional lecture-style classrooms into laboratory-style electronic classrooms is occurring in higher education as a whole. Researchers and practitioners at a number of institutions are exploring high-tech classroom design options. Electronic classrooms are also called computer classrooms, media-equipped classrooms, media laboratories, etc., and all of these names can refer to any number of classroom configurations.

This study, however, will refer to the term smart classroom that would give EMBA participants the maximum level of benefit derived from, but not confined to:

- A high level of interactivity amongst participants,

- A high level of knowledge and experience sharing,

- A high exposure to community experiences and case studies (guest speakers, video conferencing with key business professionals,...), and

- Simulation applications that highly resemble real life applications in the industry. 


\subsubsection{Key Aspects of a Computerized Classroom}

The literature review conducted by Harden (2003) in his article, Learning Artifacts in Higher Education, describes the five aspects of computerized classrooms that needed to be included in the design in order to enable the teaching of social-cultural rhetoric. A detailed explanation of the five aspects take from the article are listed below. The explanations not only include the specifics about the design, but also the reasoning behind and the benefit of each aspect.

\section{An Unobstructed Discussion and Presentation Area}

An unobstructed space in the center, enabling students to see each other during class discussion, was a priority to support class-wide interaction. The computers are to be places on tables around the outside of the room. The center space is large without visual and auditory obstruction. A series of narrow tables, five feet long, are set up in the center of the room in a horseshoe arrangement. The tables allow students to interact face to face-in pairs, small groups, and class-wide.

\section{The De-centering of the Computer and Other Technology in the Classroom}

When computing, the students face the wall. This integrates the computer into the work of the classroom without making it the center of attention and without creating physical obstacles to discussion and the social space in the center of the room. Our classroom design supports several pedagogies: interaction, collaboration, class presentation (student or teacher), and individual work. At the tables and at their computers, students can interact with students all around them.

\section{Multiple Work Places for Each Student}

The classroom design described by Harden (2003) has to support quick transition from individual to small group to class-wide activity. Lightweight chairs are the only furniture that has to be moved to accommodate these transitions. Our request for chairs on rollers was denied. Nevertheless, light weight chairs allow students to move back and forth 
freely between the table and the computer stations. This provides students with two individual workstations, one at the horseshoe table and one at a computer station.

\section{An Unobtrusive Instructor's Station}

The horseshoe table allows a collective space that is not dominated by a particular point. The instructor station is table height and situated at one end of the horseshoe's "legs." The instructor's computer is partially recessed into the tope of the instructor's desk to prevent obstructing the students' and instructor's view of each other. A visual presenter (digital document camera) and a VCR are components of the station. On the wall behind the instructor's station is a marker board. Each of the classrooms (and this is true for the whole campus) has a ceiling mounted LCD (liquid crystal display) projector, which projects onto an eight foot by eight foot screen which can be pulled down in front of the maker board. The LCD projects the instructor's computer screen, the VCR, and any items placed on the visual presenter. This collective space also facilitates unobstructed viewing of the presenter, the marker board, and a projected image on the screen. (Harden, 2003)

\section{Technology that Allows the Classroom to Cross Its Boundaries into the Larger Culture}

In the social-cultural rhetoric, the classroom is a part of the world. Computer and audiovisual technologies reduce the relative isolation of the classroom, allowing ongoing rhetorical analysis of cultural aspects that exist in the general culture. The HCC Writing Program strives to use media to bring larger cultural contexts into the classroom through Internet sites, videos, and CD-ROMS. Moreover, $\mathrm{HCC}$ writing instructors value students work and the role is plays in a learning community. The visual presenter allows handwritten notes to be projected wide screen without conversion to another form. A constant sharing of student work places a visible value on it. It also allows for instant recognition of differences, which can be the focus of further discussion and critique. In addition, instructors project slides, overheads, and print documents through the visual presenter. By using such technology skillfully, instructors help students apply concepts of forum, purpose, and cultural contexts to the events, practices, and attitudes in the world so vividly displayed by the media. (Harden, 2003) 


\subsubsection{Use of Technology: An Integral Component of the EMBA Classroom Design}

Computing and communications technologies have transformed both the business environment and graduate management education. The UCLA MBA Program emphasizes the uses and implications of advanced technologies in business and in the study of business and management. UCLA Anderson School of Management is fully networked with both a comprehensive wireless network covering the entire complex including all breakout area and library reading rooms, as well as hardwired high speed connectivity in the classrooms. UCLA Anderson's extensive intranet provides real-time access to library resources, as well as links to course materials and other information resources relevant to the full range of student needs and interests, from course work to job searches. All Anderson MBA students use laptop computers that are compatible with the UCLA Anderson network.

In fact, the most common theme in any business school brochure is how its state-of-theart high-tech business school prepares graduates for the "electronic twenty-first century." Wired classrooms, virtual private networks, PDAs, WI-Fl, closed-circuit television, and always-on web applications keep students in touch with their classmates, professors, and class work 24-7. Students are expected to own a laptop computer. Many schools issue them customized and preprogrammed. (Price, P. 67)

With virtual private networks, students can decide when to study and can easily interact with classmates and professors. The VPN assures for a safe and secure environment to chat, tutor, and exchange files around the world. Private networks enable students who frequently travel, have unpredictable work schedules, or attend satellite campuses to attend classes and augment class work with the use of technology. Through private networks they can access additional resources including sophisticated databases like Lexus Nexus. (Price, P. 68) 
Wired classrooms allow students to plug and play. Once connected in the class, professors may integrate lecture sections on the web for everyone to view and make personal notes in real time. Practically all class assignments from financial modeling to preparation of papers and delivery of PowerPoint presentations require the use of a computer. More than ninety-five percent of all students in business school use a Windows-based PC. Professors use email to issue and collect assignments. (Price, P.68)

Top ranked Duke University relies heavily on DVD, CD Rom, and web applications to deliver class content. The Duke University Global Professional MBA requires students to attend the first two weeks of study in the classroom in Durham, while the subsequent ten weeks of learning is completed online through a VPN or a take-home DVD. That is a significant amount of computer time and may not be appropriate to fit the learning needs of all students. (Price, P.68)

Wharton University on the other hand minimizes the use of technology. According to one Wharton administrator, the use of technology in place of the classroom dilutes the EMBA program experience. He questions the value of any graduate level education when computer delivery plays such a prominent role in the overall education. As one Wharton graduate contends: (Price, P.68)

The importance of face-to-face interaction with professors and classmates can't be overstated. Institutions that use too much technology, by default, reduce the interaction between people. Much of my learning experience was generated by my classmates, and trading this interaction for computers is a mistake. Technology can enhance the learning experience but should not drive the learning experience. The personal relationships gained from an EMBA are what can build the foundation that exists even years after you graduate from the program. Too much attention toward technology at the expense of student interaction risks losing the true value of attending the EMBA.

-Shelley Boyce, Wharton EMBA, and CEO of MedRisk

Other side of the world: Fordharn University EMBA students prepared with Beijing International University MBA counterparts (BIMBA program) via closed-circuit teleconferencing. When it was 11:00 P.M. EST, it was 11:00 A.M. in Beijing. 
If people miss the class we have it on video and if two or three people cannot make class rather than dub tapes we literally digitize the lectures on DVD for students to access. While our mission remains face-to-face teaching we have to recognize the flexibilities technology allows. We attempt to accommodate these busy professionals. We've bridged video conferencing from Dallas, Atlanta, Chicago, Champaign and Delaware.

-Merle Giles, Director, Executive MBA Program, University of Illinois at Urbana-Champaign

\section{Virtual Private Networks}

Virtual private networks (VPN) connect students privately onto a platform monitored and maintained by a third party. With registration and password access to the network is possible from practically anywhere on the globe. These private networks come with all sorts of functional benefits including support for closed-circuit video conferencing, chat room discussions, one-on-one learning and tutoring, exchanging files, and access to repositories of information. (Price, P.69)

Groupware applications used support the following features: (Price, P.70)

1. Complete electronic exchange of e-mail

2. Workgroup conferencing for electronic discussions, file sharing, and collaboration

3. Remote access and online information services with an intuitive, multi-tasking interface

4. A private secure electronic platform

5. Government and privately collected business relevant databases

Augmenting the classroom with technology is not typical for all EMBA programs nor is it appropriate for all students. Technology allows for virtual classrooms to exist. Critics, however, complain that virtual classes dilute the educational experience of the EMBA as Shelley Boyce, CEO of MedRisk and a Wharton EMBA graduate, explains: "Much of my learning experience was generated by my classmates and trading these interactions for computers is a mistake." Student expression, informal student and professorial discussions and even face-to-face networking are hallmarks of the learning experience and these are lost when technology replaces the classroom. (Stuart, 2005) Of course, although what Boyce mentioned is correct, the advantages of using technology in the 
classroom, and especially the EMBA classroom, far exceeds its disadvantages, and it all depends on the way technology is being used. As mentioned in Chapter I, technology, when properly used and managed, can foster communication and knowledge sharing amongst participants - a key feature of an effective EMBA classroom. 


\section{Chapter III}

\section{Design of EMBA Classrooms Worldwide}

\section{Overview}

EMBA classroom design has a very influencing effect on the learning environment in which executive students learn and interact. In fact, the design plays an important role in the process of learning. In order to introduce an EMBA classroom design, one should have an overview about the classroom designs applied in different universities around the world. In this chapter, select layouts and setups are introduced.

\section{Fisher College of Business}

The leaders of the Fisher College of Business consider themselves different in the world of EMBA. They selectively admit students with diverse backgrounds, so that they can give the chance for students to experience multiple perspectives from dynamic, international and life-experienced colleagues. Their main belief is in learning by doing - in constantly referring to their students' real world experience. The return on their investment is clear: they will gain the confidence and hands-on knowledge to become a strategic decision-maker in business opportunities throughout your career. In order to make students feel the kind of commitment, they let them become a member of the Fisher community.

Fisher received a lot of attention for its state-of-the-art facilities, but there is much more to it than that. It offers students the chance to stand out, to be heard, to move ahead and to make an impact on the companies they serve. 


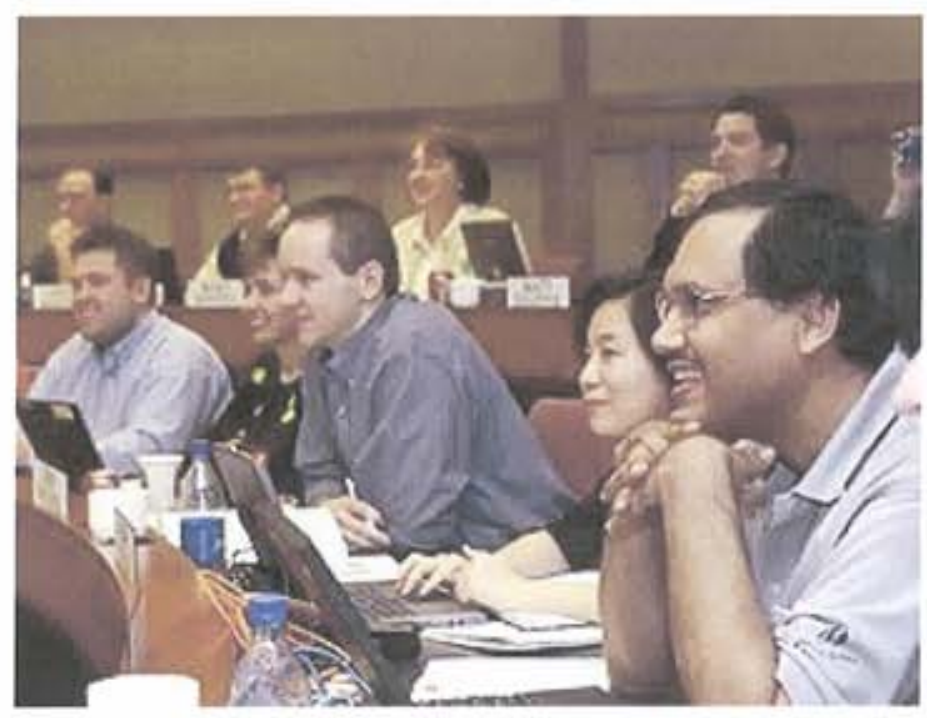

Fisher believes in the concept that classroom design has a great impact on the learning experience. As one can see in the above picture, the classroom is laid out in semicircular tables each on the upper level of the other. In this way, students will be able to interact freely and share ideas and experiences in an easier way. Also, as one can see, the students are from different cultures and this will enhance the benefit of knowledge sharing environment. As for technology, it seems that advanced technology is being integrated.

\section{South Florida Business School}

The EMBA program at South Florida Business School (SFBS) delivers a state-of-the art curriculum that is cross-disciplinary, contemporary, and relevant for both participants and their sponsoring organizations. The leaders of SFBS strive to keep it that way. They evaluate it continually and update it based on recommendations from their program's partners - their faculty, their participants, their alumni, and their advisory council, a select group of South Florida's business leaders. They also benchmark their program on a regular basis against those offered by top business schools in the U. S. and around the world. 
The courses in the program are sequenced to enable faculty to build continually on concepts and skills presented in previous courses. The business fundamentals in the early courses provide a framework for current understanding, a shared vocabulary for communicating, and a springboard for meaningful discussion and group work. Later courses expand this framework to develop perspectives derived from current global issues and competitive business pressures. Professors work as a team to coordinate course content and materials so that the entire offering is integrated and cohesive. (http://www.coba.usf.edu/alumni/building/)

Because it is a lock-step program, participants are expected to take all courses together over the eighteen months of the program. They are required to take all courses and attend the residency sessions. Those who successfully complete all program requirements are awarded the MBA degree.

Examinations and grades are given for each course. The grades of A, B, or C indicate credit; $\mathrm{F}$ indicates failure; $\mathrm{I}$ indicate incomplete. Participants must maintain an overall "B" average. An "incomplete" is recorded in those rare instances in which the participant has been granted formal permission by the instructor to defer an examination or other course requirement because of illness or other emergency. In the case of a deferral, participants must complete the work during the following year.

The program itself is divided into quarters each academic year. The first year contains four quarters - fall, Winter, Spring and Summer; the second year consists of only three-Fall, Winter, and Spring. Classes meet from 4:30-9:00 p.m. on Friday evenings and on Saturdays, from 8:30 a.m. to 5:30 p.m. A three-day residency session is held just before the start of the First Quarter. 


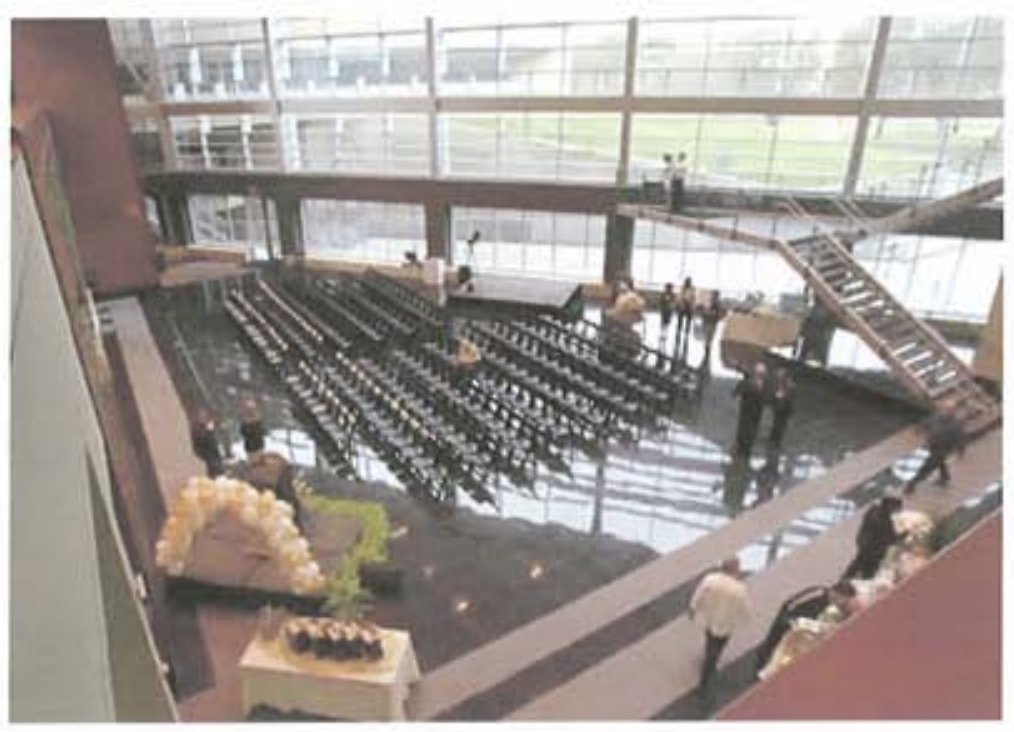

The two-story Quinn Atrium offers ideal space for students from across the University of South Florida campus to mix and mingle. The entire building is a wireless environment.

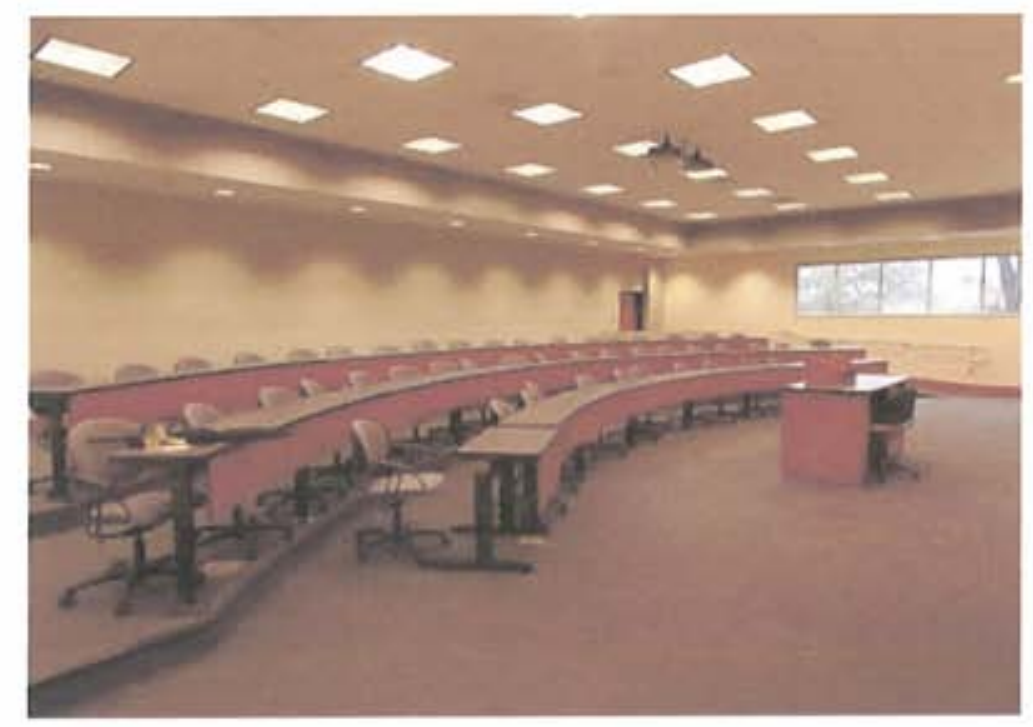

The new facility includes eight new classrooms. 


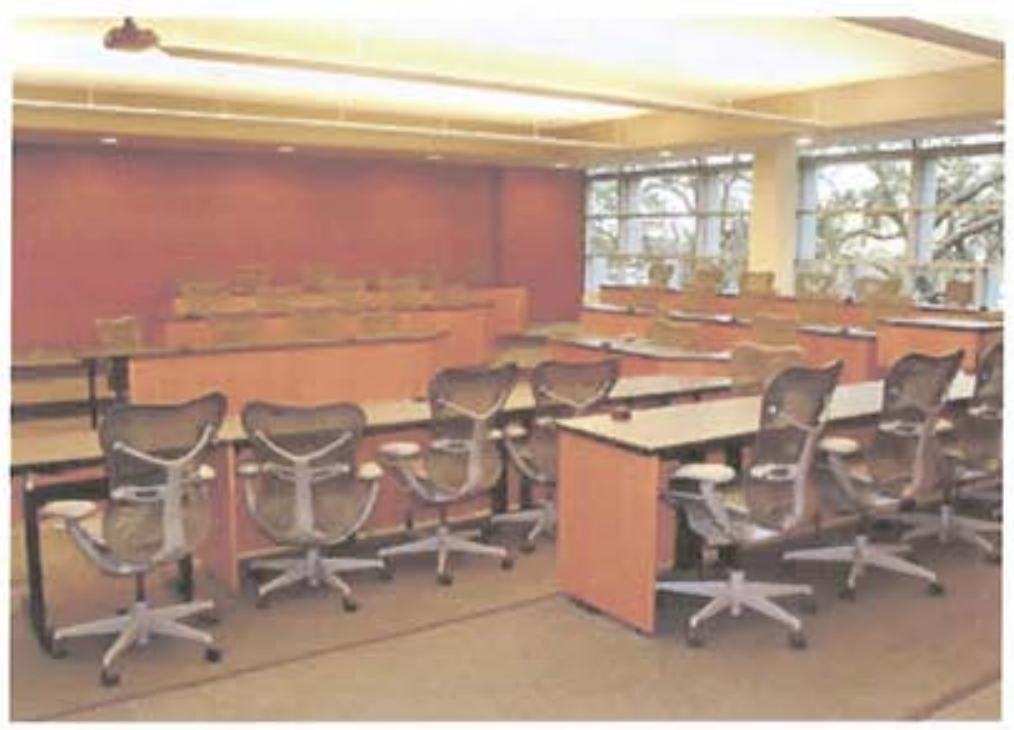

Second-floor classrooms are designed specifically for the Executive MBA program and have state-of-the-art teaching technology and wireless capability.

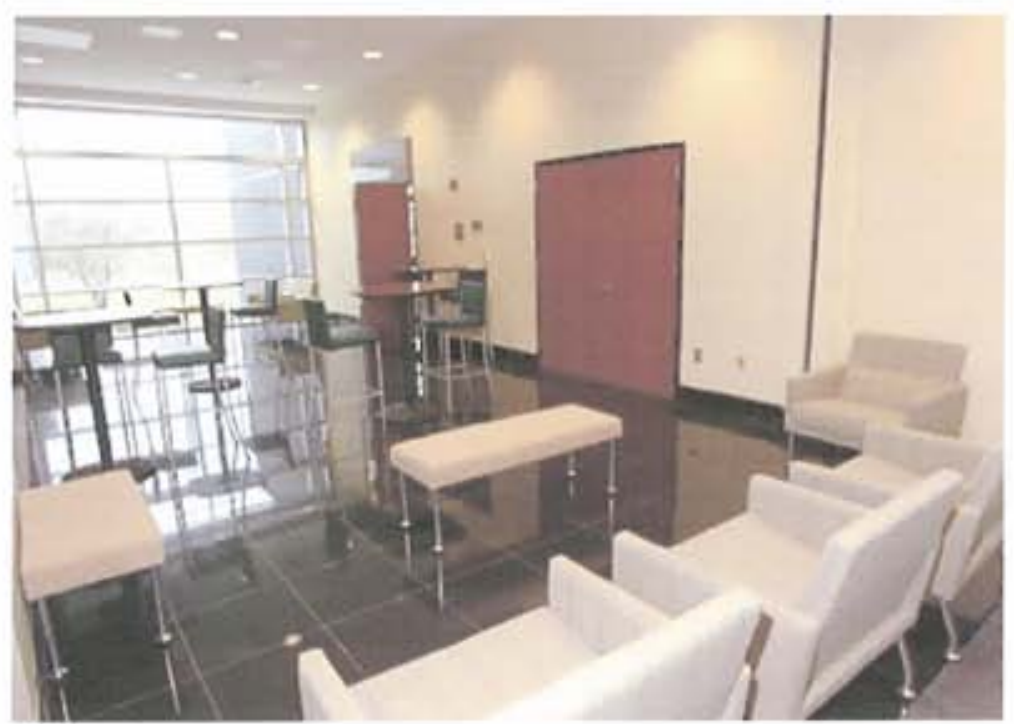

The second-floor informal café area offers space for students and faculty to interact 


\section{Allen Center}

Located on the shores of Lake Michigan in the heart of Northwestern University's Evanston campus, the James L. Allen Center is the home of Kellogg Executive Education. When the facility opened its doors in 1979, it was one of the World's first conference centers built exclusively for executive education.

"Here at the Allen Center, no detail goes ignored-we care for your mind, body, and spirit."

Because learning does not stop outside the classroom, the Allen Center offers an immersion experience. Here, leaders in the academic and management communities come together to discuss theory and practice. Living and working with one another, executives gain knowledge and insights as well as a broadened perspective. The Allen Center minimizes the distractions of the office and provides an ideal setting for growth in the field of management.

\section{http://www.kellogg.northwestern.edu/execed/allen center/index.htm}

"The Allen Center contains classrooms, study group rooms, bedrooms with private baths, dining rooms, lounges, and a fitness center. Our classrooms feature wireless Internet access and state-of-the-art multimedia equipment, and all of our study group rooms come with PCs, printers, and supplies. Our front desk is staffed around the clock to assist you, and you will have twenty-four hour access to computers, laptop hookups, laser printers, a copier, and supplies."

Although learning drives life at the Allen Center, one will find that their commitment to excellence extends beyond the classroom. They take service seriously, and their friendly spirit of Midwestern hospitality inspires them to give students the very best. Whether an executive is hoping to spend a free evening in a Chicago jazz club or just 
at a pub with colleagues in downtown Evanston, he / she will find the staff both knowledgeable and helpful.

Past participants are often amused that life at the Allen Center seems to revolve around food, and they appreciate the innovation and expertise they bring to the table. An espresso café and omelet, panini, and granary stations add character to elaborate breakfast and lunch buffets. Their head chef works hard to delight the executives' appetite, creating sumptuous dinners with an international flair. Mid-morning and mid-afternoon breaks, a cocktail hour, and well-stocked pantries for late-night snacks ensure that one will never go hungry.

Allen Center will also have access to the Northwestern University libraries, the PickStaiger Concert Hall, and the 140,000-square-foot Henry Crown Sports Pavilion and Lester J. Norris Aquatics Center. Outdoor enthusiasts also enjoy walking, jogging, and bicycling along wide paths that wind along the lakeshore and across the 240 -acre Northwestern campus.
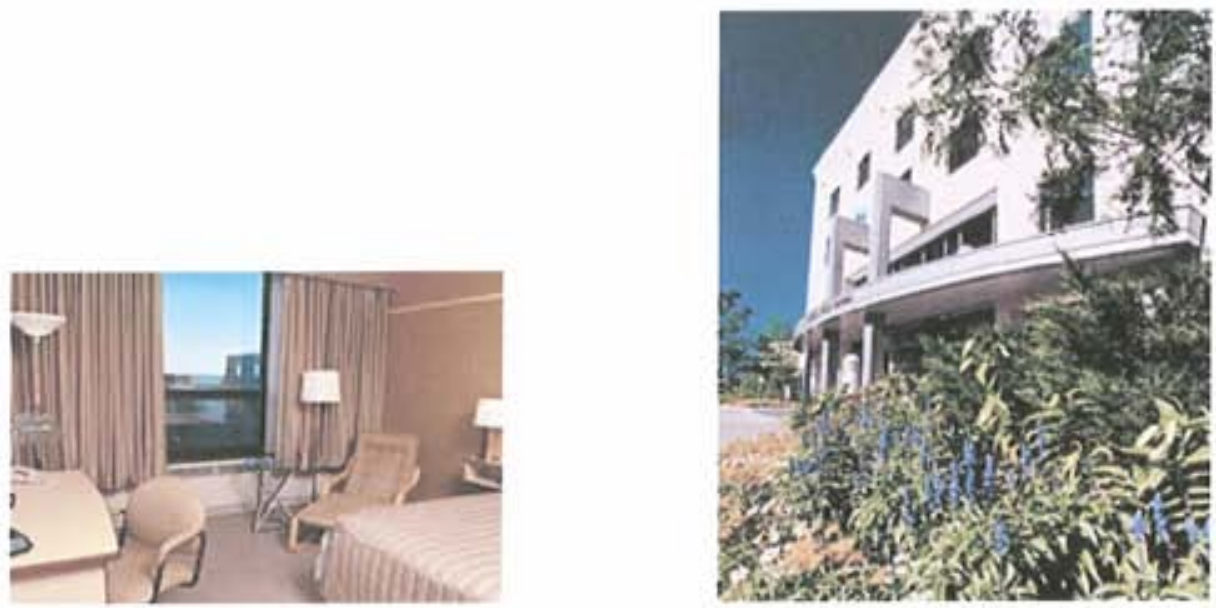


\section{The Columbia Executive MBA program}

An eight-story building at the corner of Amsterdam Avenue and 115th Street, shared by both Business and Law Schools, became home to the Executive MBA Programs in 1999. The EMBA suite includes administrative offices, student conference facilities and a student lounge, as well as technologically advanced amphitheater-style classrooms. More than 20 breakout rooms, also state-of-the-art, promote teamwork. Columbia University's campus, designed as an academic village of Italian Renaissance-style buildings by renowned turn-of-the-century New York architects McKim, Mead and White, sits on the sloping banks of the Hudson River - and is convenient to midtown offices.

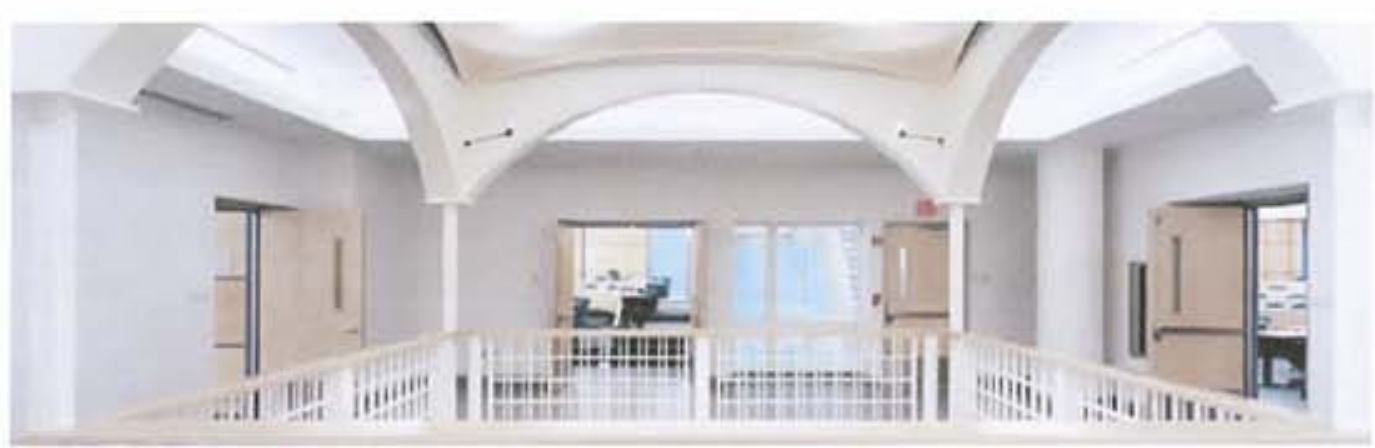

\section{The City}

"New York City is a gateway to the world and, for our EMBA students, a working model for the dynamism and creativity of today's business environment. " Many EMBA students choose to live, work and study here to take advantage of New York's cosmopolitan energy - which is part of the reason Professor Meyer Feldberg calls the School "the quintessential international business school in the quintessential international business city."

\section{The Neighborhood}

Morningside Heights, Columbia's neighborhood, is filled with the bookstores, 
outdoor cafés, ethnic restaurants, clothing stores and ice-cream parlors that are typical of a university community. Morningside Park, Riverside Park and Central Park are all only a few blocks from campus.

\section{http://www2, gsb.columbia.edu/emba/overview/mbaEnvironment.html}

\section{Boston University School of Management}

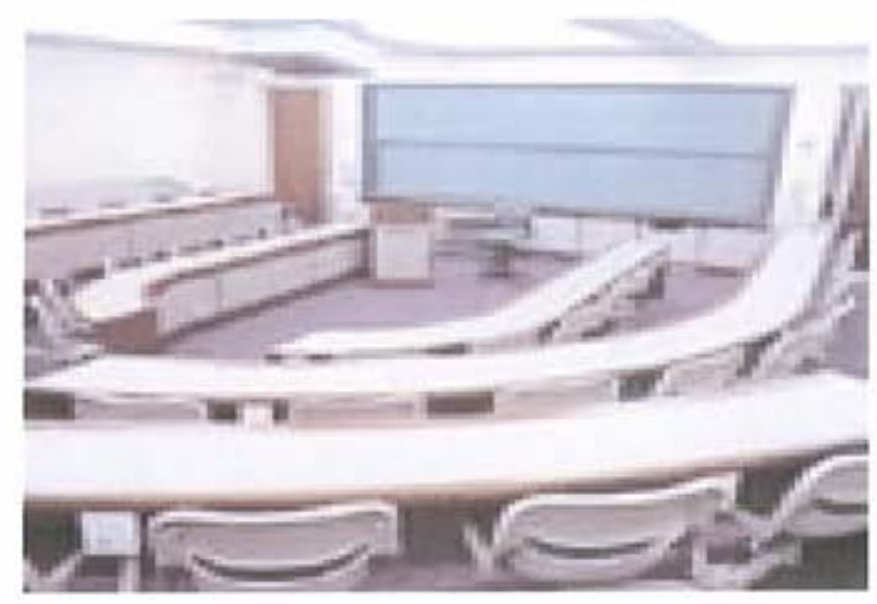

Learn in State-of-the-Art Facilities

Boston University's Executive MBA program is an accelerated seventeen-month program leading to the MBA degree. This program offers senior executives the opportunity to accelerate their careers and take leadership rolls in moving their companies to the next level. (http://www.ce.com/education/Boston-University-

\section{Executive-MBA-Program-10104034.htm)}

The EMBA Program's focus on management as an integrated system develops skills in functional areas while emphasizing the interdependencies of those individual functions within the organization. Designed for working professionals with $10+$ years of experience, classes meet every other Friday and Saturday, with an overnight stay at 
a nearby hotel. Participants continue to work while they - and their organization immediately reap the benefits of the expanded skill set.

\section{(http://management,bu.edu/exec/emba/why.asp\#)}

Boston University's Executive MBA Center was designed to fit the lifestyle of accomplished professionals. Located on its own floor of the Rafik B. Hariri Building, the Center features:

- Luxurious lounges

- Specially appointed boardroom and reception area

- Executive dining room

- Business center

- Private phone/fax lines

- High-tech corporate seminar rooms

The Center's classrooms are also just steps from The Pardee Library, with approximately 92,000 volumes on management and related subjects, hundreds of periodicals, and laptop ports at every carrel.

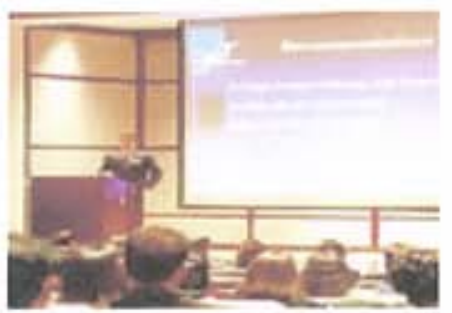

Their aim is to keep Executive Education High-Tech by staying networked with data ports at every seminar seat, connecting students to the Web and the university's intranet. At every classroom's podium, a computer is available. 


\section{Duke University}

The Multimedia Classroom in the Duke EMBA Department is a state of the art facility designed to provide an advanced multimedia setting for teaching and to facilitate the recording, archiving, and Internet broadcast of seminars, lectures, and classes.

The Multimedia Classroom was designed to facilitate the broadcast and archival of EMBA seminars and conferences. Given the worldwide demand among businessmen to share research and knowledge, seminars and conferences at Duke have traditionally drawn audiences from other Universities, both from North Carolina and from other states. In addition, Duke EMBA faculty have been engaging in a distance learning classes in order to "share" highly regarded faculty among a larger quantity of graduate students. Their hope is that this classroom will become the centerpiece of these activities, allowing guests from anywhere in the world to share in the distribution of knowledge from renowned speakers visiting (or affiliated with) Duke University. They also seek to provide a large library of recorded sessions which will both promote Duke and North Carolina as a leader in technology and business and become an invaluable source of knowledge and reference to the EMBA community at large.

\section{Hardware}

- Console Computer: This machine is a $2.4 \mathrm{Ghz}$ Pentium IV system currently running Fedora Core 2 Linux and can capture video via its Hauppauge Win/TV capture board. It is capable of emulating Windows 98 with the Win4Lin Software Package. Users are able to switch between the two operating systems seamlessly on a single machine. This is the primary 
machine used by instructors for introducing multimedia applications to classes.

- Video Capture Computer: This machine is an Athlon $1800+$ system currenting running Windows XP and is located in the back of the classroom. It has a Hauppauge Win/TV video capture board and is used with the RealProducer software to capture and broadcast lectures from the classroom.

- Eiki LCD Projector: The Eiki LCD projector is a powerful large screen projection system capable of displaying an image $1024 \times 768$ pixels in size. Producing 500 lumens projections, this system is usable in most lighting conditions and it is possible to reproduce its images clearly on video tape or broadcast during a taping of a session.

- Camera : There is a camera mounted in the rear left corner of the classroom that can be controlled by remote. Featuring several zoom levels and fine scale maneuverability, this camera covers most of the classroom.

- JVC VCR : A high quality VCR is available for recording, while simultaneously broadcasting, sessions and for playback through the Eiki projector.

- Touch Screen : Currently attached to the NT Computer, the touch screen LCD monitor allows you to write directly on the screen and display your drawings or writings on the overhead projector. Simultaneously, it can archive your images for storage on WebPages and soon, live broadcast with video lectures.

- Whiteboard : The digital whiteboard allows for real-time digital recording of pen strokes made on the board. Currently supported only under the Windows Operating System, this allows you to create high quality reproductions of 
handwriting during a lecture. These images can be printed out for instant class notes or placed on a web page for an archival of class materials.

\section{Multicast Software}

RealNetworks Real Video : RealNetworks software allows Duke to provide live broadcasts (10 second delay) of lectures and seminars and also archives of these videos for later access from a multimedia server. The video quality ranges from blocky slideshows (at $28.8 \mathrm{~kb} / \mathrm{s}$ ) to crisp movies with readable text on the blackboard (at $300 \mathrm{~kb} / \mathrm{s}$ ). They currently broadcast at 56,128 , and $256 \mathrm{~kb} / \mathrm{s}$ simultaneously for best results and availability.

Microsoft Netmeeting : Microsoft Netmeeting is a small scale video conferencing system. This software will allow for up to 8 people to engage in a video conference from remote sites.

\section{General Information}

- X Windows : The X Windows system on the Linux machine in the classroom provides a flexible environment for faculty to run and display their programs and documents. Approximately $95 \%$ of the computing facilities in the Mathematics department are Unix based. Using X Windows allows users to remotely display programs running on other machines on the console computer, and thus the overhead projector.

- Win4Lin : Given the popularity of the Microsoft operating systems, we have provided a mechanism by which to run programs designed for these systems in the classroom. Popular applications such as Microsoft Word, Excel, 
Powerpoint, and other programs specific to this OS are available for use, as is an MSDOS prompt (via the Command Prompt) for running older software.

- Console : The classroom has an advanced touch screen console that controls most of its functions. The console doubles as a television monitor allowing preview of video sources and camera alignment on screen before recording or switching to the overhead projector. It also controls the overhead projection system and the switching between the two computers linked to the classroom.

When not in the classroom, one can use Fuqua pioneered distance-learning technology to work with his/her teams to build and maintain the trust and work plans crucial to their success. He/she can work on virtual teams and communicate using email, electronic bulletin boards, chat rooms, online meetings and conference calls. In addition, students can connect with faculty or access learning materials within a customized web environment. One attraction of the Global Executive program is the opportunity to work across language barriers, cultural differences and time zones to create a routine that fits each individual student's work-related demands and personal needs.

For 19 months, they learn with other executives averaging 14 years of work experience while participating in the world's most flexible and international MBA program. This pioneering program combines unique residential sessions in Asia, South America, Europe and the United States with Internet-enabled distance learning allowing students to live and work from anywhere in the world.

A key advantage of The Duke MBA - Global Executive program is that one pursues a rigorous academic curriculum in a global setting. The residential classroom sessions within Terms 1 and 5 take place on the Duke campus, while the other three sessions 
take place in Europe, Asia and South America. Residencies outside the United States generally last two weeks, with each week being spent in a different city. Traveling to various countries throughout the program provides an opportunity to contrast business practices in emerging and developed markets, to witness the impact of globalization and to observe cultural differences within regions around the world. These residential settings allow intense face-to-face interaction between the Fuqua faculty and Global Executive students. They are in class for a minimum of six hours per day and all residential sessions are mandatory.

\section{(http://www.fuqua duke.edu/mba/executive/global/distance.html)}

\section{Bringing the World into the Classroom}

The Global Executive program effectively incorporates "local" content into its curriculum. During the Global Executive's residential learning sessions, students regularly meet with top business, academic and civic leaders at plant tours and guest speaker lectures. They gain unique, firsthand insight and knowledge of the issues and challenges of each region while studying in that part of the world. 


\section{Washington University in Saint Louis}

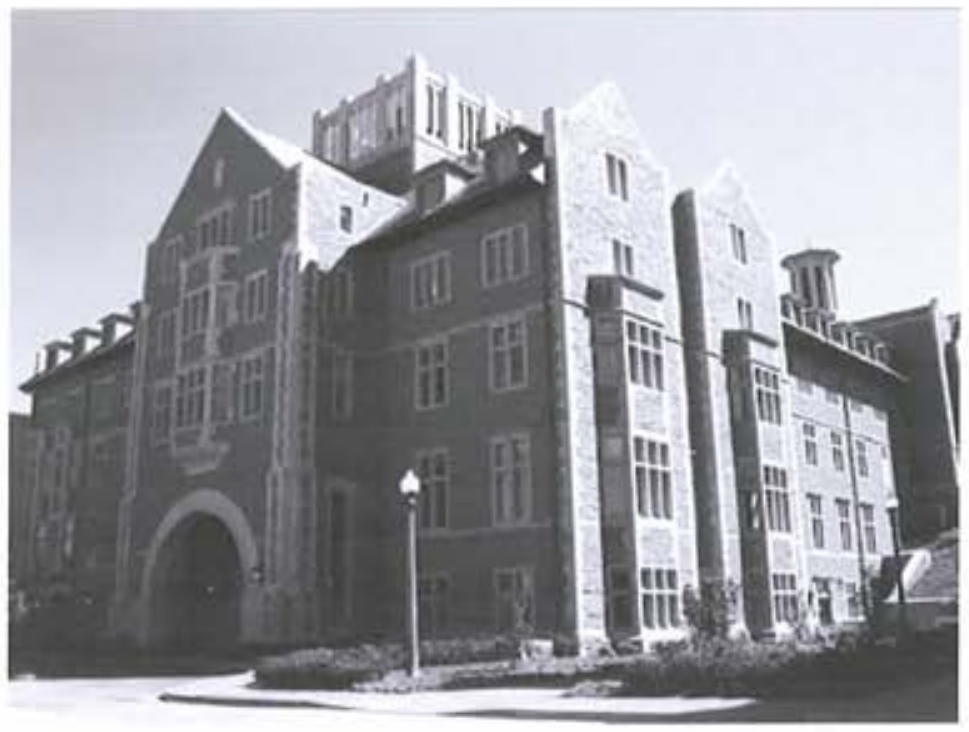

The location of the main entrance to the Charles F. Knight Executive Education

Center says a lot about its focus. It faces not towards main campus, but away from it, towards Millbrook Boulevard. Its focus not on the typical Washington University undergraduate or graduate but on recruiting and teaching 30 to 40 year-old business executives from the St. Louis area as well as from all over the United States. There are no traditional classes held in the Knight Center and its classrooms hold no traditional students. They don't use flexes and points and they certainly don't live in forced triples. Instead these students live in Ritz quality hotel rooms and eat similarly lavish meals, all part of the $\$ 50$ million, five-story Knight Center, which opened in summer 2001. Besides the 66 hotel rooms, the center also features a pub, fitness center, dining hall, and classrooms of varying sizes.

According to Brian Bannister, Associate Dean for Finance and Administration, the Knight Center was built to serve executive education degree programs. He said: "The idea is that we can take complete care of executive students - we can teach, feed, house and entertain them all in one building". 
On most days the Knight Center is quiet and its hallways sparse with people. But on Fridays and Saturdays, the center is at its highest level of activity, with students attending three classes each day from 8 a.m. to 4 p.m.

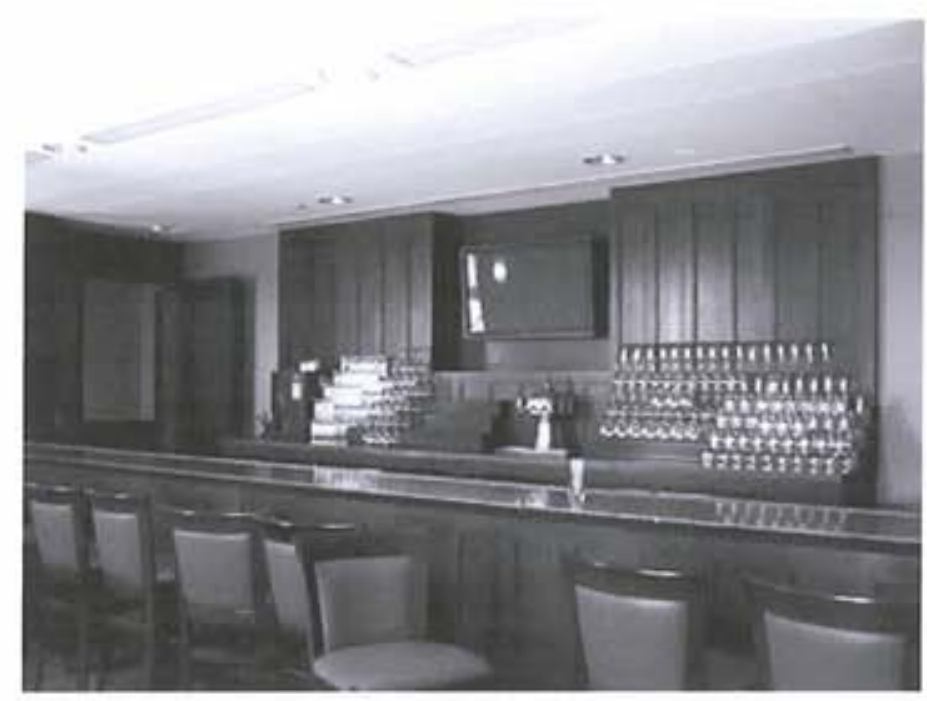

The largest classroom seats 104 students in a tiered seating arrangement, enclosed by bright white walls. Each seat rests behind a desk with Ethernet and electrical connections. Three projectors are mounted in the ceiling, and next to them, three cameras to capture the class for video or distance learning classes. Also on the ceiling are microphones to pick up student comments, which is designed to promote classroom involvement. At the front of the classroom are three screens, a white board, and an instructor's podium. Within the podium are two computers and next to it a document camera, a new kind of overhead projector that makes no noise and is simply a camera mounted facing downward. Rounding out the technology are a VCR and DVD player as well. 


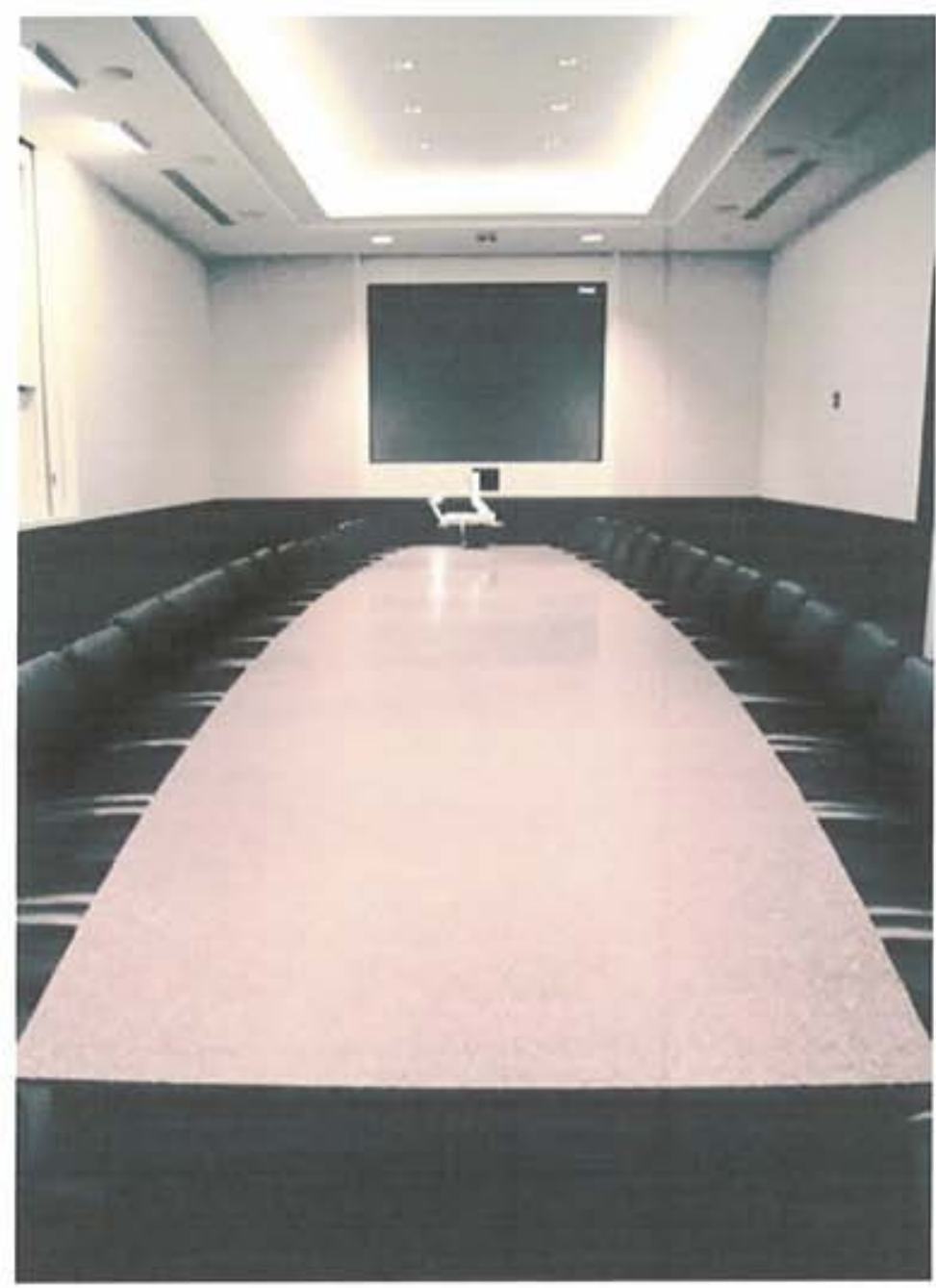

On the fourth and fifth floors of the Knight Center are a total of 66 luxury hotel rooms. Decorated in beige and forest green, the rooms are each furnished with one double bed, cushioned chair, television, and phone. The desk, nightstands, and dresser are made of a dark wood. Compared to other hotel rooms of the same price, $\$ 125$ to $\$ 150$ a night, these rooms are on the small side. Each room has an extra phone line for modem connection as well as Ethernet connections.

EMBA students do have to pay for the hotel room like anyone else.

Aramark operates the hotel and food services. Unlike other typical hotels, there are no vending machines anywhere in the Knight Center. Conference guests and EMBA 
students are offered continuous food during breaks in their day. Hotel guests are not left out when it comes to the free food. Each of the hotel floors has a small kitchen with free coffee, tea, soft drinks, and snacks.

According to Susan Horstman, Director of the Knight Center, one pays one price for the hotel room and everything's inclusive in that price. For her, guests can raid the pantry just as if they were home. Each hotel floor will also have a guest laundry room; not yet finished.

EMBA students are appreciating and enjoying all the Knight Center offers.

"The Knight Center provides an incredible environment for learning," said Mike Tucker, a 37 year-old Clinical Nurse Manager for Barnes-Jewish Hospital and firstyear student in the EMBA program. "The classrooms are set up to support and enhance student participation and interaction, which is one of the great advantages to the EMBA program... The food and the amenities are exceptional and I think go a long way toward tempering an extremely demanding curriculum and rapid time-frame for learning,"

Other classmates concur with Tucker's comments.

"I found myself lacking nothing, which allowed me to fully immerse myself in what is important to me, and that is the educational experience," said John Buck, a Senior Engineering Specialist at Systems \& Electronics Inc. in St. Louis.

He said the Knight Center's technological amenities are one of the greatest attributes. "I also realize that today's employee must be able to embrace technology, but I find myself, like some of the instructors, spending time learning the technology when I wish I had that time to immerse myself in the education," Buck said. "WU has definitely raised the bar. It is evident that a lot of thought went into this facility, and it was very well executed." 
Tuition for the two year-long EMBA program runs at $\$ 65,500$; many corporations sponsor their executives. Broken down, the cost for one student for one day runs at $\$ 700-\$ 1,000$, according to Bannister. The price of tuition includes breakfast and lunch on class days, textbooks, study materials, computer time, and on-campus daily parking permits. EMBA tuition at Northwestern University's top-ranked Kellogg School of Management---the basis for the Knight Center---runs from $\$ 84,000$ to $\$ 94,100$.

Also covered in the EMBA tuition are lodging for Orientation Week as well as lodging and group airfare for both a domestic and an international "fieldtrip." "At the end of the first year, a domestic trip to Washington, D.C. is taken, for students to meet with all entities of the government," Horstman explained. "The trip gives them a chance to see how business, Congress, and the media work together. The International trip to Asia is an opportunity to see business in an international environment. "The domestic and international trips are one of the reasons that Sally Matheson, a district manager for Maytag Appliances in St. Louis, chose WU's EMBA program. She also wanted to take classes with people who are far along in their careers and who have had significant business experiences. She spoke of the "high level of professionalism" in the program and the opportunity to expand and broaden her mind and to bring value to her company. Other students spoke of not only the business contacts, but of the friends they hoped to make in their EMBA classes. "I am interested in the human side of the EMBA program and that is the people that I will share this experience with. I hope to come out of this program with at least one new friend and several new acquaintances," said Buck. 


\section{Loyola Marymount University}

Loyola Marymount University is a member of the Executive MBA Council.

Classroom sessions are comprised of presentations by highly qualified faculty and business leaders. Learning is facilitated through interaction between participants and faculty, exercises approximating real management issues, case studies, and exploring management concepts found in research and text materials. Individual skill development is stressed, with the aim of equipping executives with strategies they can use to improve their own decision-making and leadership capabilities.

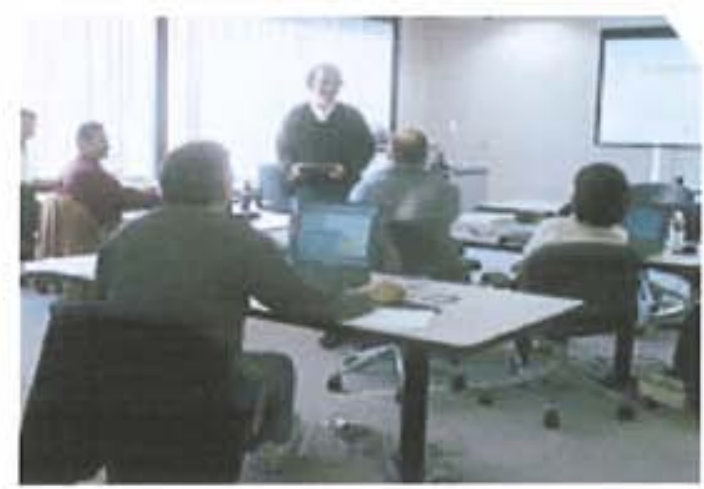

EMBA classes are held on campus in University Hall. The classroom area is designed specifically for executive learning, complete with Internet and technology for collaborative learning. The building houses an executive dining room, bookstore, ATM machine, and convenient underground parking.

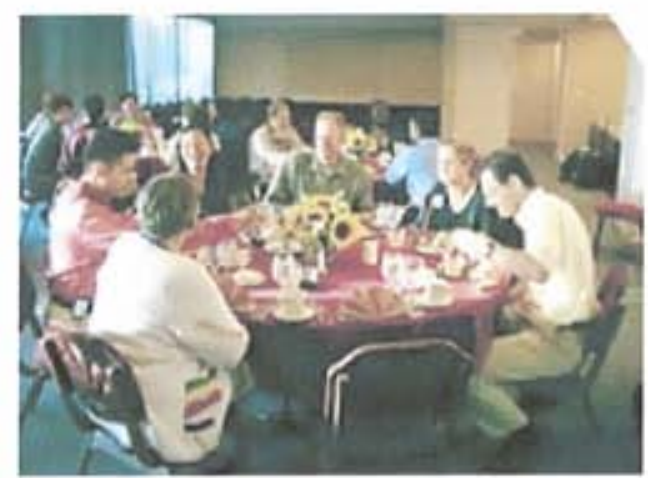


Skill application projects, performed by study teams in each module, enable students to use business concepts learned in the classroom to solve real business problems.

Projects are real business issues faced every day, such as a merger or acquisition, the development of a new product or service, opening new markets, major reorganization, or a functional business problem. Web-based group interaction and e-mail are used to facilitate completion of group assignments.

\section{(http://emba.Imu.edu/index.html)}

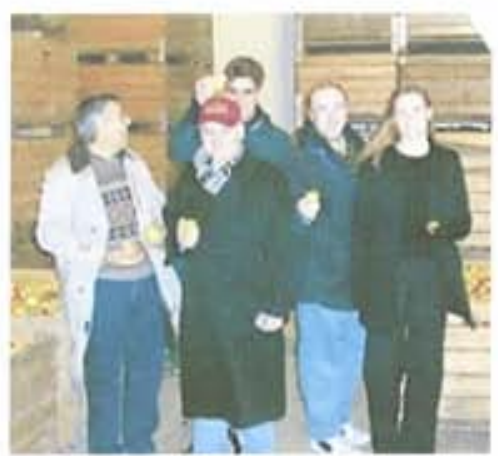

Project research in Germany

After the above-mentioned information concerning different EMBA classroom designs in various universities in the United States, one can develop an idea about the way classrooms are designed. In one way or another, the strengths, weaknesses, opportunities and threats of such classrooms have been analyzed, and a new millennium EMBA classroom design will be structured avoiding all the negative aspects and benefiting from new technological inventions. 


\section{Chapter IV}

\section{Design and Methodology}

\subsection{Overview:}

There is an old Chinese proverb,

"If you intend to plan for a year, plant rice; if you intend to plan for ten years, plant trees; if you intend to plan for a hundred years, plant education".

Education in the aspect of an Executive MBA program will be of great benefit for executives with a high level. Experience will be gained through lectures and both knowledge transfer and sharing between executives/attendants. The hallmark of an Executive MBA is the unique learning experience shared by highly motivated students and seasoned faculty. Mainly, the average number of years of experience is generally seven years greater than the average of students in most full-time traditional programs. As mentioned before, the EMBA program will enhance the students' careers and increase their competency level in the market. To achieve such a goal, a very unique EMBA program from all aspects should be studied and introduced in different perspectives.

This research is conducted in order to improve the learning process in an EMBA classroom. The study is mainly applied on working students and instructors in Lebanese universities. In this research, an evaluation of the existing MBA and EMBA programs and the expectations of selected students and professors was performed. Also, their level of satisfaction was measured, and suggestions and all the possible technological applications that can be beneficial for the EMBA new millennium 
was selected from different age groups, ranging from 25 to 50 years old with more than 6 years in work experience. Through their work experience, the EMBA students will benefit from a variety of educational backgrounds and experiences. At the same time, students, seeking a better educational status, will develop new skills and achieve progress whether they are employees or self-employed.

\subsection{The Instrument:}

To conduct this research, a survey was performed. The survey included two different questionnaires, one for students and the other for professors and instructors. The students questionnaire dealt with their level of satisfaction concerning the program, and their evaluation of it. In addition, students were asked to suggest unique EMBA classroom ideas regarding design and course content. Also, the students' opinions on different technological inventions that could make the EMBA experience a memorable one were solicited.

The instructor's questionnaires dealt with their level of satisfaction concerning the MBA and EMBA students. Also, their questionnaire included some suggestions for the new EMBA classroom from the professors' points of view. Some interviews were made with some IT specialists about all the technologies needed for such an e-enabled classroom.

Different measurement scales were applied in the questionnaires for the purpose of simplifying the questions and making them easy to answer. That's why an interval scale was applied in the age question taking into consideration the privacy of the respondents. However, a nominal scale was applied on the other demographic section 
questions. As for the other sections of the two questionnaires, a Likert scale was used where 5 choices were given from Strongly agree to strongly disagree.

\subsection{Data Analysis:}

The analysis of the questionnaires' data will drive the design of the EMBA classroom of the new millennium. The Statistical Package for Social Science (SPSS) was used to analyze the data. The data of the questionnaires was entered in SPSS, and different tests were conducted. Frequency distribution of both questionnaires was conducted and some cross-tabulation tests were made in order to know how certain variables change along with others. 


\section{Chapter V}

\section{Findings and Analysis}

\subsection{Overview:}

"You tell me and I forget. You teach me and I remember. You involve me and I learn." Ben Franklin.

For students to learn, they need to live and experience the learning environment. The best learning environment that students can benefit from is the EMBA program where most of the students as mentioned before are executives and hired in middle and senior management positions. Through these positions, these students will share their daily work experiences and solve their problems through being involved in a program like the EMBA. For this purpose, a study was made to know the possibility of attaining such an EMBA classroom for the new millennium. This study sheds light on the level of satisfaction of students and instructors with the MBA/EMBA program. It also introduced few suggestions for building the EMBA classroom of the new Millennium. The study came up with different results showing the advantages and disadvantages of the existing EMBA program. These results as mentioned before were done through the SPSS software.

\subsection{Level of Satisfaction of the Existing Program:}

As mentioned in the previous chapter, there were two questionnaires distributed one for the instructors and the other for the students. In each questionnaire we studied their level of satisfaction concerning the program in content and structure.

To start with, a question is raised here: To what extent are instructors satisfied in the EMBA program? The first thing one can take into consideration while evaluating the EMBA program is the willingness of the instructors to be involved in such a program. The results showed that 84 percent of the instructors are willing to teach the courses offered in the program. This means that most of the instructors can be available in the EMBA program.

I am willing to teach the courses offered in the program 


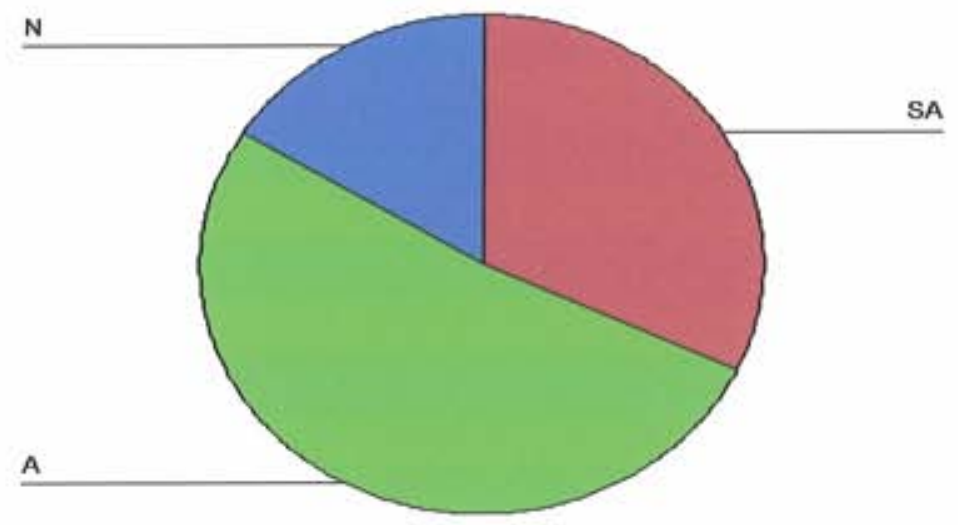

However, this is not enough. It is known that teaching is an art and the instructor is the artist that plays the major role in the success of this profession. So it is important to know the instructor's level of pleasure while teaching. The results showed that 72 percent enjoy teaching the courses in the program although they have few tips to be taken into consideration.

I enjoy teaching the courses in the program

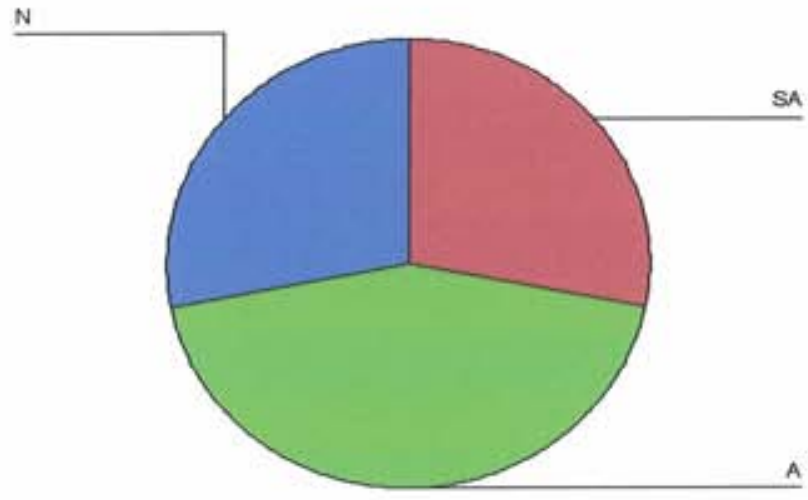

In the first place, around 40 percent of the instructors believe that the quality of students is not very good. One wonders why? Should one blame the students or the pressure of life or the whole learning environment? After all, these students are 
executives and are very busy. That's why the classroom environment should be a comfortable one in the content, technology integrated and interaction.

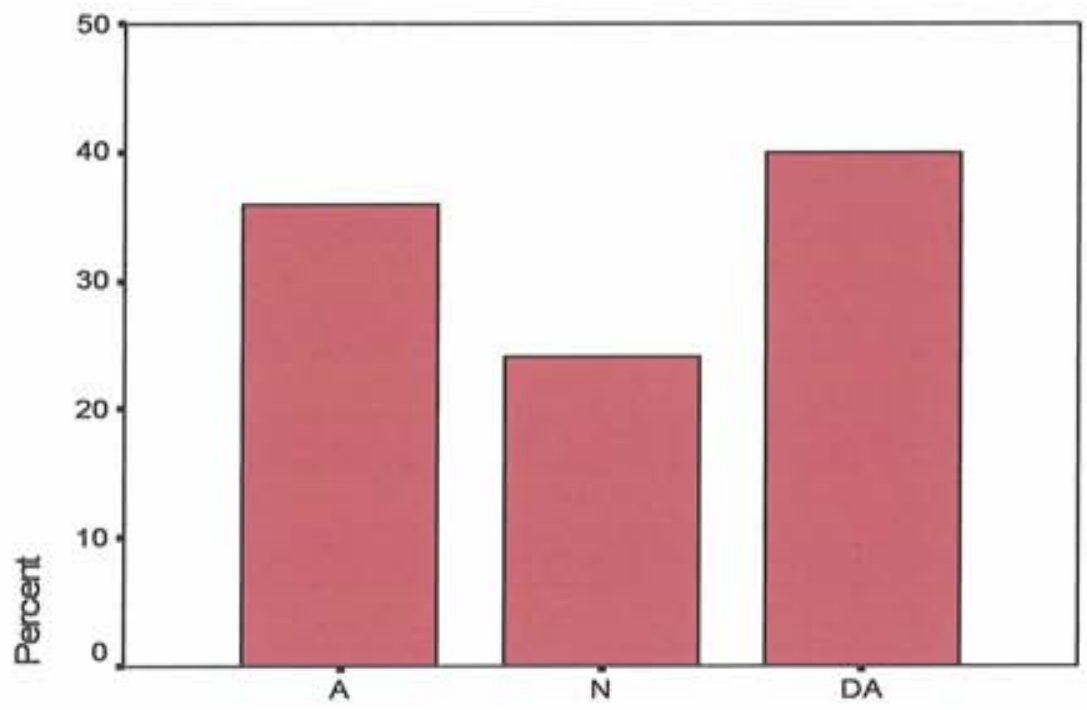

The quality of students is very good

Also, 68 percent of the instructors think that the program as a whole needs more expansion in courses and ways of teaching.

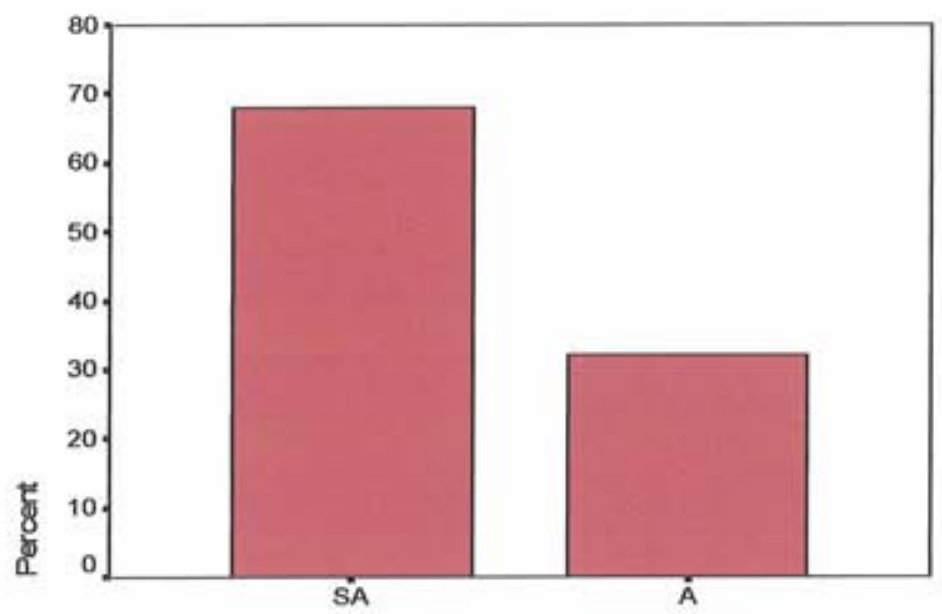

The program as a whole needs more expansion in courses an

Students agree upon the same idea where 82 percent of the students believe that some of the courses should be taught in a different way. These instructors are looking forward for making the quality of the EMBA program to be as high as that offered by competent universities worldwide. This can be achieved through some changes 
implemented in the existing program. All agreed on the fact that the program would benefit from partnership with other top EMBA programs around the world.

Also, 82 percent of the instructors believe that more contacts with industry leaders are needed and all the instructors believe in the importance of conferences and seminars. Conferences and Seminars are highly needed.

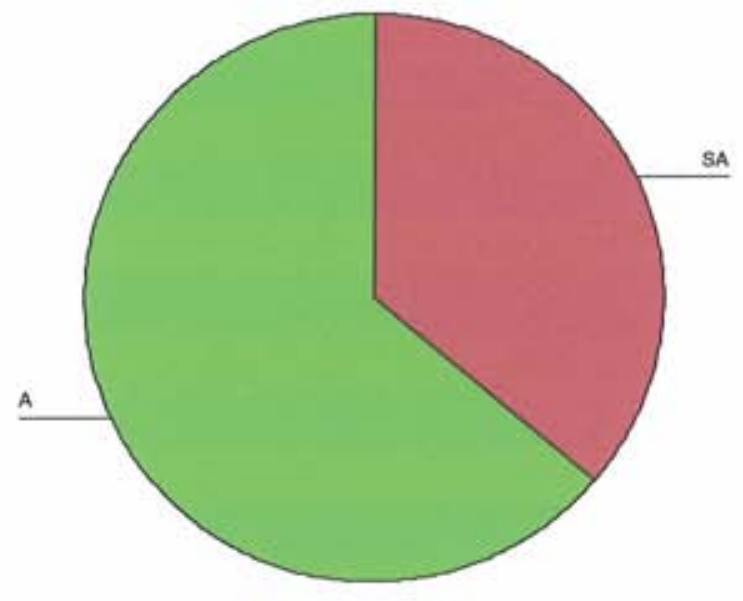

In addition to 80 percent of the sample shed light on the importance of getting guest speakers who are more qualified. After all, the instructors are satisfied with the EMBA existing program and trying through their great work experience to improve it and update it. Through their contacts and business relations, they can be able to increase the connections and suggestions for such a classroom. The main purpose for this is the benefit of students and of course the good reputation of the university. To complete it, students' level of satisfaction should be taken into consideration.

As mentioned before, students are the pillars of education. Without students, classes can not operate. In the EMBA classroom, students are executives of more than 5 years working experience. The students sample of this study were mainly managers and supervisors. To study their level of satisfaction, one can realize that the majority of the majority of the executive students are to some extent satisfied with the program. In fact, 85 percent of the students believe that the program as a whole is beneficial. Also, 82 percent of them are aware that through this program, the ability to improve their career is very high. Because of this way of thinking, it is obvious to get up with 87 percent of the students willing to complete the courses in the program. 


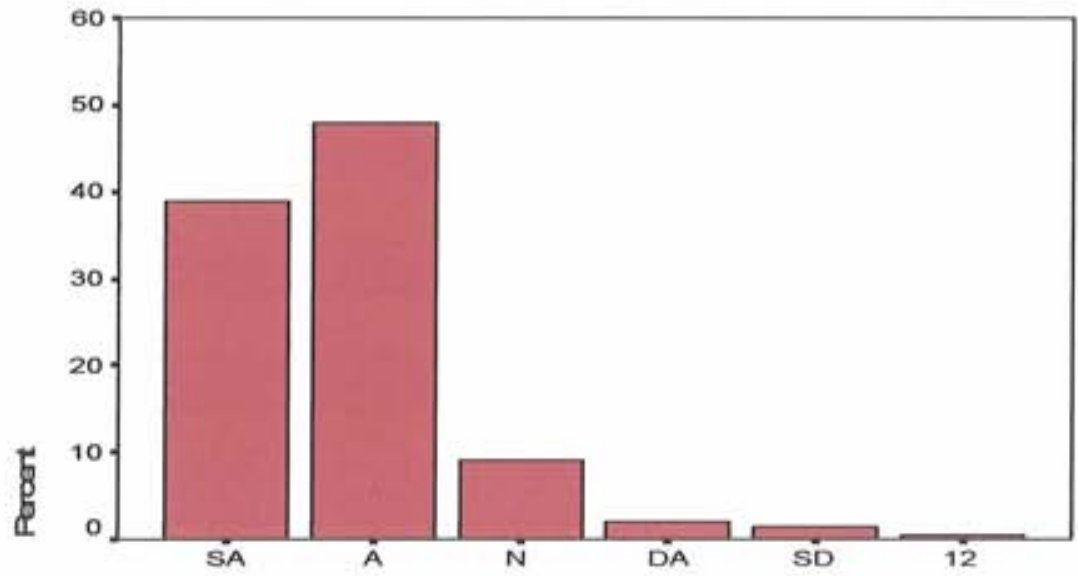

I am willing to complete the courses in the program

These executives intend to come back to study after a long time leave, working and getting busy with family obligations. They have the determination more than any other student in the traditional MBA program. However, when involved in the program, was the EMBA program up to their expectations? The answer is not really. In fact, after being enrolled in the EMBA program the majority of the students found that the program is good in content but lacks the way it is presented. 82 percent of the EMBA students realized that some of the courses should be taught in a different way.

Some courses should be taught in a different way

\begin{tabular}{|r|r|r|r|r|r|}
\hline & & Frequency & Percent & $\begin{array}{r}\text { Valid } \\
\text { Percent }\end{array}$ & $\begin{array}{r}\text { umulati } \\
\text { ve } \\
\text { Percent }\end{array}$ \\
\hline Valid & SA & 82 & 41.0 & 41.0 & 41.0 \\
\hline & $\mathrm{A}$ & 82 & 41.0 & 41.0 & 82.0 \\
\hline & $\mathrm{N}$ & 31 & 15.5 & 15.5 & 97.5 \\
\hline & $\mathrm{DA}$ & 3 & 1.5 & 1.5 & 99.0 \\
\hline & $\mathrm{SD}$ & 2 & 1.0 & 1.0 & 100.0 \\
\hline & Total & 200 & 100.0 & 100.0 & \\
\hline
\end{tabular}

About 75 percent of the sample believes that the program should be more interactive. In fact, those EMBA students are searching for an interactive learning environment where the instructor is more a facilitator than a teacher. 53 percent of these students are benefiting from the EMBA program however they believe that the program is very expensive relative to what it offers.

The quality of education is very good relative to the cost I am paying

\begin{tabular}{|r|r|r|r|r|r|}
\hline & & Frequency & Percent & Valid Percent & Cumulative Percent \\
\hline Valid & SA & 7 & 3.5 & 3.5 & 3.5 \\
\hline & $\mathrm{A}$ & 49 & 24.5 & 24.5 & 28.0 \\
\hline
\end{tabular}




\begin{tabular}{|r|r|r|r|r|r|}
\hline & $\mathrm{N}$ & 41 & 20.5 & 20.5 & 48.5 \\
\hline & DA & 66 & 33.0 & 33.0 & 81.5 \\
\hline & SD & 37 & 18.5 & 18.5 & 100.0 \\
\hline
\end{tabular}

Such students working and hired in a high level management positions are looking forward for an EMBA degree to be reflective of what the local and global market are in need for. They need to live real world experiences and share them with others and benefit from this knowledge sharing process. Most of the students, who are 86 percent, prefer the classroom environment to be a simulated environment of real business situations. Mainly managers deal with decision making and for them to come up with the right decision is not an easy task. To fulfill this task successfully, they need to be trained to be under pressure for solving certain problems and take quick decisions when needed.

Regarding the courses of the MBA/EMBA program, the majority of the courses were not beneficial for the students except for management and finance courses. Again this problem can be solved when the way of presenting the courses is different. All of the above results do not imply that the teachers of this program are not up to the level. On the contrary, 90 percent of the students believe that there is a lot of knowledgeable faculty in the MBA/EMBA program. According to most of the executive students, the teachers in the EMBA program are effective, strong in communicating with the subject; however, they believe that academic experience alone is not enough. The faculty in the program needs to be more exposed to new instruction methods and to be more experienced in the knowledge transfer process. As for the instructor/student relationship, it should be in a very interactive and technology equipped environment.

\subsection{Suggestions for the Structure of the EMBA Classroom}


To build an EMBA classroom, a research was done in order to know how other universities worldwide designed their own EMBA classrooms. Also, as mentioned before, two questionnaires were distributed to instructors and students who in return gave their own suggestions for how the structure of an EMBA classroom can be. Through their experience, the majority of the instructors believe that the number of students in an EMBA classroom can not be more than 25 for several reasons. More concentration and better discussion are some of these reasons. This result is shown in this table:

The class size should be of no more than 25 students

\begin{tabular}{|r|r|r|r|r|r|}
\hline & & Frequency & Percent & $\begin{array}{r}\text { Valid } \\
\text { Percent }\end{array}$ & $\begin{array}{r}\text { Cumulati } \\
\text { ve } \\
\text { Percent }\end{array}$ \\
\hline Valid & SA & 21 & 84.0 & 84.0 & 84.0 \\
\hline & $\mathrm{A}$ & 4 & 16.0 & 16.0 & 100.0 \\
\hline & Total & 25 & 100.0 & 100.0 & \\
\hline
\end{tabular}

Concerning the design of the classroom, making it a semi circular structure is a nice and an important suggestion. However, what is the instructors' opinion about it. In fact, the majority which is 64 percent were neutral about such a design. May be this is so because they are still unaware of the importance of the design and its influence on the learning environment. That's why one can recommend for instructors to be trained for different teaching methods where they can view the learning experience differently.

This was shown in the table below.

The EMBA classroom design should be a semi-circular structure, with 5 concentric rows, gradually stepped up per row

\begin{tabular}{|c|c|c|c|c|c|}
\hline 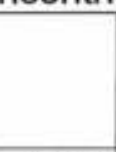 & 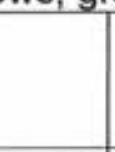 & Frequency & Percent & Valid Percent & $\begin{array}{r}\text { Cumulati } \\
\text { ve } \\
\text { Percent }\end{array}$ \\
\hline Valid & SA & 9 & 36.0 & 36.0 & 36.0 \\
\hline & $\mathrm{N}$ & 16 & 64.0 & 64.0 & 100.0 \\
\hline & Total & 25 & 100.0 & 100.0 & \\
\hline
\end{tabular}

However, concerning the ergonomics setup, most of the faculty believes that the chairs should be as comfortable as possible. This kind of chairs will help in the learning environment especially that the EMBA program is a long day study in one 
room and executives need to be comfortable in order for them to contribute well to the learning process through effective participation and knowledge sharing.

I prefer the chairs in the EMBA classroom to be very comfortable and flexible in terms of height, tilt, and swivel.

\begin{tabular}{|r|r|r|r|r|r|}
\hline & & Frequency & Percent & $\begin{array}{r}\text { Valid } \\
\text { Percent }\end{array}$ & $\begin{array}{r}\text { Cumulati } \\
\text { ve } \\
\text { Percent }\end{array}$ \\
\hline Valid & SA & 7 & 28.0 & 28.0 & 28.0 \\
\hline & $\mathrm{A}$ & 7 & 28.0 & 28.0 & 56.0 \\
\hline & $\mathrm{N}$ & 11 & 44.0 & 44.0 & 100.0 \\
\hline & Total & 25 & 100.0 & 100.0 & \\
\hline
\end{tabular}

Since the EMBA program is a long day study in one place, it is obvious to have certain coffee breaks and lunch which is a part of the Executive program. Usually, the food and refreshments are in another room separate from the classroom. However, a suggestion was made in this research where the food and refreshments section will be inside the EMBA classroom. For instructors, 44 percent of them find it nice and innovative to have the food and refreshments in the classroom.

Food and refreshments should be provided in an EMBA classroom

\begin{tabular}{|r|r|r|r|r|r|}
\hline & & Frequency & Percent & $\begin{array}{r}\text { Valid } \\
\text { Percent }\end{array}$ & $\begin{array}{r}\text { umulati } \\
\text { ve } \\
\text { Percent }\end{array}$ \\
\hline Valid & SA & 7 & 28.0 & 28.0 & 28.0 \\
\hline & $\mathrm{A}$ & 4 & 16.0 & 16.0 & 44.0 \\
\hline & $\mathrm{N}$ & 7 & 28.0 & 28.0 & 72.0 \\
\hline & $\mathrm{DA}$ & 4 & 16.0 & 16.0 & 88.0 \\
\hline & $\mathrm{SD}$ & 3 & 12.0 & 12.0 & 100.0 \\
\hline & Total & 25 & 100.0 & 100.0 & \\
\hline
\end{tabular}

As realized different views were introduced concerning the physical layout of the classroom. Most of the instructors are looking forward for a new classroom environment. In fact, most of the instructors believe that new computer enabled techniques of analyzing and teaching case studies are highly recommended and needed. Moreover, all of the instructors enjoy their teaching process in a computer simulated class environment where simulation software will be installed especially in the EMBA program. Moreover, 84 percent enjoy teaching their courses in a structured presentation class environment. After the above results, one can realize that the faculty are looking forward to enhance the level of MBA/ EMBA program. 
New computer enabled techniques of analyzing and teaching case studies are needed

\begin{tabular}{lrrrrr} 
& & $\begin{array}{r}\text { Frequen } \\
\text { cy }\end{array}$ & & \multicolumn{2}{c}{$\begin{array}{r}\text { Valid } \\
\text { Percent }\end{array}$} \\
Valid & & & & & $\begin{array}{r}\text { vercent } \\
\text { Percent }\end{array}$ \\
& SA & 16 & 64.0 & 64.0 & 64.0 \\
& A & 9 & 36.0 & 36.0 & 100.0 \\
& Total & 25 & 100.0 & 100.0 &
\end{tabular}

I enjoy teaching my courses in a computer simulated class environment

Frequen Percent Valid Cumulati

cy Percent ve

$\begin{array}{rrrrrr} & & \text { cy } & & \text { Percent } & \text { ve } \\ \text { Valid } & \text { SA } & 18 & 72.0 & 72.0 & 72.0 \\ & \text { A } & 7 & 28.0 & 28.0 & 100.0 \\ & \text { Total } & 25 & 100.0 & 100.0 & \end{array}$

I enjoy teaching my courses in a structured presentation class environment Frequency Percent Valid Cumulati Percent ve

$\begin{array}{rrrrrr} & & & & & \text { Percent } \\ \text { Valid } & \text { SA } & 2 & 8.0 & 8.0 & 8.0 \\ & \mathrm{~A} & 19 & 76.0 & 76.0 & 84.0 \\ & \mathrm{~N} & 4 & 16.0 & 16.0 & 100.0 \\ & \text { Total } & 25 & 100.0 & 100.0 & \end{array}$

As for students, it is well known that their priority is EMBA classroom design. For them, being comfortable make them concentrate a lot. Especially that they are going to stay all day long in discussions and teamwork. 63 percent of the students would like the classroom to be a semi circular structure. Because it is their comfort that matters, 87 percent of the students prefer the chairs to be very comfortable and flexible to make them feel as if they were home. Moreover, 68 percent of the students believe that food and refreshments should be available in the classroom.

The EMBA classroom design should be a semi-circular structure, with 5 concentric rows, gradually stepped up per row.

\begin{tabular}{|r|r|r|r|r|r|}
\hline & & Frequency & Percent & $\begin{array}{r}\text { Valid } \\
\text { Percent }\end{array}$ & $\begin{array}{r}\text { Cumulative } \\
\text { Percent }\end{array}$ \\
\hline Valid & SA & 17 & 8.5 & 8.5 & 8.5 \\
\hline & $\mathrm{A}$ & 109 & 54.5 & 54.5 & 63.0 \\
\hline & $\mathrm{N}$ & 68 & 34.0 & 34.0 & 97.0 \\
\hline & $\mathrm{DA}$ & 4 & 2.0 & 2.0 & 99.0 \\
\hline & $\mathrm{SD}$ & 2 & 1.0 & 1.0 & 100.0 \\
\hline
\end{tabular}




\begin{tabular}{|l|llll|}
\hline & Total & 200 & 100.0 & 100.0 \\
\hline
\end{tabular}

I prefer the chairs in the EMBA classroom to be very comfortable and flexible in terms of height, tilt, and swivel

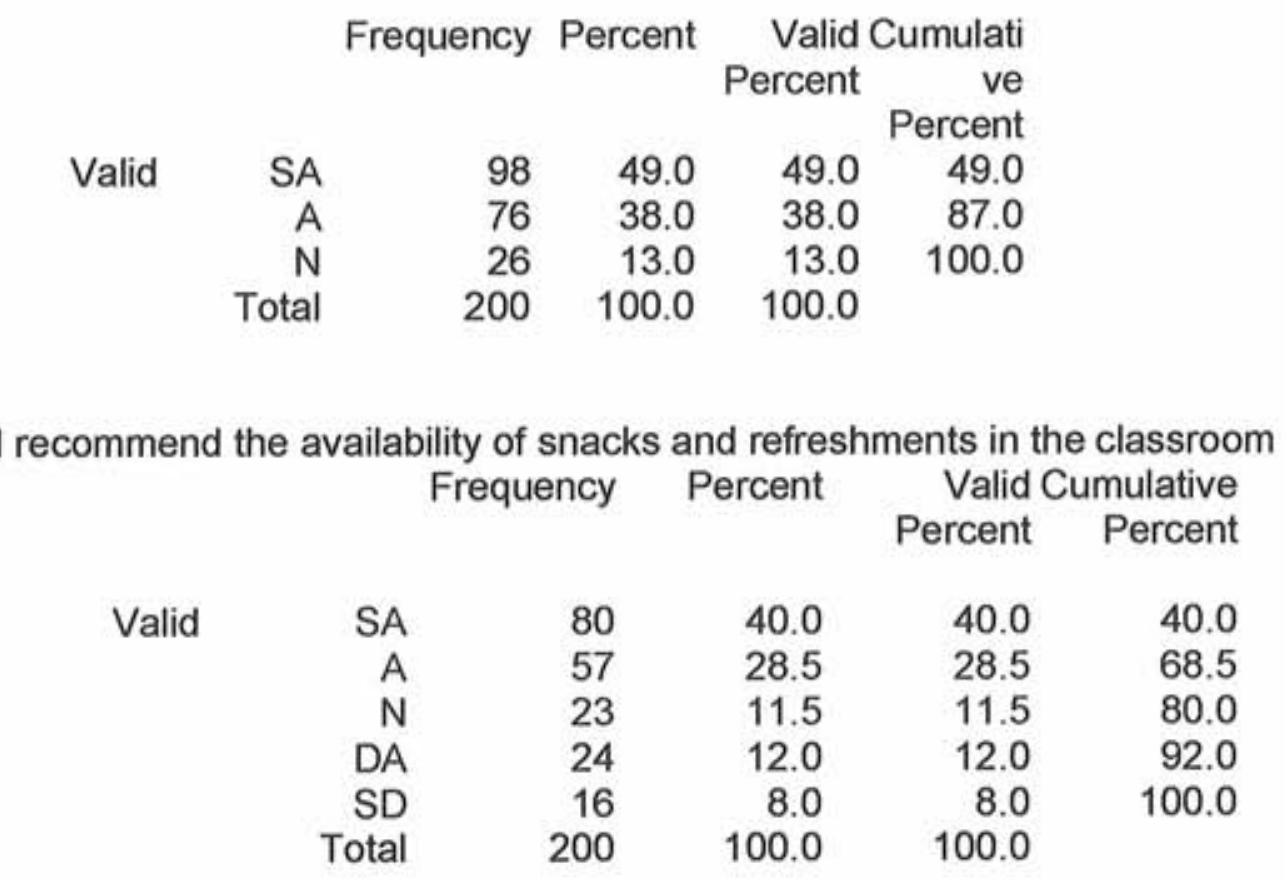

After the above results, one can benefit from the faculty and students points of views and in one way or another we can come up with a new design for the EMBA classroom especially after a total review of the designs that other universities are applying.

\subsection{Technology needed for the Classroom}

One of the things about technology and education is that a lot of people think about the technology first and the education later, however one should remember that it is not about what technology the university has, but it is about what it does with it. Technology needed must offer methods that help educators convey their message in a fast, effective and convenient way.

That's why technology used should be user friendly. From this, one can realize that because of the lack of computer knowledge, 76 percent of the faculty believes in the importance of computer training for all instructors. This is shown in the below table: Most faculty should be trained on computer use 


\begin{tabular}{|r|r|r|r|r|r|}
\hline & & $\begin{array}{r}\text { Frequen } \\
\text { cy }\end{array}$ & Percent & $\begin{array}{r}\text { Valid } \\
\text { Percent }\end{array}$ & $\begin{array}{r}\text { Cumulati } \\
\text { ve } \\
\text { Percent }\end{array}$ \\
\hline Valid & SA & 19 & 76.0 & 76.0 & 76.0 \\
\hline & $\mathrm{N}$ & 6 & 24.0 & 24.0 & 100.0 \\
\hline & Total & 25 & 100.0 & 100.0 & \\
\hline
\end{tabular}

Moreover, the entire instructors sample believed that the design of the classroom should be updated specifically to mirror an executive level office technology infrastructure. Through this technology, executives will be able to work fast and be involved more in the learning environment.

The design of teh classroom should be updated specifically to mirror an executive level office technology infrastructure Frequency Percent Valid Cumulativ

$\begin{array}{rrrrrr} & & & \text { Percent } & \text { e Percent } \\ \text { Valid } & \text { SA } & 14 & 56.0 & 56.0 & 56.0 \\ & \text { A } & 11 & 44.0 & 44.0 & 100.0 \\ & \text { Total } & 25 & 100.0 & 100.0 & \end{array}$

Technology is not only integrated physically also in the content of the program. What is meant here is that this study showed that all the instructors strongly believe that new computer enabled techniques of analyzing and teaching case studies are needed.

New computer enabled techniques of analyzing and teaching case studies are needed

Frequency Percent Valid Cumulativ

$\begin{array}{rrrrrr}\text { Valid } & & & \text { Percent } & \text { e Percent } \\ & \text { SA } & 16 & 64.0 & 64.0 & 64.0 \\ & \mathrm{~A} & 9 & 36.0 & 36.0 & 100.0 \\ & \text { Total } & 25 & 100.0 & 100.0 & \end{array}$

Here one can wonder about the level of acceptance of instructors for the technology installed. It's been shown in the research that 75 percent of the instructors enjoy teaching in a computer simulated and in a structured presentation class environment. I enjoy teaching my courses in a structured presentation class environment

$$
\text { Frequency Percent Valid Cumulativ }
$$

$\begin{array}{rrrrrr}\text { Valid } & & & & \text { Percent } & \text { e Percent } \\ & \text { SA } & 2 & 8.0 & 8.0 & 8.0 \\ & \mathrm{~A} & 19 & 76.0 & 76.0 & 84.0 \\ \mathrm{~N} & 4 & 16.0 & 16.0 & 100.0 \\ & \text { Total } & 25 & 100.0 & 100.0 & \end{array}$

This study also highlights the technologies needed in each field of study (Management, Marketing, Finance, Economics, Accounting, Strategy, Quantitative 
Methods, Entrepreneur and IT). The percentages presented in the tables below are explained as follows* from the Instructors' and Students' point of view:

\begin{tabular}{|l|c|c|c|c|c|}
\hline & & & $\begin{array}{r}\text { Computer \& } \\
\text { Video Conferencing }\end{array}$ & Projection & web enabled \\
Team work & Sound Proofing \\
\hline Management & $92 \%$ & $76 \%$ & $52 \%$ & $68 \%$ & $72 \%$ \\
\hline Marketing & $92 \%$ & $76 \%$ & $60 \%$ & $60 \%$ & $72 \%$ \\
\hline Finance & $52 \%$ & $76 \%$ & $52 \%$ & $68 \%$ & $88 \%$ \\
\hline Economics & $80 \%$ & $84 \%$ & $60 \%$ & $68 \%$ & $88 \%$ \\
\hline Accounting & $64 \%$ & $64 \%$ & $52 \%$ & $52 \%$ & $68 \%$ \\
\hline Strategy & $52 \%$ & $80 \%$ & $68 \%$ & $60 \%$ & $88 \%$ \\
\hline QM & $80 \%$ & $60 \%$ & $52 \%$ & $52 \%$ & $68 \%$ \\
\hline Entrepreneur & $72 \%$ & $60 \%$ & $60 \%$ & $60 \%$ & $88 \%$ \\
\hline IT & $80 \%$ & $80 \%$ & $92 \%$ & $92 \%$ & $56 \%$ \\
\hline
\end{tabular}

*: Black marked percentages are in favor. Red marked percentages are not in favor.

\begin{tabular}{|l|c|c|c|c|c|}
\hline & $\begin{array}{l}\text { Video } \\
\text { Conferencing }\end{array}$ & Projection & $\begin{array}{l}\text { Computer } \\
\text { \& web } \\
\text { enabled }\end{array}$ & $\begin{array}{l}\text { Team } \\
\text { work }\end{array}$ & $\begin{array}{l}\text { Sound } \\
\text { Proofing }\end{array}$ \\
\hline Management & $51 \%$ & $58 \%$ & $66 \%$ & $61 \%$ & $84 \%$ \\
\hline Marketing & $55 \%$ & $61 \%$ & $66 \%$ & $52 \%$ & $94 \%$ \\
\hline Finance & $80 \%$ & $62 \%$ & $63 \%$ & $66 \%$ & $92 \%$ \\
\hline Economics & $78 \%$ & $70 \%$ & $54 \%$ & $73 \%$ & $85 \%$ \\
\hline Accounting & $81 \%$ & $59 \%$ & $73 \%$ & $84 \%$ & $96 \%$ \\
\hline Strategy & $57 \%$ & $59 \%$ & $61 \%$ & $74 \%$ & $83 \%$ \\
\hline QM & $92 \%$ & $51 \%$ & $63 \%$ & $81 \%$ & $94 \%$ \\
\hline Entrepreneur & $78 \%$ & $81 \%$ & $83 \%$ & $65 \%$ & $96 \%$ \\
\hline IT & $76 \%$ & $53 \%$ & $51 \%$ & $82 \%$ & $96 \%$ \\
\hline
\end{tabular}

*: Black marked percentages are in favor. Red marked percentages are not in favor.

It can be shown from the above table how students are against the integration of technology in most of the courses. However, this is not the case. In fact, students are not aware of the technologies needed for certain courses because the way they are presented does not satisfy them. When distributing the questionnaires, many students commented on the program that they got bored from the lecture way of presenting the MBA/EMBA courses where the student is just receiving information without discussion and living real world experiences.

\subsection{Comparison between LAU and AUB Results}


After conducting the research in LAU and AUB, one can realize that the Instructors and students of the existing EMBA program are satisfied to some extent. As mentioned before, instructors were not totally satisfied with the students, however, these results differs between LAU and AUB sample. In fact, statistics showed that AUB instructors were satisfied with the students by only 50 percent where the rest are dissatisfied. However, 29 percent of LAU instructors believe that the quality of students is good and 35 percent believed the opposite. The rest of the sample which is 36 percent was neutral about it. That means that the quality of students at LAU is to some extent better than that of AUB. This is so maybe because the program at AUB is still new and students are still not used to programs built on topic basis. As for the rest of the statistics, both LAU and AUB instructor believe in the change process that is needed by the EMBA program. They agree with the fact that the program is good in content but needs some modifications in the way it is presented and the technology integrated. What is meant here is that all the instructors are aware of the technological advancements that the world is going through and that is why they strongly believe in its urgent need in the program. The purpose of technology in the EMBA program is to give the chance for these executives to be updated with the latest technologies and be exposed to worldwide experiences in order to benefit in return their companies. It is only through technology that they can live, experience and share knowledge from different cultures worldwide. Also, some recommendations were agreed on dealing with the structure of the classroom. As for LAU and AUB students, they are not highly satisfied for they think there is a great possibility of building an e-enabled classroom with the necessary technology needed and a different way in presenting lectures. From all the above results, the next chapter will introduce the recommended EMBA classroom for the new millennium. 


\section{Chapter VI \\ EMBA Classroom Design}

\subsection{Overview}

Every time one walks into a new college classroom and notices obvious design flaws, someone remarks, "I can't believe our review process didn't catch that!" A question to raise here is: How can properly designed furniture add to improved learning and increased executive students' satisfaction? When starting or adding new classrooms, especially for an Executive MBA program, most coordinators get caught up in new construction, choosing hardware/software and calculating electrical requirements. A very important piece to this puzzle, which is often afterthought, is furniture design and how it relates to the hardware and room layout. It is a well-known fact that no matter how good your instructors, courseware or hardware are, if the students are uncomfortable, their ability to learn drops dramatically.

In the past, the setup of classrooms in EMBA programs was time consuming where each instructor needed to enter the classroom, reset the computer and the projector, according to his/her needs. However, now the instructor can control the entire classroom and enhance knowledge sharing experiences through the most advanced technological setup.

In order to maintain a unique classroom environment for the EMBA program, a certain design should be provided for a better learning and technological engaged environment. The objective from this design is to introduce an e-enabled classroom for executives and make it as user friendly as possible.

The EMBA classroom design is a fully technologically equipped classroom. It is characterized by all the facilities that make students more comfortable and able to share knowledge at the same time. A new classroom should look handsome during 
class when the technology is being used. Interior design should integrate technology, not just hide hardware to make the classroom look attractive only during class breaks.

\subsection{Ergonomics}

This is a term that has been overused in recent years to sell everything from cars to can openers. Simply put, it is the study of man's relationship to his work environment. If there is no budget for furniture, there is no choice. If the classroom is to be built around new technology, it is important to give the computer a place and to define its place within the classroom by using furniture that has been designed specifically to serve this purpose.

The classroom is designed in a semi-circular setup where there are five trapezoidal tables, which, when put together, a semi-circular table will be formed.

These tables are also necessary to ensure that each videoconference participant is seen by the camera. Also, a table for the instructor will be facing the students and integrated in it a tablet monitor with remote control software to control the students' computers,
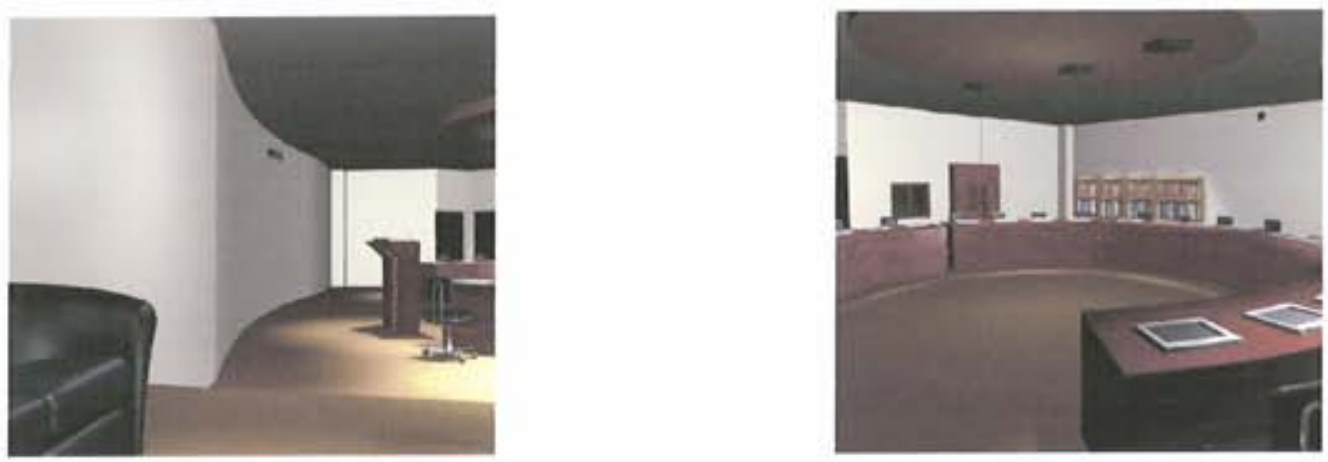

Five tablet monitors with wireless keyboards will be integrated in each table. The monitors should be at arms' length and positioned in the table below eye level. The relaxed eye has the tendency to look downward. An additional benefit to positioning the monitor in this recessed position is a clear view for the student over the top of the monitor. Perhaps the most compelling reason to get the computer off the desktop is that it is an impediment to eye contact between the student and the instructor. As mentioned before, the computers are integrated into desks. In all other areas of education where the computer plays a significant role in classroom activity, it is 
important to examine the reasons why students are in the classroom. In most cases it is to get more from training than is available, say, at home with an Internet connection and a directed course of study; i.e., human interaction between classmates and instructors and the significance of space and time in education in addition to sharing of others experiences.

By placing the computer below the work surface, educators get the benefit of :

A classroom of students not monitors. The greatest objection made by educators is that students "hide" behind the computer. Students miss important information and instructors cannot gauge the effectiveness of presentations and lectures.

$>$ Increased interaction between students. It is easier for students to work in teams if the equipment does not get in the way.

The opportunity to offer more traditional educational materials without distraction. Workbooks, literature and testing materials can't fit on the desk if the surface is taken up by a CPU, Monitor, keyboard and mouse. Everything will be computerized and done through Intranet. Another feature of this technology is the ability of adding notes to PowerPoint presentations, lectures, and NetMeeting conferences.

\subsection{Smart Podiums:}

"Smart Lecterns" as they are often called contain anything from a microphone and simple control panel all the way up to and including the majority of the AV system. General Projection has built systems around every conceivable type of lectern. In fact, a tablet monitor is integrated in this podium with remote control software in order to control the projectors and screens for presentations. The lectern for the presentation computer needs to be small and placed at the right or left front of the room, allowing the presenter to face the audience. Small lecterns do not create the psychological barriers between presenter and audience that complex bunkers do. 


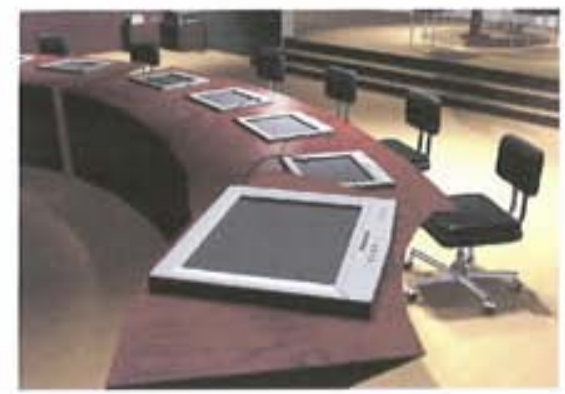

\subsection{Sound System:}

The sound-field systems are basically Public Address (PA) systems with the inclusion of a wireless microphone. These microphones will be integrated in the five tables with a light for the permission to speak. Two wireless microphones are integrated in each table. Ceiling speakers are placed behind the position of students so that they can hear their voices clearly and purely. In addition, a microphone will be placed at the podium for the instructor/presenter to speak in. The sound control position is normally situated in the control room at end of the classroom, and remotely driven by the presenter at the podium.

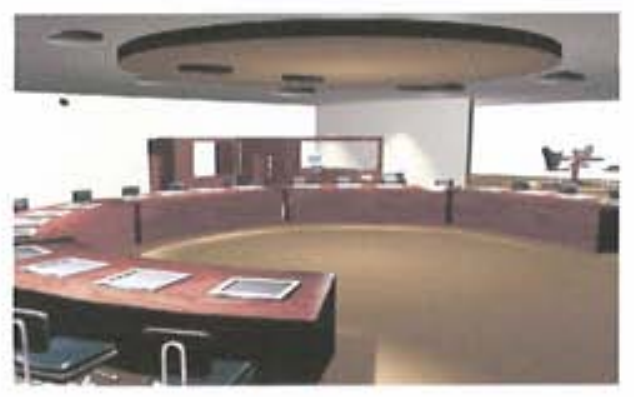

\subsection{The Chair:}

The chair is the single most important interface between the human body and the computer. An executive classroom chair needs to be selected in a way that offers students the ability to assume proper ergonomic posture. Students who spend many hours at the computer both at home and in the classroom run the same risks of CTDs (cumulative trauma disorders) as office workers yet they have less control of the environments in which they work. Use of standard classroom chairs that do not meet these needs puts most students at a distinct disadvantage . 
The chair needs to possess the following attributes:

- Height adjustability (preferably pneumatic): Ease of adjustment insures that students have the ability to achieve proper posture.

- Back tilt is a useful feature in that it enables students to adjust eye-to-monitor distance within the space allowed .

- Durability and tip resistance, including solid welds and heavy-duty mechanisms should be part of the chair infrastructure. A good test of tip resistance is to raise the chair to its highest position and hang a heavy jacket or book bag on the chair back.

- A broad seat and back design with adequate comfort and minimal sculpting: This meets the needs of a larger percentile of users. Though lumbar support and forward-tilt functions may be a necessity in the office, it is more important to make more users comfortable for the class duration. Please note that students usually present a greater range of body sizes than the general office worker population.

To assist in specifying the right chair, the best choice is Herman Miller products known as the Aeron chairs. Don Chadwick and Bill Stumpf designed the Aeron Chairs. Combing distinctive looks with pioneering ergonomics, Aeron performs like no other chair. It adapts naturally and adjusts precisely to fit people of all sizes and postures doing all kinds of activities, all day long. The imaginative design of both the work and side chairs gives superior comfort, body support, and style that are widely copied but never matched. The Aeron chair is characterized by a high performance, long-term seating in three sizes with a full complement of adjustments and innovative suspension. It is beneficial for computer work and casual or formal meetings. It provides natural, custom-fitted lower-back support below beltline for healthier posture and outstanding lower-back comfort. All threechair sizes have a high and wide contoured back that takes weight off the lower spine. Also, they are easy on the arms where wide, soft armrests are sloped in the front.

Furthermore, the Aeron chair has a smooth ride where the tilt lets people move naturally and effortlessly, from forward leaning through reclining. Finally, whether 
the user is in motion or at rest, the chair spontaneously supports the preferred posture. The Aeron Chair has really an inclusive look that blends both classic and contemporary influences for a unique appearance that fits in wherever it is used.

Below is an Aeron chair with three positions:

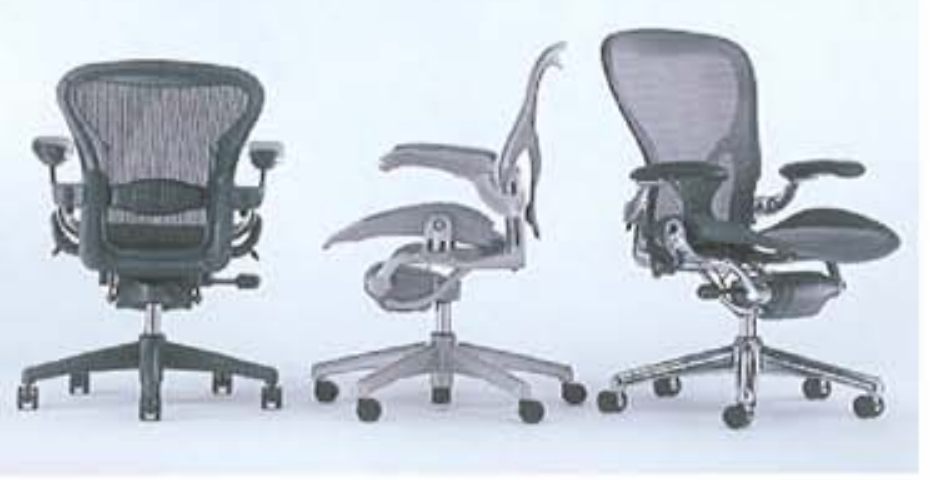

\subsection{Cable Management \& Control Room}

Anyone who has ever set up a classroom knows that cables can be overwhelming. This problem not only creates a cluttered or messy looking environment but can also be a safety hazard. Cables left unmanaged can be tripped over, causing harm to both student and hardware alike. So whether one is after a professional image or a safe classroom, one should make sure that the furniture selection offers a well-thought-out cable management system. What is meant here is that each table should have both power sockets and tubes for the cables.

With today's wireless technologies, the computer network connection is done without cables, freeing space and clutter from the tables. Furthermore, the AV system interface and connection can also be done wirelessly. A Wi-Fi (Wireless Fidelity) Access Point will be installed in the room to provide network coverage. 
The Control Room is where all the technologies will be managed through. It will placed in a discrete location inside the classroom, behind colored glass. The equipment needed in the Control Room will be as follows:

口 Server

ㅁ Audio Control System

a VCR / DVD Writer

口 Two amplifiers

ㅁ Extron switchers

a Video conference unit - Crestron system remote control

a Internet and ISDN connections

․ Wireless Access Point

․ Telephone Line

ㄴ Lighting Control System

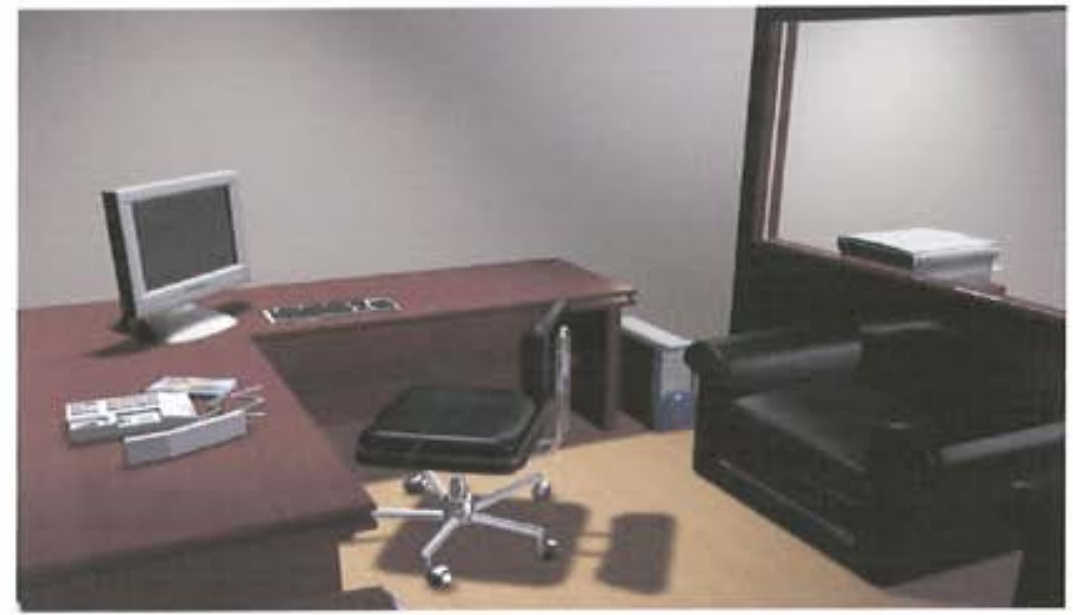

\subsection{Projectors:}

In order to empower faculty and engage both students and teams inside the classroom, the latest in projector technology will be provided. Multiple wireless projectors will give the presenter the essential control of equipment operation and class environment. These projectors will project on a curved wall the content that the faculty selects, either from his/her computer, tablet computer in class, or a particular video source. No screens need to be placed on the curved wall for the projection to take place. Three wireless projectors will be integrated in the ceiling of the room (ceiling height is 4 meters). These three projectors will give different projections on the curved wall screen according to the needs of the presenter. This will permit simultaneous display 
of multiple images for comparing and contrasting. In this way, one can enhance the discussions in class, and provide an engaged environment for presenting multiple facets of each topic.

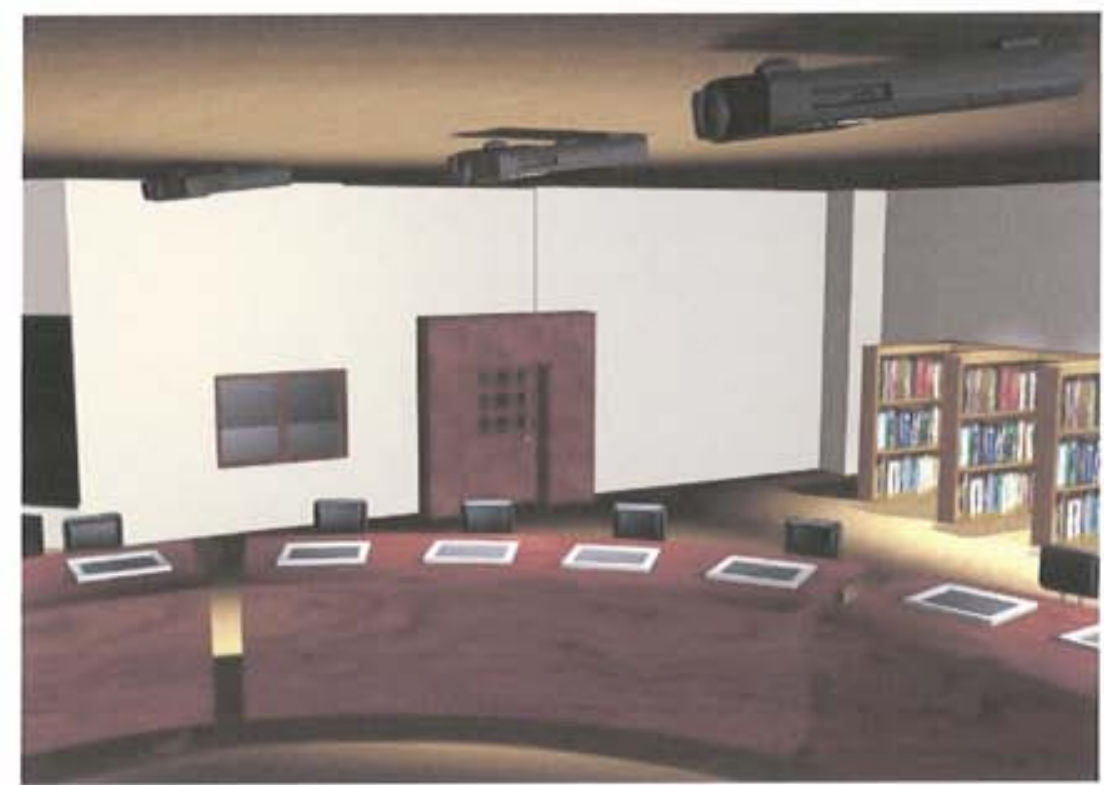

\subsection{Smart Board:}

A Smart and Movable Board will be placed at either side of the Curved wall. The Smart Board's interactive whiteboard transforms the classroom into an interactive working and learning environment, where information written could appear on any tablet computer, get saved for later viewing, or emailed to colleagues for later review. Simply touch the Smart Board's interactive whiteboard to highlight key points, access applications and web sites, and write notes in electronic ink. Then save all the work to one file that one can print, e-mail, or post to a web site.

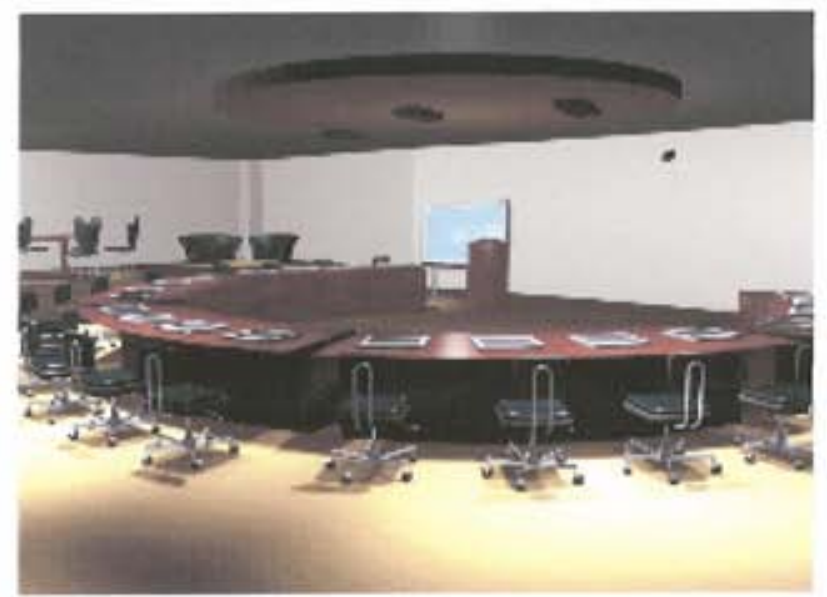




\subsection{Video Conferencing:}

Video conferencing is a medium where individuals or groups far away from each other can video-meet in real time to interact. It requires a computer (Mac or PC) with CU-SeeMe software, a video camera and an Internet connection, preferably ISDN or better. Bringing the world into the classroom through the use of this technology is becoming increasingly more popular. To do this, two video cameras are integrated in the wall opposite to each other so that both students and faculty can appear on the video sccreen.
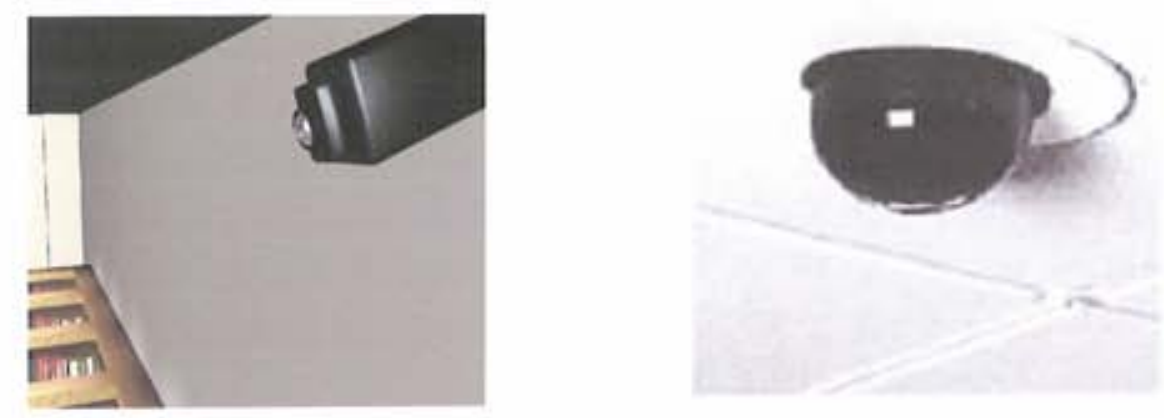

Video conferencing often adds an interesting element to such a design since most often one will want the majority of participants to be "oriented" in a certain direction. Furthermore, a table must support the briefing or presentation function if the presenter will be in a stationary position. The ergonomics and human factors of such designs are taken into account during our engineering process.

Some advantages of Video Conferencing are listed below:

- Better Planning: Planning ahead is an essential part of the videoconference.

The preparation time yields big returns when students and teachers are well prepared for the exchange of information.

- Interaction with Experts: Students are able to get answers to questions from experts who, because of time and distance, would otherwise be inaccessible.

- Participants Learn about cultural differences: Students are able to interact with other students and adults who live in different cultures from themselves. 
- Addresses different Learning Styles: It can include media such as video clips, animations, audio and graphics. This first hand learning is especially good for visual learners.

- Increases Motivation: You will find that students are much more willing to do the research when they know that they will be presenting it to other classes. Most students enjoy using the new technology.

- Better Retention: Students are learning from a primary source rather than a textbook.

- Enhances Presentation and Speaking Skills

The complete two video camera set includes software that allows one to record a clip, make photos, postcards etc, post the recorded clip to a website, or email photos or clips to the participants.

\subsection{Lighting System}

Quality light is a critical — and often unrecognized - tool in learning. Today, high quality lighting technologies are available at affordable prices for all types of lighting systems. As lighting technology developed, classes increasingly were provided with fluorescent lighting. Typically, the lighting consisted of direct/indirect, pendantmounted fixtures; these fixtures were fitted with magnetic ballasts and T-12 lamps.

Maintenance always has been an issue for schools, and lighting is no exception. Often, classroom lighting would end up with a variety of lamp colors (cool white, warm white, etc.) and worn-out, noisy ballasts. The lighting fixtures often were no matches for the demanding environment experienced in a school. Today, the selection of a classroom lighting system depends upon a list of variables: ceiling height, ceiling type, classroom type and use, interior or exterior location. Despite the many variables, common goals exist when lighting a classroom: even distribution of light, durable and safe fixtures, appropriate lamp color, energy efficiency, flexible control and maintainability. 


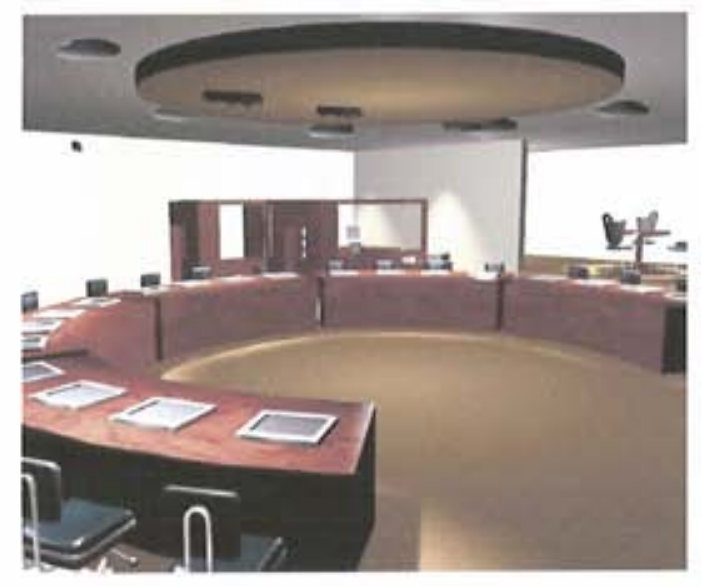

\subsection{Software needed to Control such a Classroom}

In order to control such an e-enabled classroom, VNC software should be installed. VNC stands for Virtual Network Computing. VNC is a "remote control" software, which allows one to view and interact with one computer (the server) using a simple program (the viewer) on another computer anywhere on the Internet. The two computers don't even have to be of the same type; so for example one can use VNC to view an office Linux machine on your Windows PC at home. VNC is freely and publicly available and is widely used in both academic and private environments.

$\mathrm{VNC}$ has a wide range of applications including system administration, IT support and helpdesks. The system allows several connections to the same desktop, providing an invaluable tool for collaborative or shared working in a workplace or classroom. VNC can also be used in educational contexts, for example to allow a distributed group of students simultaneously to view a computer screen being manipulated by an instructor, or to allow the instructor to take control of the students' computers to provide assistance. That is exactly what the EMBA classroom needs. From the podium, which has a tablet monitor, the instructor can remotely control all the students' computers and can project them to the screen for the entire class to see. Moreover, the VNC can control the video conferencing process where one can control the cameras and their projections. 


\subsection{Sitting Area}

At the back of the EMBA classroom, a cornered cushion is placed in order for the executives to have some rest after spending an entire session working on the computer, presenting, listening and analyzing. Next to this cushion, a small kitchenette is setup where refreshments and food are served, in addition to some electrical equipment for hot drinks.
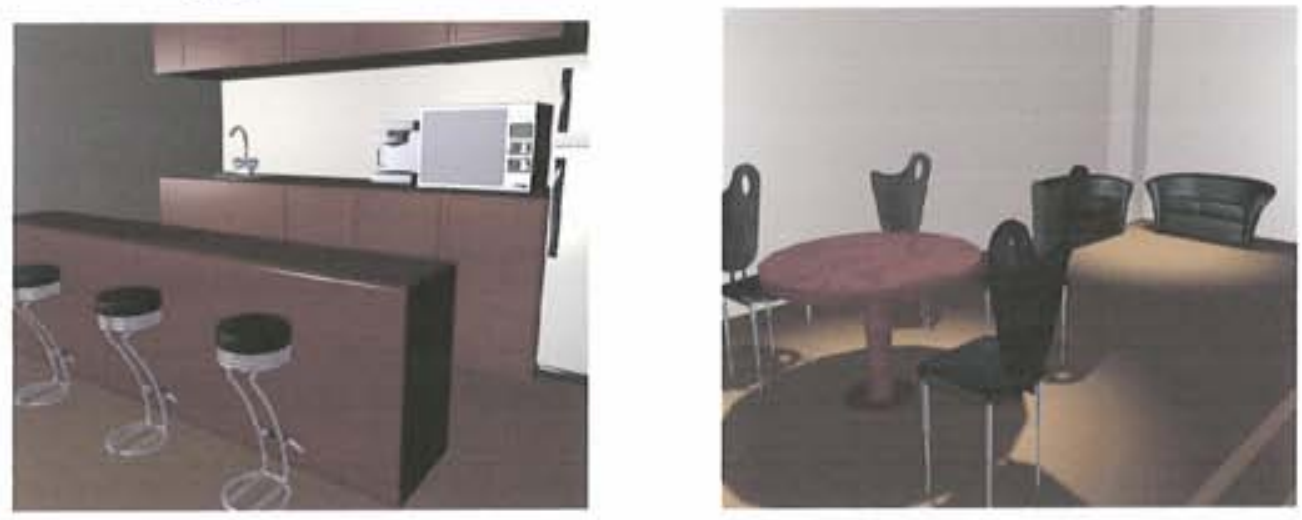

Next to the sitting area, some shelves will be available for books, journals, magazines and newspapers, and a color Xerox multifunction machine will be setup for printing and photocopying.

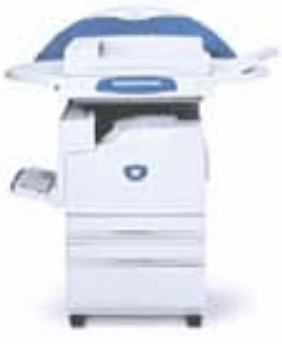

\subsection{Prayer Room}

In the spirit of embracing diversity, the University recognizes that the Islamic faith requires prayers at specific times and in certain conditions. A prayer room with two doors to allow separate entrance for women and men is highly recommended in an EMBA classroom. Prayer mat should be kept within the room and the Islamic society, by negotiation with the Campus Services Manager, may put up a curtain to 
separate the two halves. This room should be reasonably close to male \& female toilets with foot washing facilities. 


\section{Chapter VII}

\section{Conclusion and recommendations}

\subsection{Overview}

The university as an institution is at a decisive moment in its history. It is confronted with numerous outside challenges: the demand as well as the supply of education is globalizing, the coming generation of students differs significantly from preceding ones, the need for life-long education is replacing the classical learning period between ages 18 and 23, and new technologies call for new learning models. If concepts like "learning organization" and "learning society" are valid, then the university should be a pioneer in this field.

However, despite the changes of the past 30 years, the university system in our country has not been altered fundamentally. Learning still precedes working. Professors teach students the outcomes of their research, or they teach what they have read before. Students attend lectures, read books and articles, and take exams. Most of the time, learning processes at the university still take place in the splendid isolation of the ivory tower. This was concluded from the survey results that was conducted with MBA/EMBA students and faculty, and from the classroom designs that were explored in other universities worldwide (USA, Canada, UK, UAE).

One of the most disturbing aspects of universities is that learning continues to be viewed as a passive process. The teacher is perceived as the unquestioned dispenser of objective knowledge, and students as the uncritical receivers. Students can complete their study by sheer absorption and accumulation of knowledge. The actual learning process 
follows a predetermined route, that is, a fixed curriculum, even though universities tend to emphasize self-guidance on the part of students in carrying out learning tasks. The teacher's role is restricted to designing the curriculum, prescribing the learning path to be followed, and giving students' feedback on the extent to which they have acquired the learning content. Moreover, most students work their way toward graduation in solitude.

Of course, this cannot be applied in the EMBA environment, where participants come with the intention and desire to enhance and enrich their working experience. This should be accompanied with the fact that the EMBA participants are a group of professional people, seeking higher ranks in the managerial ladder.

Based on this, the Learning by sharing model was suggested for the EMBA Class Program, where participants will be provided with the possibility for three types of interaction:

- Between the professional students and their professors (Learning by investigating)

- Between the professors/teachers and the business leaders (Learning by experimenting)

- Between the professional students and the business leaders (Learning by practice)

For this model to work, a technology integrated classroom should be available. The technology used should enhance the learning process by maximizing the level of interaction between all the constituencies involved. Technologies like video conferencing, wireless projectors, an effective sound system, a smart podium, a smart board, and VNC software were all recommended in the new classroom. This also went along a furniture 
set and a design for tables and chairs that took into consideration high level and globally recommended ergonomic factors.

- It's highly technological, i.e. an e-enabled classroom.

- It allows for a very high level of interaction amongst participants themselves.

- It allows for a lot of interaction with the business community (local and global).

- It is equipped with course management software that allows participants to have access to the material outside the classroom.

- It provides participants with a high level of comfort and convenience.

- It takes into consideration the cultural diversity issue.

- It is an executive environment designed for executives.

\subsection{Recommendations}

Technology and classroom designs cannot work alone if they are not well supported by organizational, management, and HR competence factors. Based on this, and after working on this study, certain recommendations were suggested to be taken into consideration:

- The new design to be taken into consideration by the University management and administration.

- An experimental design to be set for one or two courses to be used as a prototype to evaluate the impact of technology integration on the achievement of learning outcomes.

- Teachers need to implement a change in their instruction methods (learner oriented rather than teaching oriented)

- Teachers themselves need to be life long learners always seeking self development and course development. 
- The university should support technology integration in the EMBA class (as well as in all classes).

- Training should be provided for instructors on instructional technologies including:

- Course Management Software (such as WebCT, e-college)

- Multimedia tools

- Electronic assessment methods (On-line quizzes, interactive tests)

- Use of data base tools to manage information

- Use of electronic collaboration methods

- Use of simulation tools and techniques

The recommendations were suggested based on the fact that for a design and technology to work in an educational setting, content and contextual factors should be taken into consideration. In this respect, the instruction should be more learning centered, the learning process should be highly collaborative, interaction with the business community should be ensured, top management commitment should always be provided, and the organizational culture should be supportive. Development sessions, training, and facilitation should be used to make the new procedures and resources smoothly adopted and used by faculty.

When a person thinks of joining an EMBA Program, the decision made is based on the benefit to be gained and the experience to be lived. LAU has been a pioneer in so many areas; it has overcome a lot of difficulties, and stood strong in the face of so many challenges. Now, while a strategic planning is being conducted, with a high emphasis on quality and academic excellence, let's take this challenge....a unique outreach to the community through a world-class EMBA program, with a quality curriculum, a state-ofart technology, and professional faculty that knows very well how to make this experience a lifelong-learning experience. 


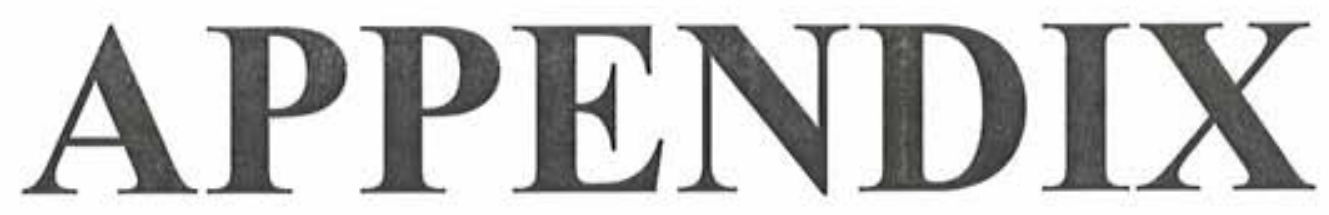




\section{Questionnaire The New Millennium Executive MBA Classroom}

This questionnaire will help in assessing the functions, environment, structure, and design of the New Millennium Executive MBA (EMBA) Classroom.

The data you will provide will be treated with extreme confidentiality.

Thank you for your time.

SECTION I: DEMOGRAPHICS

1. Age:

$\square$ 20-25

$\square$ 26-35

$\square 36-46$

$\square>46$

2. Gender:
$\square$ Male
$\square$ Female

3. Level of Education:

$\square$ BS/BA

$\square$ MS

$\square$ MBA / EMBA

$\square \mathbf{P h D}$

\section{Major:}

$\square$ Business

$\square$ Education

$\square$ Computer Science

$\square$ Medicine

$\square$ Communication Arts

$\square$ Others, specify

5. University where you teach:

$\square$ LAU

$\square$ AUB

$\square$ ESA 
6. Do you have any work experience, in addition to your teaching experience?

$\square$ Yes $\square$ No

If Yes, Years of Experience:
$\square \mathrm{Up}$ to $5 \mathrm{yrs}$
$\square 6-10 \mathrm{yrs}$
$\square 11-15$ yrs
$\square 16-20$ yrs
$\square>20$ yrs
$\square$ No experience

7. Current Employment Position / Rank:
$\square$ Manager
$\square$ Supervisor
$\square$ Instructor
$\square$ Chairman
$\square$ Dean
Lecturer
$\square$ Assistant Professor
$\square$ Associate Professor
$\square$ Professor

8. Place of Work:

$\square$ Beirut

$\square$ Mount Lebanon

$\square$ South

$\square$ North

$\square$ Bekaa

SECTION II: FACULTY'S EVALUATION OF CURRENT MBA / EMBA PROGRAMS

SA: Strongly agree

A: Agree

N: Neutral

DA: Disagree

SD: Strongly disagree

1. The program as a whole needs more expansion in courses and ways of teaching.
$\square$ SA
$\square \mathbf{A}$
$\square \mathbf{N}$
$\square$ DA
$\square$ SD

2. The quality of students is very good.
$\square$ SA
$\square \mathbf{A}$
$\square \mathbf{N}$
$\square$ DA
$\square$ SD

3. The quality of the program is as high as that offered by competent universities worldwide.
$\square$ SA
$\square \mathbf{A}$
$\square \mathbf{N}$
$\square$ DA
$\square$ SD

4. Content of core curriculum is extremely good.
$\square \mathbf{S A}$
$\square \mathbf{A}$
$\square \mathbf{N}$
$\square$ DA
$\square$ SD 
5. I am willing to teach the courses offered in the program.
$\square$ SA
$\square \mathbf{A}$
$\square \mathbf{N}$
DA
$\square$ SD

6. I enjoy teaching the courses in the program.
$\square$ SA
$\square \mathbf{A}$
$\square \mathbf{N}$
DA
$\square$ SD

7. Guest speakers should be more qualified.
$\square$ SA
$\square \mathbf{A}$
$\square \mathbf{N}$
DA
SD

8. Most faculty should be trained on computer use.
DSA
$\square \mathbf{A}$
$\square \mathbf{N}$
DA
$\square$ SD

9. The program would benefit form partnership with other top EMBA programs around the world.
DSA
$\square \mathbf{A}$
$\square \mathbf{N}$
$\square$ DA
SD

10. More contacts with industry leaders are needed.
$\square \mathbf{S A}$
$\square \mathbf{A}$
$\square \mathbf{N}$
$\square$ DA
$\square$ SD

11. Conferences and Seminars are highly needed.
SA
$\square \mathbf{A}$
$\square \mathbf{N}$
$\square$ DA
$\square$ SD

12. Lebanese Universities support MBA / EMBA in their local area and in the surrounding region through partnership with other schools, government and businesses.
$\square$ SA
$\square \mathbf{A}$
$\square \mathbf{N}$
DA
$\square$ SD

13. The university budget for MBA/ EMBA programs should be higher.
$\square$ SA
$\square \mathbf{A}$
$\square \mathbf{N}$
DA
$\square$ SD

14. The budget in our university for the EMBA program should include a substantial amount for simulation programs and computer enabled teaching methods.
$\square$ SA
$\square \mathbf{A}$
$\square \mathbf{N}$
DA
$\square$ SD 
15. The design of the classroom should be updated specifically to mirror an executive level office technology infrastructure.
SA
$\square \mathbf{A}$
$\square \mathbf{N}$
$\square$ DA
SD

16. The class size should be of no more than 25 students.
$\square \mathbf{S A}$
$\square \mathbf{A}$
$\square \mathbf{N}$
$\square$ DA
SD

17. New computer enabled techniques of analyzing and teaching case studies are needed.
$\square$ SA
$\square \mathbf{A}$
$\square \mathbf{N}$
$\square$ DA
GSD

18. I enjoy teaching my courses in a computer simulated class environment.
$\square \mathbf{S A}$
$\square \mathbf{A}$
$\square \mathbf{N}$
$\square$ DA
$\square$ SD

19. I enjoy teaching my courses in a structured presentation class environment.
SA
$\square \mathbf{A}$
$\square \mathbf{N}$
DA
$\square$ SD

20. Snacks and refreshments should be provided in an EMBA classroom.
$\square \mathbf{S A}$
$\square \mathbf{A}$
$\square \mathbf{N}$
DA
$\square$ SD

21. The EMBA classroom design should be a semi-circular structure, with $\mathbf{5}$ concentric rows, gradually stepped up per row.
$\square$ SA
$\square \mathbf{A}$
$\square \mathbf{N}$
DA
$\square$ SD

22. I prefer the chairs in the EMBA classroom to be very comfortable and flexible in terms of height, tilt, and swivel.
$\square$ SA
$\square \mathbf{A}$
$\square \mathbf{N}$
$\square$ DA
$\square$ SD 
23. Per EMBA Class Material, which of the facilities listed below is/are appropriate to enhance the learning and knowledge transfer experience?

\begin{tabular}{|l|c|c|c|c|c|c|}
\hline & $\begin{array}{l}\text { Video } \\
\text { Conferencing }\end{array}$ & $\begin{array}{l}\text { Computer } \\
\text { Projection }\end{array}$ & $\begin{array}{l}\text { Computer } \\
\text { \& Web } \\
\text { Enabled } \\
\text { Workstation } \\
\text { Per student }\end{array}$ & $\begin{array}{l}\text { Teamwork } \\
\text { Enhancing } \\
\text { Modular } \\
\text { Tables }\end{array}$ & $\begin{array}{l}\text { Focused } \\
\text { Lighting } \\
\text { (Color \& } \\
\text { Position) }\end{array}$ & $\begin{array}{l}\text { Sound } \\
\text { Proofing }\end{array}$ \\
\hline Management & $\square$ & $\square$ & $\square$ & $\square$ & & $\square$ \\
\hline Marketing & $\square$ & $\square$ & $\square$ & $\square$ & & $\square$ \\
\hline Finance & $\square$ & $\square$ & $\square$ & $\square$ & & $\square$ \\
\hline Economics & $\square$ & $\square$ & $\square$ & $\square$ & & $\square$ \\
\hline Accounting & $\square$ & $\square$ & $\square$ & $\square$ & & $\square$ \\
\hline Strategy & $\square$ & $\square$ & $\square$ & $\square$ & & $\square$ \\
\hline $\begin{array}{l}\text { Quantitative } \\
\text { Methods }\end{array}$ & $\square$ & $\square$ & $\square$ & $\square$ & & $\square$ \\
\hline Entrepreneurship & $\square$ & $\square$ & $\square$ & $\square$ & & $\square$ \\
\hline IT Systems & $\square$ & $\square$ & $\square$ & $\square$ & & $\square$ \\
\hline
\end{tabular}

Once again thank you for taking the time to fill out this questionnaire. Your kind cooperation is highly appreciated. 


\section{Questionnaire The New Millennium Executive MBA Classroom}

This questionnaire will help in assessing the functions, environment, structure, and design of the New Millennium Executive MBA (EMBA) Classroom.

The data you will provide will be treated with extreme confidentiality.

Thank you for your time.

\section{SECTION I: DEMOGRAPHICS}

1. Age:

$\square 20-25$

$\square 26-35$

$\square 36-46$

$\square>46$

2. Gender:

$\square$ Male

$\square$ Female

3. Level of Education:

$\square$ BS/BA

$\square$ MS

$\square$ EMBA / MBA

$\square$ PhD

4. Major (Prior to MBA/ EMBA):
$\square$ Business
$\square$ Engineering
$\square$ Education
$\square$ Pharmacy
$\square$ Computer Science
$\square$ Social Studies
$\square$ Medicine
$\square$ Communication Arts
$\square$ Others, specify

5. University where MBA / EMBA attended:

$\square$ LAU

$\square$ AUB

$\square$ ESA

6. Do you work? 
$\square$ Yes

If Yes, Years of Experience:
$\square$ Up to 5 yrs
$\square$ 6-10 yrs
$\square$ 11-15 yrs
$\square 16-20 \mathrm{yrs}$
$\square>20$ yrs

7. Employment Position / Rank:
$\square$ Medical Doctor
$\square$ Manager
$\square$ Lawyer
$\square$ Supervisor
$\square$ Accountant
$\square$ Executive Assistant
$\square$ Professional
$\square$ Other
8. Work Location:
9. Home Location
$\square$ Beirut
$\square$ Beirut
South
$\square$ South
North
$\square$ North
$\square$ Bekaa
$\square$ Bekaa
$\square$ Mount Lebanon
$\square$ Mount Lebanon
$\square$ Outside Lebanon

\section{SECTION II: LEVEL OF SATISFACTION OF STUDENTS TOWARDS MBA / EMBA PROGRAMS}

SA: Strongly agree
A: Agree
N: Neutral
DA: Disagree
SD: Strongly disagree

1. The program's ability to improve my career is very high.
$\square$ SA
$\square \mathbf{A}$
$\square \mathbf{N}$
$\square$ DA
$\square$ SD

2. The program as a whole is beneficial.
$\square$ SA
$\square \mathbf{A}$
$\square \mathbf{N}$
DA
$\square$ SD

3. The quality of the program is as high as that offered by competent universities worldwide.
$\square$ SA
$\square \mathbf{A}$
$\square \mathbf{N}$
DA
$\square$ SD 
4. Some courses should be taught in a different way.
$\square$ SA
$\square \mathbf{A}$
$\square \mathbf{N}$
$\square$ DA
$\square$ SD

5. I am willing to complete the courses in the program.
$\square$ SA
$\square \mathbf{A}$
$\square \mathbf{N}$
DA
$\square$ SD

6. The program should be more interactive.
$\square$ SA
口 A
$\square \mathbf{N}$
DA
$\square$ SD

7. I do not think I am benefiting from the MBA / EMBA.
$\square$ SA
$\square \mathbf{A}$
$\square \mathbf{N}$
DA
$\square$ SD

8. Technology use is very basic in the courses.
$\square$ SA
$\square \mathbf{A}$
$\square \mathbf{N}$
$\square$ DA
$\square$ SD

9. The quality of education is very good relative to the cost $I$ am paying.
$\square \mathbf{S A}$
$\square \mathbf{A}$
$\square \mathbf{N}$
DA
$\square$ SD

10. As a result of entering the program, I believe $I$ added a great value to my organization.
$\square$ SA
$\square \mathbf{A}$
$\square \mathbf{N}$
DA
$\square$ SD

11. I got promoted as a result of entering the program.
$\square$ SA
$\square \mathbf{A}$
$\square \mathbf{N}$
DA
$\square$ SD

12. I prefer the classroom environment to be a simulated environment of real business situations.
$\square$ SA
$\square \mathbf{A}$
$\square \mathbf{N}$
DA
$\square$ SD

13. The program needs to be more reflective of what the local market is in need for.
$\square$ SA
$\square \mathbf{A}$
$\square \mathbf{N}$
DA
$\square$ SD

14. The program needs to be more reflective of what the global market is in need for.
$\square$ SA
$\square \mathbf{A}$
$\square \mathbf{N}$
DA
$\square$ SD 
15. The most beneficial functional areas we are studying is: (Select all that apply)
$\square$ Marketing
$\square$ Management
$\square$ Finance
$\square$ Economics
$\square$ Accounting
$\square$ IT Systems
$\square$ Strategy
$\square$ Entrepreneurship
$\square$ Quantitative Methods

\section{SECTION III: DESIGN OF EMBA CLASSROOM}

16. Per EMBA Class Material, which of the facilities listed below is/are appropriate to enhance the learning and knowledge transfer experience?

\begin{tabular}{|l|c|c|c|c|c|c|}
\hline & $\begin{array}{l}\text { Video } \\
\text { Conferencing }\end{array}$ & $\begin{array}{l}\text { Computer } \\
\text { Projection }\end{array}$ & $\begin{array}{l}\text { Computer } \\
\text { \& Web } \\
\text { Enabled } \\
\text { Workstation } \\
\text { Per student }\end{array}$ & $\begin{array}{l}\text { Teamwork } \\
\text { Enhancing } \\
\text { Modular } \\
\text { Tables }\end{array}$ & $\begin{array}{l}\text { Focused } \\
\text { Lighting } \\
\text { (Color \& } \\
\text { Position) }\end{array}$ & $\begin{array}{l}\text { Sound } \\
\text { Proofing }\end{array}$ \\
\hline Management & $\square$ & $\square$ & $\square$ & $\square$ & & $\square$ \\
\hline Marketing & $\square$ & $\square$ & $\square$ & $\square$ & & $\square$ \\
\hline Finance & $\square$ & $\square$ & $\square$ & $\square$ & & $\square$ \\
\hline Economics & $\square$ & $\square$ & $\square$ & $\square$ & & $\square$ \\
\hline Accounting & $\square$ & $\square$ & $\square$ & $\square$ & & $\square$ \\
\hline Strategy & $\square$ & $\square$ & $\square$ & $\square$ & & $\square$ \\
\hline $\begin{array}{l}\text { Quantitative } \\
\text { Methods }\end{array}$ & $\square$ & $\square$ & $\square$ & $\square$ & & $\square$ \\
\hline Entrepreneurship & $\square$ & $\square$ & $\square$ & $\square$ & & $\square$ \\
\hline IT Systems & $\square$ & $\square$ & $\square$ & $\square$ & & $\square$ \\
\hline
\end{tabular}

17. I recommend the availability of snacks and refreshments in the classrooms.
$\square$ SA
$\square \mathbf{A}$
$\square \mathbf{N}$
$\square$ DA
$\square$ SD

18. The EMBA classroom design should be a semi-circular structure, with 5 concentric rows, gradually stepped up per row.
$\square$ SA
$\square \mathbf{A}$
$\square \mathbf{N}$
$\square$ DA
$\square$ SD 
19. I prefer the chairs in the EMBA classroom to be very comfortable and flexible in terms of height, tilt, and swivel.
$\square$ SA
$\square \mathbf{A}$
$\square \mathbf{N}$
DA
$\square$ SD

\section{SECTION IV: EVALUATION OF FACULTY IN THE MBA/EMBA PROGRAM}

20. There is a lot of knowledgeable faculty in the MBA/EMBA program.
$\square$ SA
$\square \mathbf{A}$
$\square \mathbf{N}$
DA
$\square$ SD

21. The faculty in the MBA/EMBA is an effective teacher.
$\square$ SA
$\square \mathbf{A}$
$\square \mathbf{N}$
DA
$\square$ SD

22. The accessibility to faculty is high.
$\square \mathbf{S A}$
$\square \mathbf{A}$
$\square \mathbf{N}$
口DA
$\square$ SD

23. The faculty makes efficient use of class time.
$\square$ SA
$\square \mathbf{A}$
$\square \mathbf{N}$
DA
$\square$ SD

24. The faculty's ability to communicate the subject matter is strong.
$\square$ SA
$\square \mathbf{A}$
$\square \mathbf{N}$
口DA
$\square$ SD

25. The faculty has significant industry experience in the subject matter they are teaching.
$\square$ SA
$\square \mathbf{A}$
$\square \mathbf{N}$
DA
$\square$ SD

26. The program needs more experienced faculty to be involved in the knowledge transfer process.
$\square$ SA
$\square \mathbf{A}$
$\square \mathbf{N}$
ＤA
$\square$ SD

27. The faculty in the program needs to be more exposed to new instruction methods.
$\square$ SA
$\square \mathbf{A}$
$\square \mathbf{N}$
DA
$\square$ SD

28. The faculty-student relationship is very interactive.
$\square$ SA
$\square \mathbf{A}$
$\square \mathbf{N}$
DA
$\square$ SD 
29. The faculty should be a coach / facilitator more than an instructor.
$\square$ SA
$\square \mathbf{A}$
$\square \mathbf{N}$
DA
$\square$ SD

30. The faculty in the program needs to be better equipped with technology and computerrelated skills.
$\square$ SA
$\square \mathbf{A}$
$\square \mathbf{N}$
DA
$\square$ SD

\section{SECTION V: PROFESSIONAL DEVELOPMENT}

Since Joining the program I have improved in various skills.
1. Critical Thinking
V.much
$\square$ Improved
$\square \mathbf{N}$
A little $\square$ Not at all
2. Creativity
$\square$ V.much
$\square$ Improved $\square \mathbf{N}$
$\square$ A little $\square$ Not at all
3. Leadership
V.much
$\square$ Improved $\square \mathbf{N}$
$\square$ A little $\square$ Not at all
4. Communication
$\square$ V.much
$\square$ Improved $\square \mathbf{N}$
$\square$ A little $\square$ Not at all
5. Team Building
V.much
$\square$ Improved $\square \mathbf{N}$
$\square$ A little $\square$ Not at all
6. Decision making
$\square$ V.much
$\square$ Improved
$\square \mathbf{N}$
$\square$ A little $\square$ Not at all
7. Ethical Awareness
$\square$ V.much
$\square$ Improved
$\square \mathbf{N}$
$\square$ A little $\square$ Not at all
8. Integration of business discipline:
$\square$ V.much $\square$ Improved
A little
$\square$ Not at all

9. Understanding the influence of new technologies:
$\square$ V.much
$\square$ Improved
$\square \mathbf{N}$
$\square$ A little
$\square$ Not at all

Once again thank you for taking the time to fill out this questionnaire. Your kind cooperation is highly appreciated. 


\section{References for Chapter II:}

Achacoso, Michelle, Evaluating Technology and Instruction: Literature Review and Recommendations, The University of Texas at Austin: Division of Instructional Innovation and Assessment, October 31, 2003, from: http://www.utexas.edu/academic/mec/publication/pdf/

B. Oakley, R.M. Felder, R. Brent, and I. Elhaji, Turning Student Groups into Effective Teams. Journal of Student Centered Learning, 2(1), 9-34 (2004), from: http://www.ncsu.edu/felder-public/Papers/Oakley-paper(JSCL).pdf

Brochure on the UCLA Anderson MBA Program, from: http://www.anderson.ucla.edu/x2965.xml

Di Benedetto, April O., Does Technology Influence Teaching Practices in the Classroom? Instructional Technology Center: National Educational Computing Conference, January 29, 2005 from: http://center.uoregon.edu/ISTE/uploads/NECC2005/KEY 6820721/DiBenedetto NECC_Paper_RP.pdf

Harden, Rochelle, Learning Artifacts in Higher Education, University of Illinois at Urbana-Champaign, Parkland College, from:

http://w3.ed.uiuc.edu/courses/edpsy317/sp03/challengereports/Learning_Artifacts.htm\# 
Interview in which Dr. Richard Felder discusses different aspects of active and cooperative learning, (March 19, 2001) from: http://clte.asu.edu/active/feldertranscript.htm

Mendenhall, Robert W., Technology: Creating New Models in Higher Education, from: www.nga.org/cda/files/HIGHEREDTECH.pdf

Min, R., Vos, Kommers, H. P., and van Dijkum, C., A Concept Model for Learning, Journal of Interactive Learning Research (the formal Journal of Artificial Intelligence in Education) Vol.11, no. 3/4, 2000, p.485-506.

Saddington, Tony, What is Experiential Learning, 2004, from: http://www.el.uct.ac.za/

Serban, Andreea, Technology Training Project Study, The Center for Student Success: Santa Monica College, July 2002, from: http://css.rpgroup.org/uploads/Project-I-ONE-LitReview-full-report.pdf

Smith \& Fletcher, 2004:

http://www.journalofexecutiveeducation.com/v3-1-04\%20smith.pdf

Smith, Mark, David Kolb on e-learning, 2005, from: http://www.infed.org/biblio/b-explrn.htm

Stuart, Spencer

http://www.spencerstuart.com/yourcareer/development/861/

Thijssen, Thomas J.P., Maes, Rik and Vernooij, Fons T.J., Learning by Sharing: A Model for Lifelong Learning, October, 2003, from: http://www.clubofamsterdam.com/cat content.asp? contentid $=328 \&$ catid $=118$ 
Thijssen, Thomas J.P., Maes, Rik and Vernooij, Fons T.J., Learning by Sharing: A Model for Lifelong Learning, October, 2003, from:

http://www.clubofamsterdam.com/cat content.asp? contentid $=328 \&$ catid $=118$

TSM School of Business, EMBA Brochure, from the Website address:

http://www.tsm.nl/contact/brochure/brochures/EMBA

University of Minnesota Duluth, Learning Styles, February, 2002, from:

http://www.d.umn.edu/student/loon/acad/strat/Irnsty.html

and links to:

http:/tip.psychology.org/manage.html

http://tip.psychology.org/strategy.html

http://tip.psychology.org/creativity.html 


\section{References for Chapter III \& VI:}

http://www.coba.usf.edu/alumni/building/

http://www2.gsb.columbia.edu/emba/overview/mbaEnvironment.html

http://www.studlife.com/media/paper337/news/2001/09/21/Cadenza/Big-

New.And.Way.Too.White.Collar.For.You-99918.shtmI

http://www.kellogg.northwestern.edu/execed/allen_center/index.htm

http://www.ce.com/education/Boston-University-Executive-MBA-Program-

10104034.htm

http://management.bu.edu/exec/emba/why.asp\#

http://www.anderson.ucla.edu/x6979.xml

http://emba.lmu.edu/index.html

(http://www.fuqua.duke.edu/mba/executive/global/distance.html)

(SMITH \& FLETCHER, 2004: http://www.journalofexecutiveeducation.com/v3-1-

04\%20smith.pdf LitRev1)

TSM School of Business, EMBA Brochure, from the Website address:

http://www.tsm.nl/contact/brochure/brochures/EMBA

(www.computercomforts.com/furnish-success.htm)

www.hermanmiller.com/CDA/SSA/Product/0,1592.al0-c440-p8,00.html

www.intmark.info/smart.html

www.realvnc.com

http://www.ampli.com/

http://www.ampli.com/hardwoods/catalog/dta_tables.html\#

http://www.classrooms.com/principles.html\#design

http://www.classrooms.com/principles.html\#tips 
http://www.bogen.com/products/conespeakers/

http://www.directron.com/directron/1pm150.html

http://www.cumbernauldtheatre.co.uk/technical.html

http://www.netopia.com/software/products/tb2/

http://www.proxim.com/products/wifi/ap/

http://www.intmark.info/aethra.html

http://www.proacousticsusa.com/products.php?sId=51

http://www.audioholics.com/news/pressreleases/wirelessDLPprojector.php

http://www.ampli.com/hardwoods/home lecterns.html

http://www.classrooms.com/principles.html\#design 